\title{
An Evaluation of Model Predictive Control of Automated Shading to Optimize Passive Solar Gains
}

\author{
by \\ Nuriat Tiwatayo Lawal, B.Sc. Mathematics and Engineering \\ Queen's University
}

A thesis submitted to the

Faculty of Graduate and Postdoctoral Affairs

in partial fulfillment of the requirements for the degree of

Master of Applied Science in Sustainable Energy

Department of Mechanical and Aerospace Engineering

Carleton University

Ottawa, Ontario

August, 2015

(C) Copyright

Nuriat Tiwatayo Lawal, 2015 
The undersigned hereby recommends to the

Faculty of Graduate and Postdoctoral Affairs acceptance of the thesis

\section{An Evaluation of Model Predictive Control of Automated Shading to Optimize Passive Solar Gains}

submitted by Nuriat Tiwatayo Lawal, B.Sc. Mathematics and Engineering

in partial fulfillment of the requirements for the degree of

Master of Applied Science in Sustainable Energy

Professor Ian Beausoleil-Morrison, Thesis Supervisor

Professor Metin I. Yaras, Chair, Department of Mechanical and Aerospace Engineering

Department of Mechanical and Aerospace Engineering Carleton University

August, 2015 


\section{Abstract}

Space heating and cooling account for $65 \%$ of the total energy consumption in Canada's residential sector. As a result, the design and construction of passive houses is becoming mainstream. However, passive houses are prone to overheating, even sometimes in the winter. Proper operation of window shading devices can provide substantial savings to the space conditioning loads in homes.

Model predictive control (MPC) of automated window blinds has proved to be effective at managing solar gains to reduce the heating and cooling loads in buildings. MPC involves predicting a system's response to a control input over a finite period of time in order to determine the best current control decision. This predictive quality of MPC is beneficial in buildings due to their delayed thermal response to solar gains.

This thesis details the framework for an MPC application for automated blind control of a single-family home in Ottawa. Building performance simulation (BPS) software was used to predict the interactions between the blind positions and the energy demand in the home. Optimizations were performed to minimize the total energy demand attributed to heating and cooling the home.

The performance of the MPC application was simulated over representative weeks of the year, and compared to a reactive, rule-based controller (RBC), which is the standard practice in blind automation. Energy savings of up to $36 \%$ were recorded in comparison to the RBC. 


\section{Acknowledgments}

I would first like to acknowledge my supervisor, Dr. Ian Beausoleil-Morrison for his patience, support, and immense knowledge. His guidance was instrumental to my research and the writing of this thesis and I am extremely grateful.

My sincere thanks go to Bart Lomanowski at Natural Resources Canada for his assistance with the CFC facility in ESP-r, and to Michael Wetter at Lawrence Berkeley National Laboratory for answering some of my GenOpt-related questions.

I would also like to acknowledge my colleagues in the Sustainable Building Energy Systems Laboratory for their assistance and friendship. In particular, thanks to Yawen Han, Adam Wills, Sebastien Brideau, and Nina Dmytrenko. Additionally, I wish to thank my office colleagues, Roxana Barcelo, Sadeem Al-Attar and Amr Daouk, for making my time in Ottawa enjoyable.

Lastly, I would like to thank my friends and family for their continuous support and encouragement. Thanks to my parents and sisters for always being there for me in my time of need, and to Nafisa Jadavji for her excellent mentorship. 


\section{Table of Contents}

Abstract $\quad$ iii

Acknowledgments $\quad$ iv

Table of Contents $\quad$ v

List of Tables viii

List of Figures $\quad$ ix

Nomenclature $\quad$ xi

1 Introduction 1

1.1 Background .......................... 1

1.2 Urbandale Centre for Home Energy Research (CHEeR) Project . . . 2

1.3 Literature Review . . . . . . . . . . . . . . . . . . . 3

1.3.1 Window Shading for Energy Savings . . . . . . . . . . . . . 3

1.3.2 Model Predictive Control (MPC) . . . . . . . . . . . 5

1.4 Scope of Work . . . . . . . . . . . . . . . . . . . . . 11

1.5 Thesis Outline........................ 11

2 Building Performance Simulation in ESP-r 13

2.1 Overview of the Thermal Model . . . . . . . . . . . . . . . 13

2.2 External Radiation . . . . . . . . . . . . . . . . 15

2.3 Insolation and Shading . . . . . . . . . . . . . . . . . 16

2.4 Fenestration and Window Blinds . . . . . . . . . . . . . 17

2.4.1 Thermal Modelling of Glazing Systems . . . . . . . . . . . . . 17

2.4.2 Flow Complexities Associated with Window Blinds . . . . . . 19 
2.4.3 Treatment of Window Blinds within the CFC Facility . . . . . 21

2.5 Urbandale CHEeR House Model . . . . . . . . . . . . . . . . . . . . . 24

2.5.1 Building Description . . . . . . . . . . . . 25

2.5.2 Existing Model Details . . . . . . . . . . . . 25

2.5.3 Modifications to Existing Model and Introduction of Venetian Blinds ...................... . . 29

2.6 Closing Remarks . . . . . . . . . . . . . . . . . . . . . . . 31

3 Solving the Optimization Problem 33

3.1 Optimization Problem . . . . . . . . . . . . . . 33

3.2 Optimization Algorithm . . . . . . . . . . . . . . 34

3.2.1 Factors Influencing the Choice of Algorithm . . . . . . . . . . 34

3.2.2 Particle Swarm Optimization . . . . . . . . . . . . . 35

3.2.3 Hooke-Jeeves Algorithm . . . . . . . . . . . . . . 36

3.3 Solving the Optimization Problem in GenOpt . . . . . . . . . . . 39

3.3.1 Objective Function . . . . . . . . . . . . . . . . 39

3.3.2 Variable Parameters . . . . . . . . . . . . . . 41

3.3.3 Software Coupling . . . . . . . . . . . . . . 41

3.4 Closing Remarks . . . . . . . . . . . . . . . . . 43

4 MPC Scheme $\quad 44$

4.1 Prediction Horizon . . . . . . . . . . . . . . . . . . 44

4.2 Modifications to ESP-r source files . . . . . . . . . . . . 46

4.2.1 Queen compilation ... . . . . . . . . . . 47

4.2.2 Pawn compilation . . . . . . . . . . . . . . . . 51

4.3 Managing optimizations and results . . . . . . . . . . . . . . 52

4.4 Closing Remarks . . . . . . . . . . . . . . . . . . 55

5 Results and Analysis $\quad 58$

5.1 Computational Cost of Optimizations . . . . . . . . . . . 59

5.2 Spring Performance . . . . . . . . . . . . . . 60

5.3 Summer Performance . . . . . . . . . . . . . . . . 63

5.4 Fall Performance . . . . . . . . . . . . . . . 65

5.5 Winter Performance . . . . . . . . . . . . . . 68

$5.6 \mathrm{MPC}$ of Blinds on East and West Faces . . . . . . . . . . . . . . 70 
5.7 Closing Remarks . . . . . . . . . . . . . . . . . 71

6 Conclusions and Recommendations $\quad 74$

6.1 Conclusions . . . . . . . . . . . . . . . . . . . 74

6.2 Recommendations for Future Work . . . . . . . . . . . . . . 77

$\begin{array}{lr}\text { List of References } & \mathbf{8 0}\end{array}$

Appendix A MPC Results for East and West-facing Blinds 84

Appendix B Hooke-Jeeves Algorithm 85

$\begin{array}{lll}\text { Appendix C } & \text { Files } & 88\end{array}$

C.1 GenOpt Files . . . . . . . . . . . . . . . . . . . . 88

C.1.1 Hybrid PSO/HJ Optimization Settings in Command file . . . 88

C.1.2 Additional GenOpt Files . . . . . . . . . . . . . . . . . 89

C.2 MPC Files . . . . . . . . . . . . . . . . . . . . . . . . . . . 89

C.2.1 Queen ESP-r modifications . . . . . . . . . . . . . . . 89

C.3 Pawn ESP-r modifications . . . . . . . . . . . . . . . . . . . . . . . 91

C.4 Additional MPC Files . . . . . . . . . . . . . . . . . . . . 92 


\section{List of Tables}

2.1 Glazing optical properties at normal incidence . . . . . . . . . . . . 29

2.2 Temperature set-points for heating and cooling . . . . . . . . . . . 29

2.3 Blind solar and longwave optical properties at normal incidence . . . 30

5.1 Sensitivity of thermal loads to blind orientation during representative weeks. . . . . . . . . . . . . . . . . . . 73 


\section{List of Figures}

1.1 Canadian energy consumption $[1] \ldots \ldots \ldots \ldots \ldots$

1.2 Use of a roof overhang to avoid overheating during the summer months 4

1.3 A graphical representation of thermal lag in buildings . . . . . . . 7

1.4 Typical setup for MPC implementation . . . . . . . . . . 8

1.5 RC-network model for a wall with a window . . . . . . . . . 9

1.6 Schematic of Coffey et al.'s MPC strategy . . . . . . . . . . . . 10

2.1 Relevant energy flow paths and discretization of building components 14

2.2 Treatment of insolation and shading in ESP-r f . . . . . . 16

2.3 Control volume discretization of a homogeneous layer in ESP-r . . . . 18

2.4 Radiative thermal network of a double-glazed window with indoor blinds installed . . . . . . . . . . . . . . . . 20

2.5 Convective thermal network of a double-glazed window with indoor blinds installed . . . . . . . . . . . . . . 20

2.6 Representation of slat control configuration . . . . . . . . . . 21

2.7 Injection/extraction radiant fluxes to represent all longwave exchanges between layers . . . . . . . . . . . . . . . . . . . 23

2.8 Injection/extraction convective fluxes to represent jump resistors . . . 25

2.9 Urbandale CHEeR house, showing window positions . . . . . . . . 26

2.10 Glazing construction for casement windows . . . . . . . . . . 27

2.11 Wireframe representation of the Urbandale CHEeR house model in

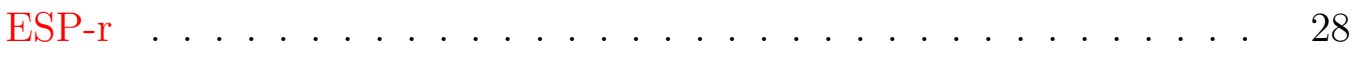

2.12 Outline of control schedule, showing blind control periods and variables for a single day . . . . . . . . . . . . . . . . . . 31

3.1 Von Neumann neighbourhood topology for two-dimensional search space 37

3.2 Flow chart of a sample PSO algorithm . . . . . . . . . 38

3.3 A general routine of Hooke Jeeves algorithm with a step reduction of $2 \quad 40$

3.4 Data flow of GenOpt/ESP-r coupling . . . . . . . . . . . . 41 
3.5 Transfer of information between ESP-r and GenOpt for a single iteration 43

4.1 Thermal response of the Urbandale CHEeR house . . . . . . . . . . . 45

4.2 Adaptation of typical MPC setup for this work . . . . . . . . . . . 46

4.3 Simplified flowchart of Queen showing modifications to relevant sub-

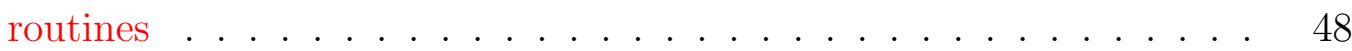

4.4 Simplified flowchart of Pawn showing modifications to relevant subrou-

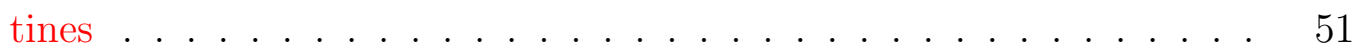

4.5 Transfer of thermal state from Queen to Pawn at each time step . . . 53

4.6 Flowchart of the MPC scheme . . . . . . . . . . . . . . . 57

5.1 Optimization iterations for a single hour . . . . . . . . . . . 59

5.2 Total heating and cooling demand for a week in March . . . . . . . . 60

5.3 Blind positions and thermal conditions during a single day in March . 62

5.4 Total heating and cooling demand for a week in June . . . . . . . . . 63

5.5 Blind positions and thermal conditions during a single day in June . . 64

5.6 Total heating and cooling demand for a week in October . . . . . . . 65

5.7 Blind positions and thermal conditions during a single day in October 67

5.8 Total heating and cooling demand for a week in December . . . . . . 68

5.9 Blind positions and thermal conditions during a single day in December 69

A.1 Blind positions for East and West facing blinds for a single day in March using $\mathrm{MPC}$. . . . . . . . . . . . . . . . . 84

B.1 Exploratory search for a two-variable optimization problem . . . . . . 86

B.2 Pattern move in the direction of improvement . . . . . . . . . 87 


\title{
Nomenclature
}

\author{
Abbreviations \\ BPS Building performance simulation \\ CHEeR Urbandale Center for Home Energy Research \\ $\mathrm{CFC}$ Complex fenestration construction \\ CV Control volume \\ gBest Global best \\ HJ Hooke-Jeeves \\ HOY Hour-of-year number \\ HVAC Heating, ventilating, and air-conditioning \\ lBest Local best \\ lw Longwave \\ MPC Model predictive control \\ PSO Particle Swarm Optimization \\ RBC Rule-based control \\ RC Resistance-Capacitance
}




\title{
Symbols
}

\author{
$\alpha \quad$ Blind slat angle \\ $\beta \quad$ Blind position (retracted or deployed) \\ $\rho \quad$ Reflectivity \\ $\tau \quad$ Transmissivity \\ $\epsilon \quad$ Emissivity \\ $h \quad$ Convective heat transfer coefficient $\left[\mathrm{W} / \mathrm{m}^{2} \mathrm{~K}\right]$ \\ $k \quad$ Thermal conductivity $[\mathrm{W} / \mathrm{mK}]$ \\ T Temperature $\left[{ }^{\circ} \mathrm{C}\right]$ \\ $q \quad$ Heat flux $[\mathrm{W}]$ \\ $R \quad$ Thermal resistance $[\mathrm{K} / \mathrm{W}]$ \\ QFA Future thermal flux into air nodes [W] \\ QFC Future thermal flux into construction nodes [W] \\ QFS Future thermal flux into surface nodes [W] \\ TFA Future temperature of air nodes $\left[{ }^{\circ} \mathrm{C}\right]$ \\ TFC Future temperature of construction nodes $\left[{ }^{\circ} \mathrm{C}\right]$ \\ TFS Future temperature of surface nodes $\left[{ }^{\circ} \mathrm{C}\right]$
}




\section{Chapter 1}

\section{Introduction}

\subsection{Background}

Canada's residential sector accounts for $16 \%$ of its total energy use. $65 \%$ of this energy is attributed to space conditioning, primarily heating (see Figure 1.1). With an expanding economy, a growing population and larger houses, efficient building operation is highly advantageous to reducing Canada's overall energy use. As a result, homes featuring energy-saving techniques are increasingly being designed. One common approach is to incorporate passive solar heating in building design.

Passive solar designs use walls, windows and floors to collect solar energy and distribute it as heat, thereby reducing the home's heating requirements. Such designs typically admit an abundance of solar gains into the house, which is usually advantageous to reducing heating loads during the cold, winter months. However, in the summer months, admitting excess solar gains may overheat the building and subsequently increase cooling requirements. With proper management of solar gains, passive solar designs may be maximally exploited without significantly increasing cooling loads.

Window blinds are commonly used for privacy and light control, but they can also be useful for managing solar gains in buildings. The United States Department of Energy (DOE) reports that in the summer smart management of window coverings can reduce solar heat gain in homes by $77 \%$ [2]. Window blinds are generally manually controlled, but there is an increasing interest in automating window shading, as this allows for improved effectiveness of reducing building energy loads. Although the majority of homes use manual window blinds, a simple method of controlling 


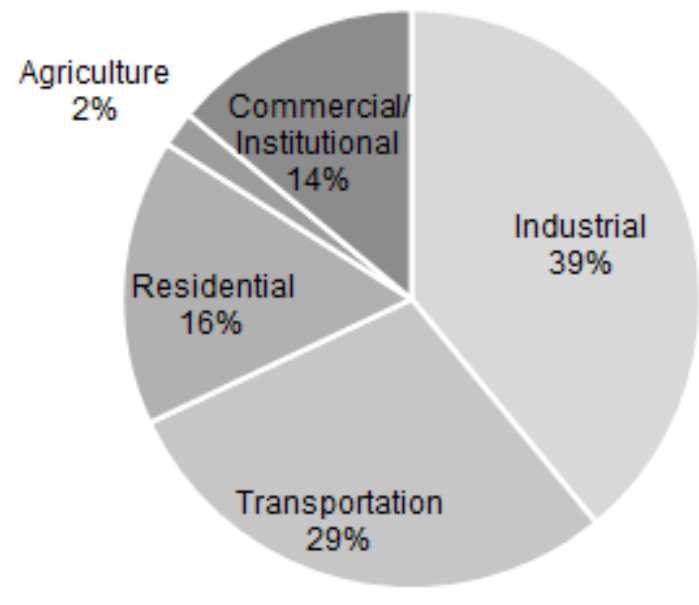

(a) Canada by sector

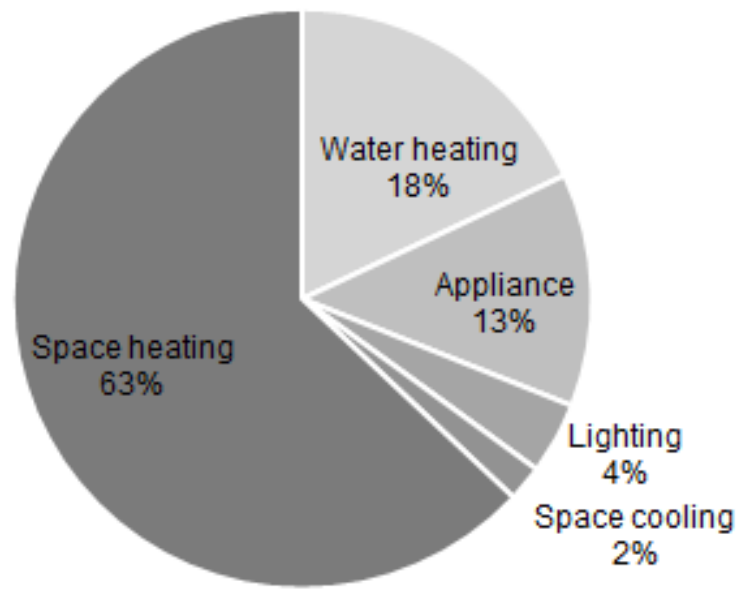

(b) Residential sector by end-use

Figure 1.1: Canadian energy consumption [1]

automated blinds is using a rule-based controller (RBC). Rule-based controllers program the blinds to follow a schedule or react to the building's thermal or lighting conditions. Such strategies are easy to implement and may be fairly effective at reducing energy consumption. However, recent work suggests that energy savings may be further improved using model predictive control (MPC) strategies [3].

An MPC strategy uses predictions of the building's future thermal state to make current control decisions. Considering the future thermal behaviour of a building is important for effective management of solar gains, as the building's interior has a slow and delayed response to exterior solar gains and increases in the surrounding temperature. This chapter will describe MPC's relevance to window blind control in houses and review existing applications within the literature. The research objectives of this thesis are also clearly identified. The case study used for this work is the Urbandale Centre for Home Energy Research (CHEeR), which is briefly described in the following section.

\subsection{Urbandale Centre for Home Energy Research (CHEeR) Project}

The Urbandale CHEeR housing project is a facility currently undergoing construction on Carleton University campus in Ottawa, Ontario, Canada. The facility is a single 
family house, which is intended to serve as a research centre for evaluating concepts and technologies aimed at improving energy efficiency of Canadian homes. One of these concepts is MPC for window blind control in Canadian homes. The MPC scheme featured in this work is applied to a thermal model of the Urbandale CHEeR house. A detailed description of the Urbandale CHEeR house is given in Chapter 2 of this thesis.

The following section reviews the literature regarding the use of window blinds for energy management in buildings, as well as previous applications of MPC in buildings.

\subsection{Literature Review}

\subsubsection{Window Shading for Energy Savings}

During the summer, external heat gains are the primary source of unwanted heat in homes. These heat gains could be directly from the sun or warm air surrounding the home. External heat is especially detrimental to cooling passively heated buildings which admit a large amount of solar gains. Designers utilize several control measures to reduce the cooling loads in passively heated buildings during the summer months. These measures could be in the form of design techniques (home orientation, cantilevered floor plans and window placement) or shading devices. Additionally, shading devices may be fixed (like overhangs and stationary louvres) or dynamic (such as window blinds). Figure 1.2 shows how an overhang may be used to admit the low winter sun, but shield the high summer sun from south facing windows. Trees and other forms of vegetation may also be used to shade buildings.

Energy savings from adopting several shading measures have been documented in the literature. Akbari et al. [4] recorded cooling energy savings of $30 \%$ after planting trees to shade the west and south facing sides of a house in Sacramento, USA. Takashi et al. [5] successfully reduced energy consumption using thermotropic glass for windows in an office space in Tokyo, Japan. Thermotropic glass has the ability to adopt a transparent or cloudy appearance, and hence shade the building's interior, based on the surrounding temperature. Bellia et al. [6] showed annual energy savings ranging between $8 \%$ and $20 \%$ after implementing louvres and overhangs in a model simulated under three different Italian climates. 


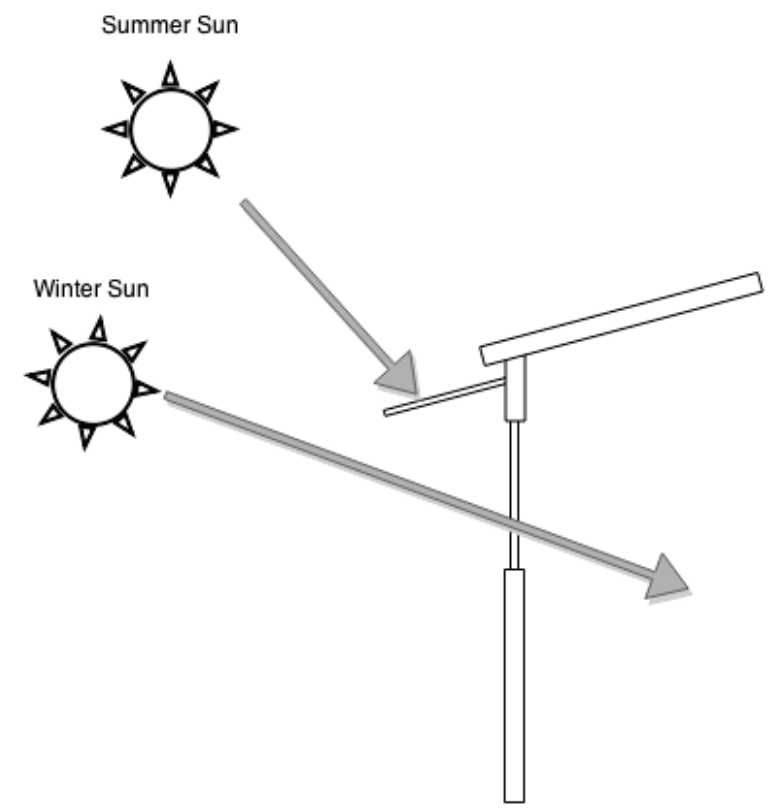

Figure 1.2: Use of a roof overhang to avoid overheating during the summer months

Fixed shading designs are beneficial for their minimal maintenance levels. Optimizing the geometry of fixed shading related features has been investigated in the literature. Manzan managed an $18 \%$ reduction of primary energy consumption from optimizing an external, fixed shading device [7]. Caldas and Norford [8] also optimized window sizes for minimum energy consumption. However, one drawback of fixed designs is that they are stationary while the sun's angle is not. This disadvantage is especially apparent during the cold months, when sunlight is advantageous to reducing heating loads and fixed shading devices obstruct the sun. Based on simulations, Raeissi and Taheri [9] optimized overhang dimensions for energy saving purposes. Their results showed a reduction in summer cooling loads, while only slightly increasing winter heating loads in a house located in Shiraz, Iran. However, in temperate climates like Ottawa, where heating loads significantly contribute to the total energy consumption, permanent designs may not be as effective.

The position of a shading device relative to the building's facade is critical to improving energy savings. Shading devices could be placed on the interior side of a window, housed between window panes, or on the exterior of the window. External shading is favourable during the cooling season since it prevents solar radiation from striking the window, thereby reducing longwave radiation transfer from the glass to the building's interior surfaces [10]. Conversely, internal shading decreases heating 
loads. Nikoofard et al.'s [11] study on the Canadian housing stock also shows that the colour of a shading device affects energy performance. Darker colour blinds reduce heating loads in the winter, and increase cooling loads in the summer due to their low solar reflectance.

The importance of proper control to improve the efficiency of movable shading systems is also highlighted in the literature. Although automated blinds are still rarely implemented in North America, rule based control (RBC) algorithms are the standard method of blind control. RBC controllers activate shading based on predetermined schedules or the building's current state (for example, temperature or illuminance levels). Van Moeseke [12] studied the impact of RBC shading devices on energy savings. The author simulated and studied the effects of controlling an external mobile screen based on sensing irradiation levels or the internal temperature. The screen is opened or closed when the temperature or irradiation exceeds or falls below the specified set points. The temperature and solar irradiation set points are also varied within each control strategy. The results showed that sensing temperature was a more effective strategy for reducing energy consumption than sensing irradiation levels. Littlefair et al. [13] simulated the effects of fixed and RBC shading on the interior and exterior of three buildings in three different cities in the United Kingdom (UK). In all three cases, the minimum energy delivered was recorded for indoor RBC window blinds, with set points based on indoor temperature.

Moreover, recent work from the OptiControl project shows that energy savings can be further improved using model predictive control (MPC) strategies, compared to RBC methods [14], [15]. The OptiControl project is an interdisciplinary team of academics and industry professionals studying building control engineering in Switzerland. Among other goals, this project aims to develop novel MPC algorithms tailored to buildings. The next section discusses MPC in further detail.

\subsubsection{Model Predictive Control (MPC)}

Due to the finite nature of most resources, optimization is highly advantageous to many applications. In building management and design, optimization often translates to minimizing certain parameters such as energy cost or consumption, and maximizing others like efficiency, output or performance. Optimal results may then be used to control the building's systems. While optimal solutions are much easier to implement in static systems, dynamic systems like building conditioning systems often require 
sophisticated optimization methods.

Furthermore, the thermal response of a building to external temperature disturbances is often nonlinear [16]. For example, increasing the amount of solar gains entering a building will not likely cause a proportional increase in the cooling load requirements of the building. Hence, the building's thermal state cannot be accurately described by a set of linear equations. The system's non-linearity poses some challenges as the system must first be linearized about a chosen point in order to use more popular methods of optimal control such as linear quadratic regulator (LQR) and proportional control [17]. Although linearization simplifies the optimization problem, the solution will be an approximation which becomes less accurate at points further away from the chosen initial point.

In addition, the thermal mass property of building materials poses another difficulty with controlling building systems. Thermal mass is a material's ability to absorb and slowly release heat when the there is an increase in the amount of solar radiation or in the surrounding temperature. There is a delay between the moment there is a change in temperature and the moment the building begins to react to this change, termed thermal lag. A representation of thermal lag is shown in Figure 1.3. Materials with a high thermal mass release absorbed heat slower than those with a low thermal mass. Thermal mass is a very important aspect of passive building design. During the winter months, thermal mass may be used to retain solar heat gains for longer periods to reduce the building's heating requirements. Hence, for optimal blind control, the controller must account for the release of heat from the building's materials over time to effectively manage solar gains in the building.

Rule-based controllers (RBC) follow a schedule or react to the building's current state. Consequently, they generally do not consider the building's future thermal response to the present control decisions. Hence, RBC controllers are unlikely to control the window blinds optimally.

MPC is a method of optimal control that uses a dynamic model to forecast a system's behaviour over a finite period in the future. This method of control determines the current best control action based on this forecast, while satisfying the system's constraints. MPC uses an iterative process to calculate the objective function from applying different control strategies, based on the system's current state, over a prediction time horizon. The best strategy over the horizon is chosen, but only the first step is implemented. The prediction horizon is shifted forward and the process is 


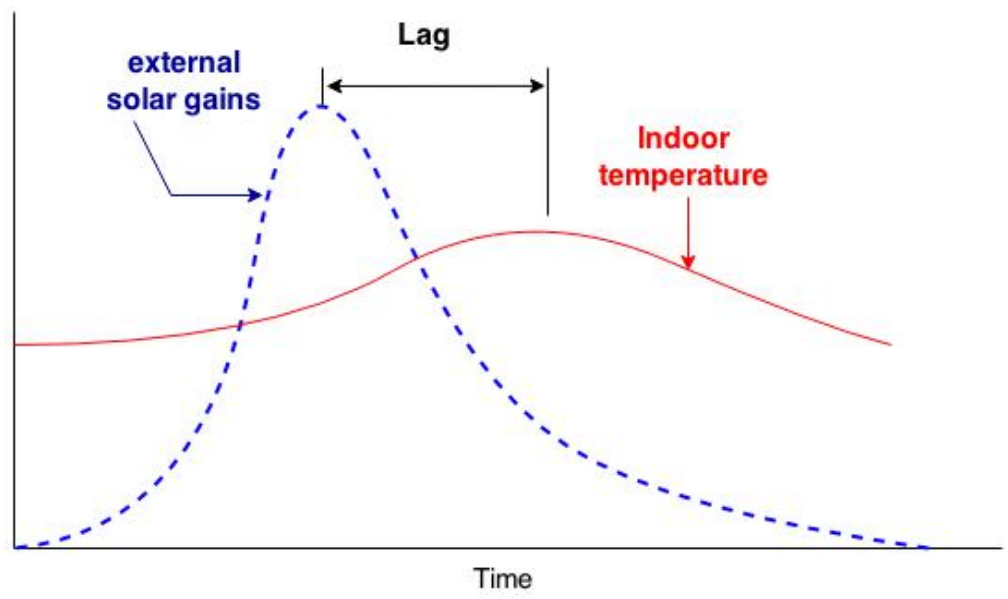

Figure 1.3: A graphical representation of thermal lag in buildings. Adapted from [18]

repeated using the new current state of the system. The predictive property of MPC makes it applicable to systems with slow system dynamics like buildings.

A generic minimization, MPC formulation is given by the following sets of equations:

$$
\begin{gathered}
\min \sum_{t=0}^{T-1} L_{t}\left(x_{t}, u_{t}\right) \\
x_{t+1}=f_{t}\left(x_{t}, u_{t}\right) \\
\left\{x_{t}, u_{t}\right\} \in \boldsymbol{X}_{t} \times \boldsymbol{U}_{t}
\end{gathered}
$$

where $L(x, u)$ represents the objective function, $T$ is the length of the prediction horizon, $x_{t}$ and $u_{t}$ are the state and control input of the system at time $t$ respectively, $\boldsymbol{X}_{t}$ and $\boldsymbol{U}_{t}$ are the set of the state and control constraints respectively, and the system's dynamics are represented in Equation 1.1b.

In practice, MPC in buildings generally combines a virtual model of the building with an optimizer. Information on the current state of the building is obtained from sensors. The objective function is evaluated by simulating the virtual model under various future control scenarios. The optimizer uses the simulation results to determine the optimal control decision. Hence, the accuracy of the virtual model and the choice of the optimization algorithm are critical to the MPC scheme.

Resistance-capacitance ( $\mathrm{RC}$ ) building models may be used for MPC in buildings. The OptiControl project's application of MPC to HVAC and lighting systems in a 


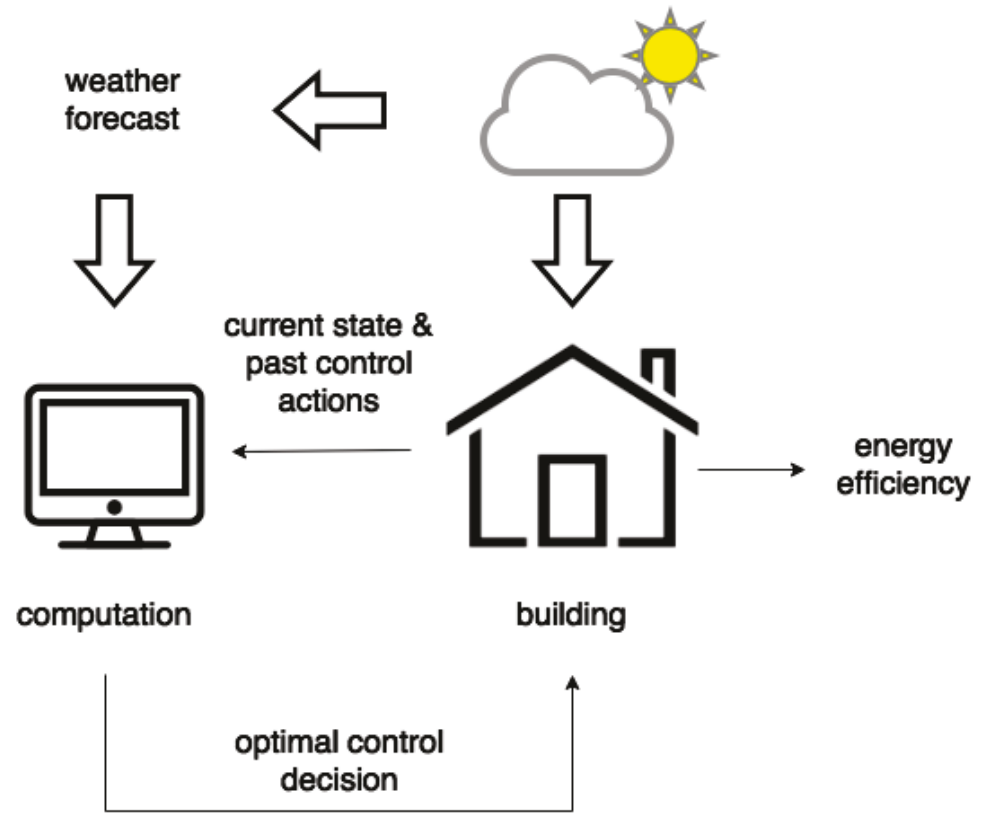

Figure 1.4: Typical setup for MPC implementation. Adapted from [3]

Swiss office building uses an RC model [19]. The results from their work showed simulated energy savings of $17 \%$, compared to the industry-standard RBC. Also, Huchuk's work on MPC of blinds using an RC model resulted in 34\% energy savings, when applied to an office space in Ottawa [20]. Unlike detailed building simulation based on first principles of heat transfer, an RC model uses a simplified representation of the building. Similar to an electric circuit, an RC model represents the heat flow in a building as a network of discrete resistances and capacitances, as shown in Figure 1.5. The resistance component is a measure of heat flow in a control volume based on temperature differences, while the capacitance component models a thermal zone's ability to store heat. This simplification generally reduces the computational cost of optimizations. However, the level of detail in a full building simulation provides information that may be lost using a simplified model. For example, using an RC model, we can obtain information such as whether an entire building requires heating, but may not recognize that one zone in the building requires cooling [21]. Improving the accuracy of an RC model is generally accomplished by increasing the number of resistors and capacitors representing the building's components. However, this action increases the complexity of the model and subsequently, the computational cost. 

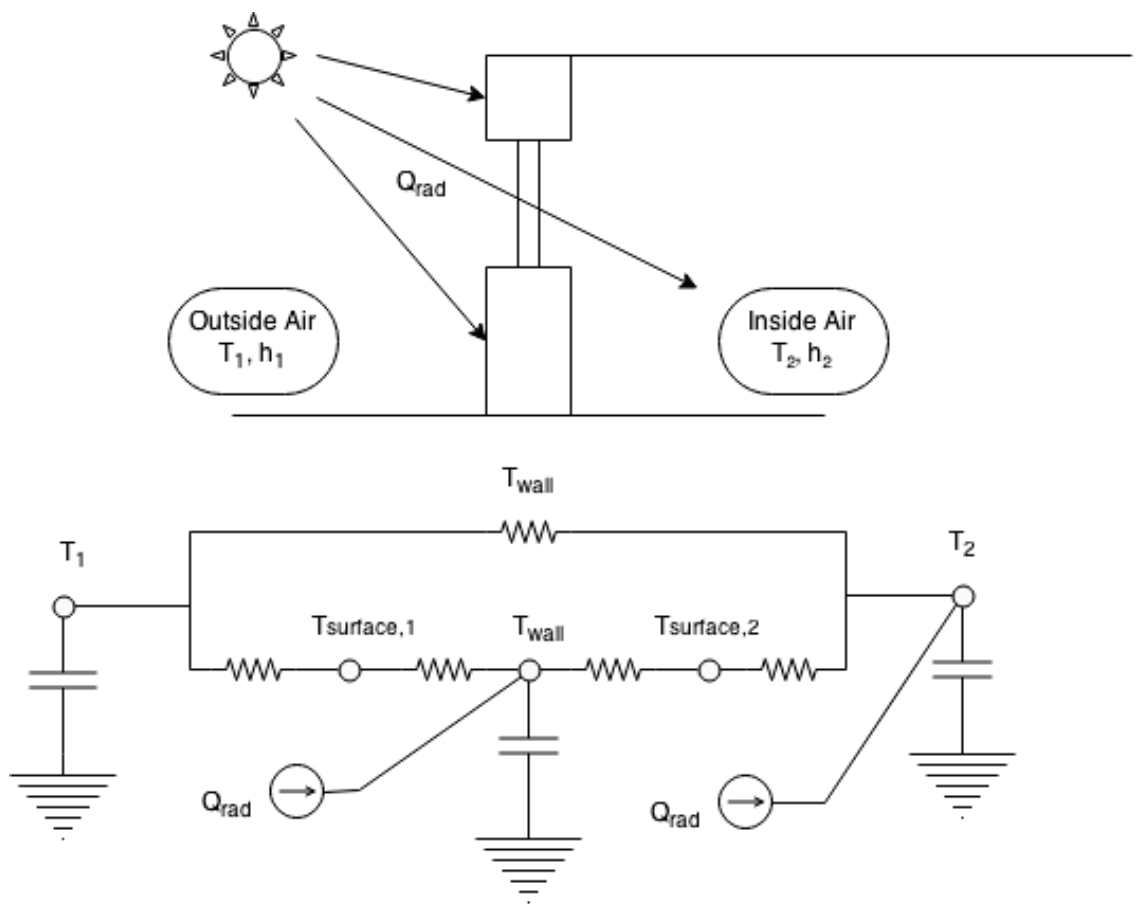

Figure 1.5: RC-network model for a wall with a window. Adapted from [22]

Alternatively, some researchers couple building performance simulation (BPS) tools like EnergyPlus and TRNSYS for modelling, with optimization toolboxes in MATLAB for MPC applications. Corbin et al. [23] developed online and offline MPC optimization environments for a commercial building using MATLAB and EnergyPlus. Online MPC uses real-time weather forecasts for calculations, while offline MPC uses historical weather data. The offline MPC was used to (i) determine hourly cooling set points to minimize energy cost, and (ii) determine hourly supply water temperature to minimize energy consumption in the building. The results showed $5 \%$ cost savings and $54 \%$ energy savings compared to the base case.

Generally, programs must be compatible with each other to support coupling. This compatibility requirement limits the user to only a few programs, and excludes other viable software options. Coffey et al. [24] addresses this limitation by developing an MPC framework using a generic optimization software called GenOpt. GenOpt is a free, java-based program which is compatible with any text-based simulation tool. GenOpt's coupling capabilities with energy modelling software like TRNSYS, Modelica, EnergyPlus and ESP-r has been proved in the literature [25-29].

Coffey et al.'s approach, as shown in Figure 1.6, divides the problem into three 


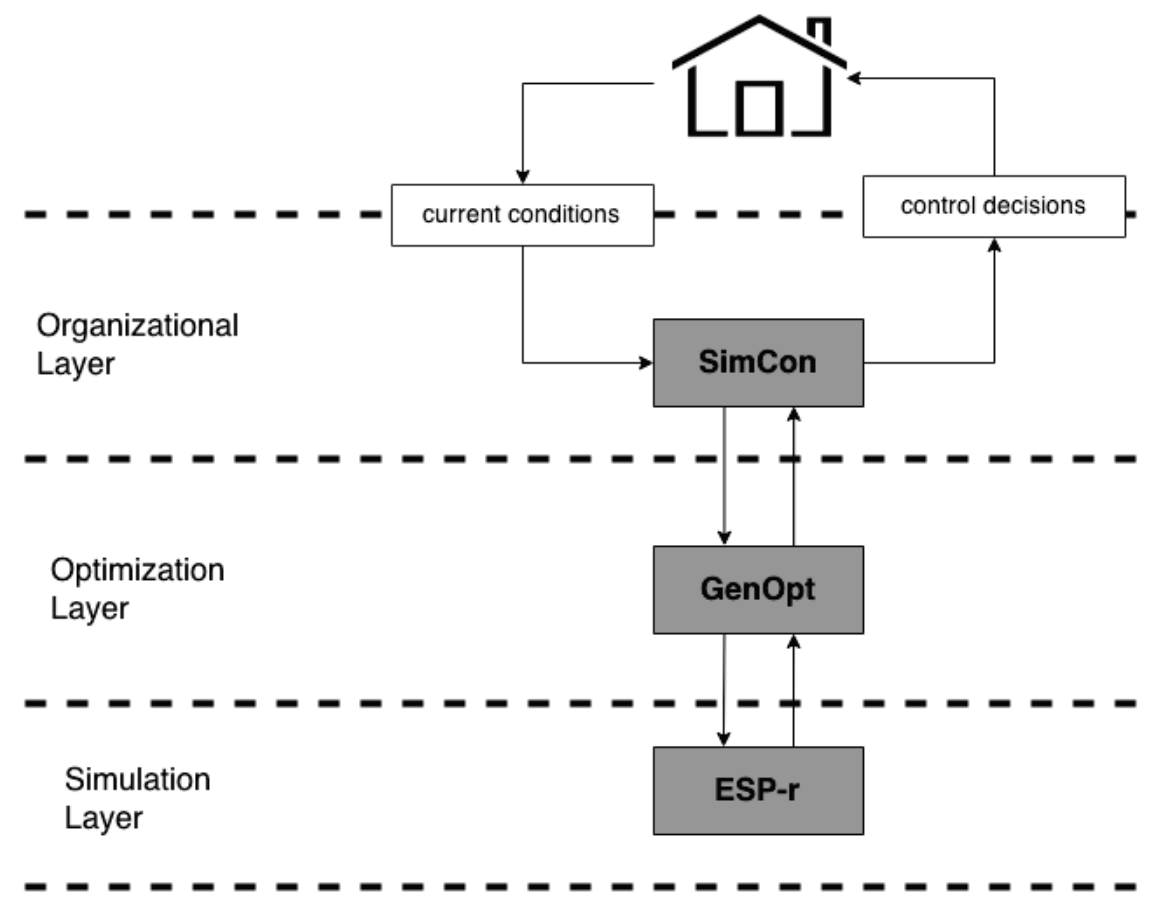

Figure 1.6: Schematic of Coffey et al.'s MPC strategy. Adapted from [24]

layers. The simulation layer consists of ESP-r, which is used to simulate building performance. The optimization layer uses GenOpt to conduct optimizations based on results from the simulation layer. The authors developed a genetic optimization algorithm within this layer due to the algorithm's accuracy and the option of using multiple starting points. The organization layer uses SimCon, a program the authors developed to coordinate optimizations based on current building conditions. SimCon also interfaces with the building's control system. The MPC framework was simulated for an office space in Ottawa to optimize demand trimming (reducing energy demand during peak periods to avoid blackouts or need for additional electricity production). The MPC's performance was simulated in ESP-r and compared to heuristic controllers, in which the HVAC temperature set points within the trim period are given as a linear, logarithmic, or fixed function of time. The impact of perfect model matching was also investigated, whereby the virtual model was created to deviate from the model of the actual building. The MPC outperformed the heuristic controllers when there were no time constraints on optimizations and the models were perfectly matched. However, when the algorithm's computation time was constrained or the models were mismatched, the MPC performed worse. These results imply that MPC is effective when accurate building models and quick, but 
exhaustive optimization algorithms are used.

\subsection{Scope of Work}

Model predictive control applications in buildings have not been greatly investigated until recently. Existing cases in the literature show that MPC has great potential for building control applications, particularly automated window shading. In addition to other energy-saving design concepts, the Urbandale CHEeR project aims to study MPC for blind control in Canadian homes. The Urbandale CHEeR project's test facility is a detached, two-storey house, which is intended to represent a typicallysized, energy-efficient Canadian dwelling for a single family. As part of the Urbandale CHEeR project, this thesis aims to develop an MPC scheme for effective window blind control, targeted at minimizing energy demand in the test facility. The performance of the MPC scheme will also be evaluated, and compared to other blind control strategies.

To achieve the above objectives, computer simulations are used. The MPC scheme is developed using a computer model of the building and an optimizer. Its performance is simulated using building performance simulation tool, ESP-r. Optimizations within the scheme are performed using optimization software, GenOpt. Chapter 2 and 3 discuss the processes and methods used within ESP-r and GenOpt respectively.

\subsection{Thesis Outline}

The remainder of this thesis is organized as follows:

- Chapter 2: Building Performance Simulation in ESP-r gives a mathematical description of ESP-r's modelling methods, which are relevant to this thesis. Also, the ESP-r model of the Urbandale CHEeR house is summarized.

- Chapter 3: Optimization in GenOpt describes the optimization problem, the chosen algorithm, and the process of setting up an optimization problem in GenOpt

- Chapter 4: MPC Scheme explains the development and components of the MPC framework used in this thesis 
- Chapter 5: Results and Analysis presents the results of the MPC application

- Chapter 6: Conclusions concludes this thesis and provides recommendations for future research 


\section{Chapter 2}

\section{Building Performance Simulation in ESP-r}

An accurate energy model of the building is required to accurately predict the future conditions of the building for proper MPC implementation. For the MPC application in this thesis, this model should capture the interactions between the blind positions and the energy requirements for space conditioning (heating and cooling). Building performance simulation (BPS) tools are computer programs that mathematically model the behaviour of buildings using thermophysical concepts like heat and mass transfer, fluid mechanics and thermodynamics. From these models, the user can assess a building's performance in terms of energy, electrical power, lighting and acoustics. For this work, ESP-r was chosen to model the energy demand of the house. ESP-r is a rigorous, open-source BPS tool developed by the Energy Systems Research Unit (ESRU) at the University of Strathclyde, Scotland. It has been extensively used and validated by researchers worldwide.

This chapter discusses the modelling methods in ESP-r, which are relevant to this work.

\subsection{Overview of the Thermal Model}

ESP-r uses a finite difference, heat balance approach to perform thermal simulations of the building. This approach is carried out in three steps.

First, the building's envelope, air volumes, solid-fluid interfaces and plant components are discretized. This process involves placing nodes along the main directions of heat flow in the building. Discretization simplifies the continuous differential equations describing the heat balance of the building's components into a series of discrete equations, which are suitable for numerical computation. By default, ESP-r assumes 
heat transfer is one-dimensional and the nodes are placed accordingly. For multilayered constructions, nodes are placed within each construction layer to account for the different thermal properties. The number of nodes within a layer can be specified by the user. A representation of node placement and energy flow paths calculated in ESP-r is shown in Figure 2.1.

Second, a control volume is placed around each node, and the corresponding

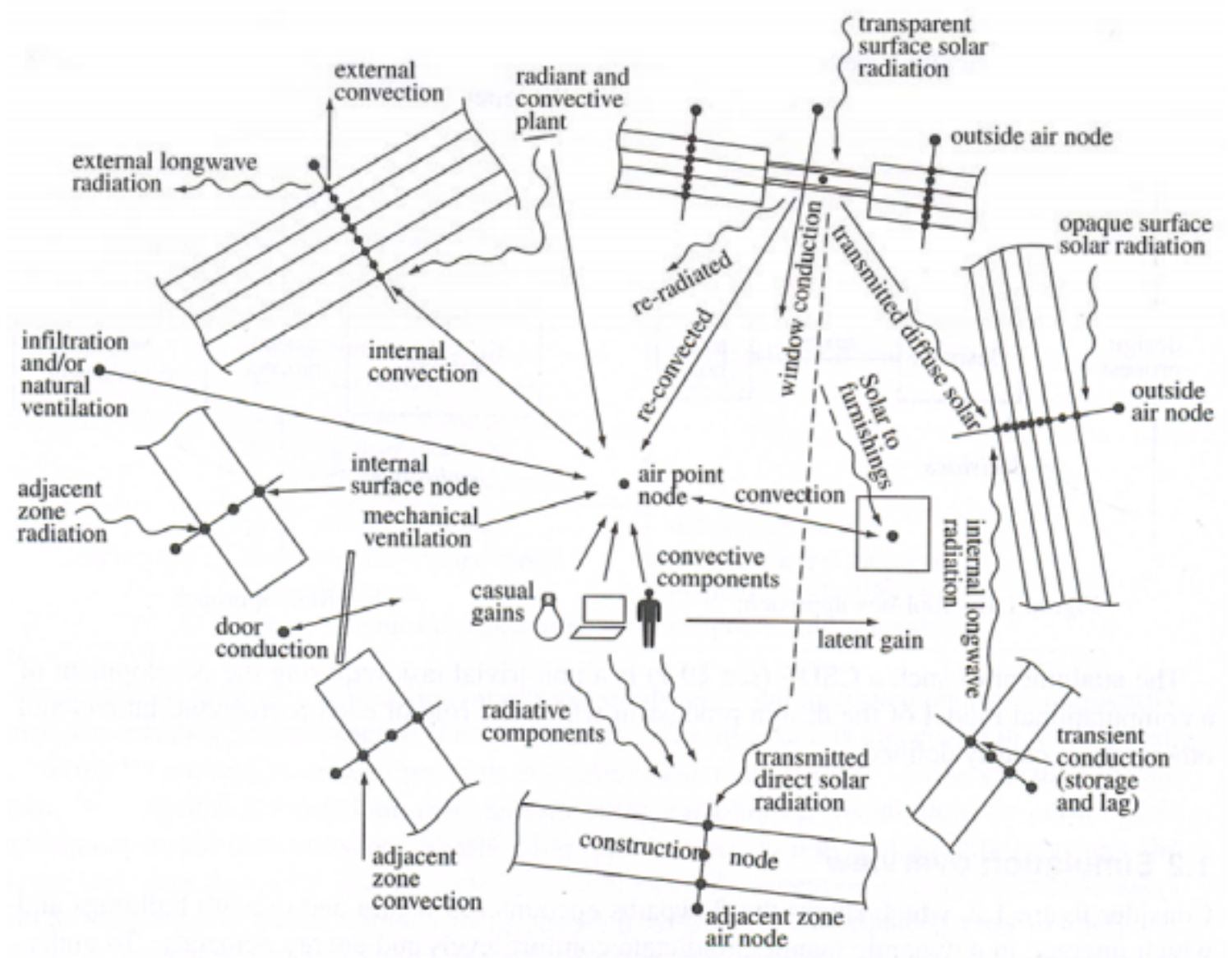

Figure 2.1: Relevant energy flow paths and discretization of building components. Reproduced with permission from [30]

heat balance equation is written. By default, ESP-r considers only the relevant heat flows through a node. ESP-r uses the Crank-Nicolson finite differencing scheme to approximate these equations. The Crank-Nicolson scheme is a weighted average between implicit and explicit finite differencing, which is beneficial for its consistency and numerical stability. By default, ESP-r assigns equal weightings to the explicit 
and implicit terms; however, weighting can also be user-specified. The explicit finite differencing formulation expresses the solution for the present time using quantities from the previous time step, while the implicit formulation expresses the solution for the present time step using present quantities. The derived, Crank-Nicolson heat balance equations thus feature present temperatures (known) and future temperatures (unknown). The heat balance equations relate each node to its neighbours, resulting in a system of interconnected finite difference equations.

Third, the system of finite difference equations is solved simultaneously, using matrix inversion, to determine the temperature of each node and the heat flows between the nodes. The second and third steps are repeated at the start of each simulation time step.

For a more thorough description of the derivation of heat balance equations in ESP-r, the reader is directed to [31].

\subsection{External Radiation}

The incident solar radiation on an external surface is a combination of the radiation coming directly from the sun, diffuse radiation from the sky, and the ground reflected radiation.

$$
\left\{\begin{array}{c}
\text { incident solar } \\
\text { radiation }
\end{array}\right\}=\left\{\begin{array}{c}
\text { direct beam } \\
\text { radiation }
\end{array}\right\}+\left\{\begin{array}{c}
\text { sky diffuse } \\
\text { radiation }
\end{array}\right\}+\left\{\begin{array}{c}
\text { ground reflected } \\
\text { radiation }
\end{array}\right\}
$$

From this energy balance, the incident irradiance (flux per unit area) on an external surface can be written as shown in Equation 2.1

$$
G_{s}=\left(I_{d \beta}+I_{s \beta}+I_{r \beta}\right)
$$

where $G_{s}$ is the incident irradiance, $I_{d \beta}$ is the direct beam radiation, $I_{s \beta}$ is the sky diffuse radiation and $I_{r \beta}$ is the ground reflected radiation, all given in $\mathrm{W} / \mathrm{m}^{2}$.

ESP-r uses the direct normal solar irradiance and the diffuse solar irradiance on the horizontal to calculate the solar radiation on an external surface. This information is extracted from the input weather files. By default, sky diffuse radiation is calculated using the Perez anisotropic model [32]. Anisotropy implies that solar radiation is 
directionally-dependent, which is typical in the real world.

The ground reflected radiation is calculated using the ground's reflectivity. Reflectivity values can be specified by the user to account for various ground coverings and site exposure. This value may be defined as a constant for the entire year of simulation. Alternatively, the user can invoke more rigorous modelling methods, for example, Thevenard and Haddad's snow albedo model [33].

\subsection{Insolation and Shading}

The amount of solar radiation received on a surface in the building is dependent on the sun's position and the geometry of obstructions and surrounding features. ESP-r users must define solar obstructions, as the default settings neglect external shading by other surfaces within the same zone. ESP-r treats shaded surfaces by placing a two-dimensional grid on the surface and projecting the position of the obstruction on this grid, parallel to the sun's rays. The area of the shaded portion is excluded from insolation calculations.
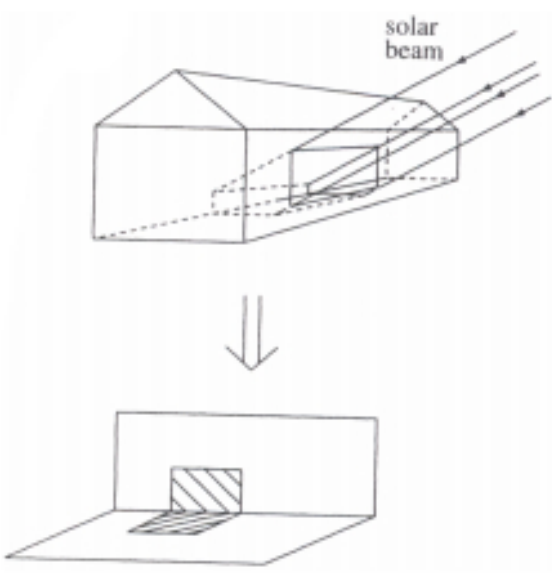

(a) Insolation of internal surfaces
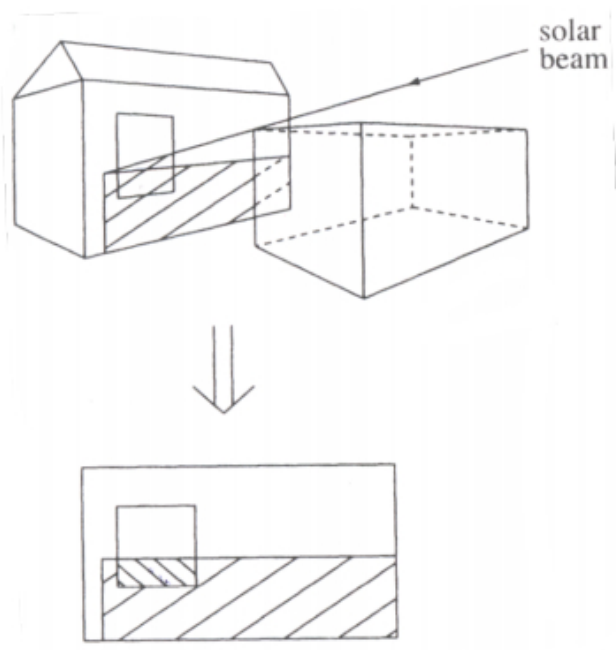

(b) Shading from external obstruction

Figure 2.2: Treatment of insolation and shading in ESP-r. Reproduced with permission from [30]

Furthermore, all solar radiation absorbed and reflected within the interior is distributed among all surfaces in the zone, based on an area-weighting. Optionally, 
ray-tracing calculations may be carried out to determine the view-factors of all interior surfaces, and distribute radiation based on these calculations.

\subsection{Fenestration and Window Blinds}

The characteristic equations for heat transfer in glazing systems are well established. However, when shading devices like venetian blinds are introduced, heat transfer becomes more complex. The complex fenestration construction (CFC) facility in ESP-r was developed to manage the complexities associated with using window blinds in buildings. The CFC facility provides an avenue for modelling window blinds and screens. Also, dynamic control of slat-type blinds is permitted within the CFC functionality.

ESP-r's CFC facility was used to model the interior, venetian blinds featured in this work. This section discusses the processes used by ESP-r to determine the heat flow through glazing systems with interior venetian blinds. For an extensive discussion of the development of the CFC facility and validation of the model, the reader is directed to [34].

\subsubsection{Thermal Modelling of Glazing Systems}

Similar to its modelling techniques for opaque constructions, ESP-r uses a onedimensional, multinodal, heat-balance approach for fenestration. Heat flow through glazing systems can be characterized as: (1) From the glass to the interior, (2) From the glass to the frame, (3) From the frame to the interior. ESP-r's fenestration calculations are strictly concerned with the heat flow from the glass to the interior, which occurs at the centre of the glass, as this accounts for the majority of the heat flow. The frame area may be treated as a separate construction to capture the heat flow from the frame to the interior.

Glass is opaque to longwave radiation, meaning that longwave radiation exchanges within multilayer glazing systems only occur between adjacent glazing surfaces. Conversely, solar radiation incident on a window can be absorbed, reflected, or transmitted through each glazing layer into the building's interior. Since the characteristics of these exchanges are very different, BPS tools like ESP-r usually separate the treatment of solar and longwave radiation processes. By default, ESP-r places nodes at the centre and edges of glass and gas gaps present within the fenestration (see Figure 
2.3). The total heat gain through the fenestration can be calculated from the energy balance equation for each node. Heat balance equations for nodes within and on the interior surface of a glazing layer are derived similarly to their opaque counterparts.

For a node at the centre of a glass layer:

$$
\left\{\begin{array}{c}
\text { storage of } \\
\text { energy in } C V
\end{array}\right\}=\left\{\begin{array}{c}
\text { net conduction } \\
\text { into } C V
\end{array}\right\}+\left\{\begin{array}{c}
\text { sources of energy } \\
\text { within } C V
\end{array}\right\}
$$

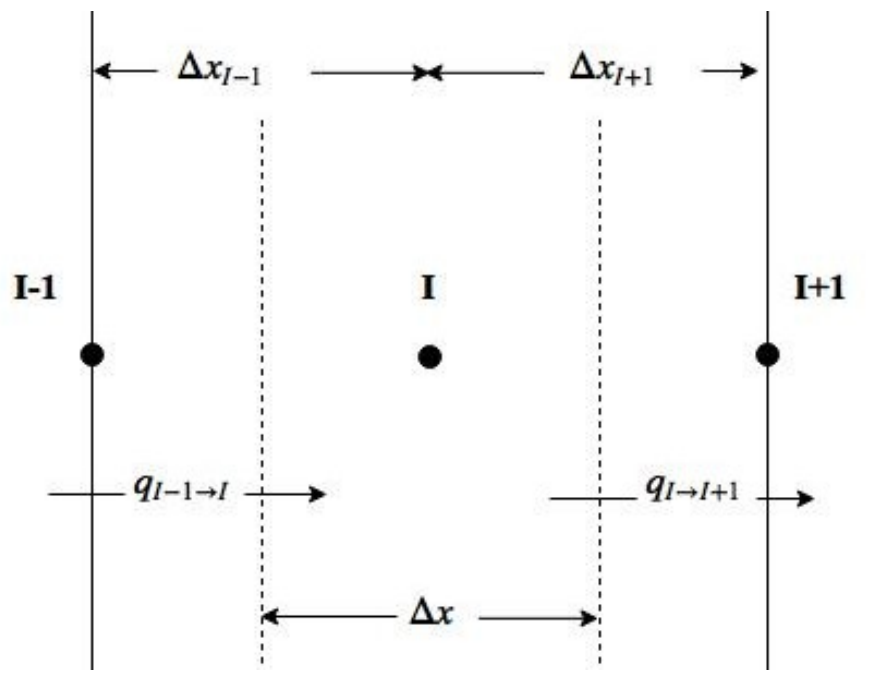

Figure 2.3: Control volume discretization of a homogeneous layer in ESP-r. Adapted from [31]

The absorbed solar radiation at each glazing layer is treated as a source term, and distributed among the nodes within the control volume. By integrating over the control volume, the heat balance equation for a node $i$ within a glazing layer can be expressed as:

$$
\begin{gathered}
\left(\rho c_{p} \Delta x \Delta y \Delta z\right)_{i} \frac{\partial T}{\partial t}=q_{i-1 \rightarrow i}-q_{i \rightarrow i+1}+q_{\text {solar }, i} \\
q_{i-1 \rightarrow i} \approx \frac{k_{i} \Delta y \Delta z}{\Delta x_{i-1}}\left(T_{i-1}-T_{i}\right) \\
q_{i \rightarrow i+1} \approx \frac{k_{i} \Delta y \Delta z}{\Delta x_{i+1}}\left(T_{i}-T_{i+1}\right)
\end{gathered}
$$

where $k_{i}$ is the thermal conductivity, $\rho$ is the density, $c_{p}$ is the specific heat capacity, $T_{i-1}$ and $T_{i}$ are the temperatures at nodes $i-1$ and $i$ respectively. $q_{i-1 \rightarrow i}$ and 
$q_{i \rightarrow i+1}$ are conduction fluxes from the neighbouring nodes, and $q_{s o l a r, i}$ is the solar flux absorbed at $i$.

Convective exchanges also occur within the gas gaps located between adjacent glazing layers. For a node adjacent to a gas gap, the energy balance is given by:

$$
\begin{array}{r}
\left\{\begin{array}{c}
\text { storage of } \\
\text { energy in } C V
\end{array}\right\}=\left\{\begin{array}{c}
\text { net conduction } \\
\text { into } C V
\end{array}\right\}+\left\{\begin{array}{c}
\text { sources of energy } \\
\text { within } C V
\end{array}\right\} \\
+\left\{\begin{array}{c}
\text { net longwave radiation } \\
\text { into } C V
\end{array}\right\}+\left\{\begin{array}{c}
\text { net convection } \\
\text { into } C V
\end{array}\right\}
\end{array}
$$

\subsubsection{Flow Complexities Associated with Window Blinds}

When a venetian blind is placed on either side or within a glazing unit, additional heat flow paths are introduced to the model.

First, unlike glass, the optical properties of blind materials are modelled as nonspecular. This means that solar beam radiation is scattered upon reflection. The now diffuse radiation also undergoes further reflections between the slats and the glazing layer. This behaviour must be captured by the model for accurate evaluation of solar-optical properties of the glazing/shading unit.

Second, while glass is opaque to longwave radiation, the slat layers of venetian blinds are not. Longwave radiation can be transmitted through slat openings and from slat surfaces. As such, venetian blinds can be described as diathermanous (permeable by solar and longwave radiation). Longwave thermal exchanges can occur between non-adjacent layers of the glazing/shading unit. These exchanges may be captured using "so-called" jump resistors (see Figure 2.4). Conventional methods of determining heat flow in an gas gap depend on the ease with which the convection and radiation thermal resistances can be combined (the total resistance of a resistance network in series is much easier to calculate than when some resistance components are in parallel). Such methods may be erroneous when jump resistors are present.

Third, the presence of a shading layer affects the surrounding convective airflow, particularly with indoor and outdoor blinds. The blinds impact the velocity profile of the airflow around the window, and the resulting convective heat transfer effects must now be accounted for. Convective exchanges occurring between non-adjacent 
layers are also addressed using jump resistors, as illustrated in Figure 2.5.

The methods used within the CFC facility address these limitations. These are briefly discussed in the following subsection.

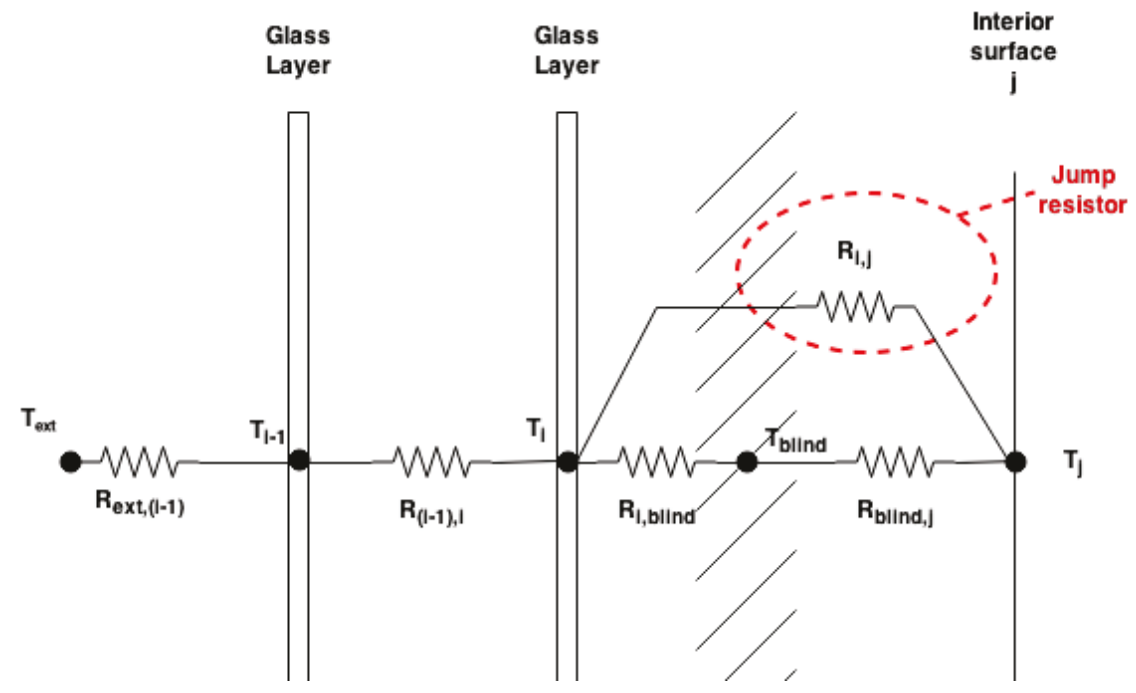

Figure 2.4: Radiative thermal network of a double-glazed window with indoor blinds installed

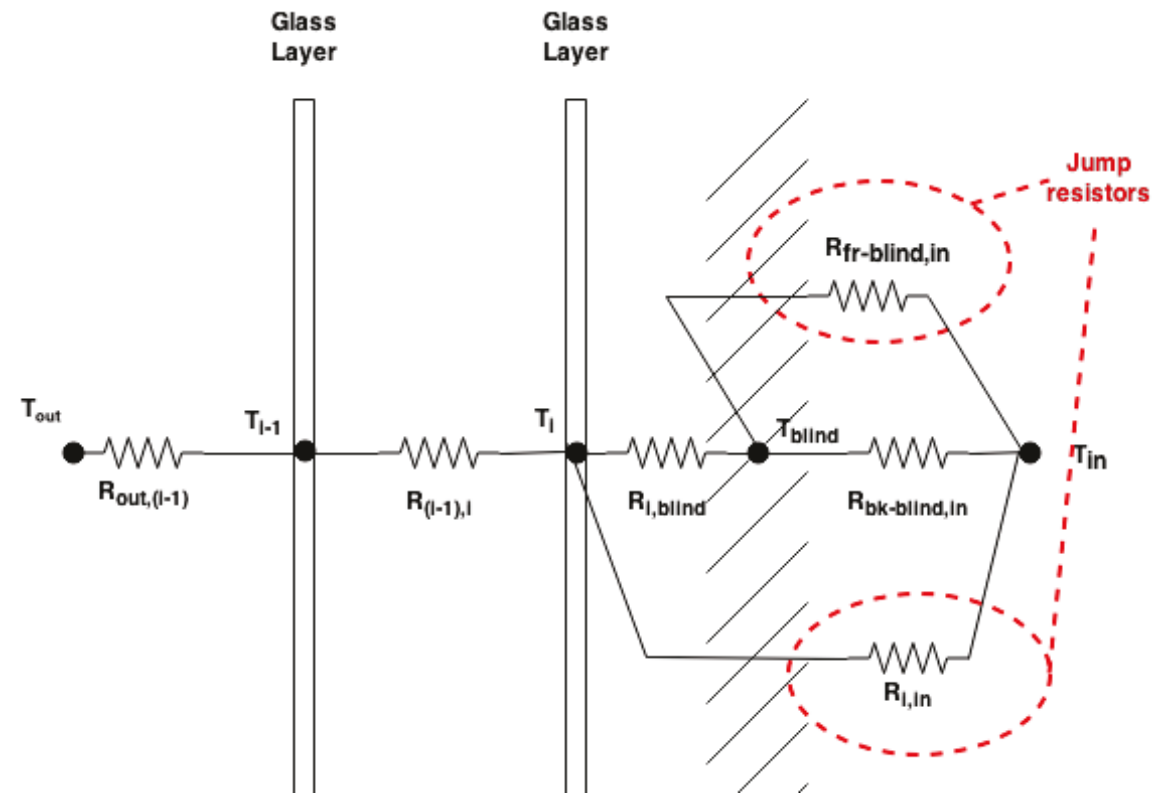

Figure 2.5: Convective thermal network of a double-glazed window with indoor blinds installed 


\subsubsection{Treatment of Window Blinds within the CFC Facility}

The methodologies employed within the CFC facility are suitable for energy calculations involving window blinds positioned inside, outside or within glazing layers. However, only the underlying models and assumptions for the treatment of indoor venetian blinds are discussed. The CFC functionality allows active control of blind positions and slat angles (see Figure 2.6) of venetian blinds based on user-defined set-points or schedules. The control variables are shown in Figure 2.6.

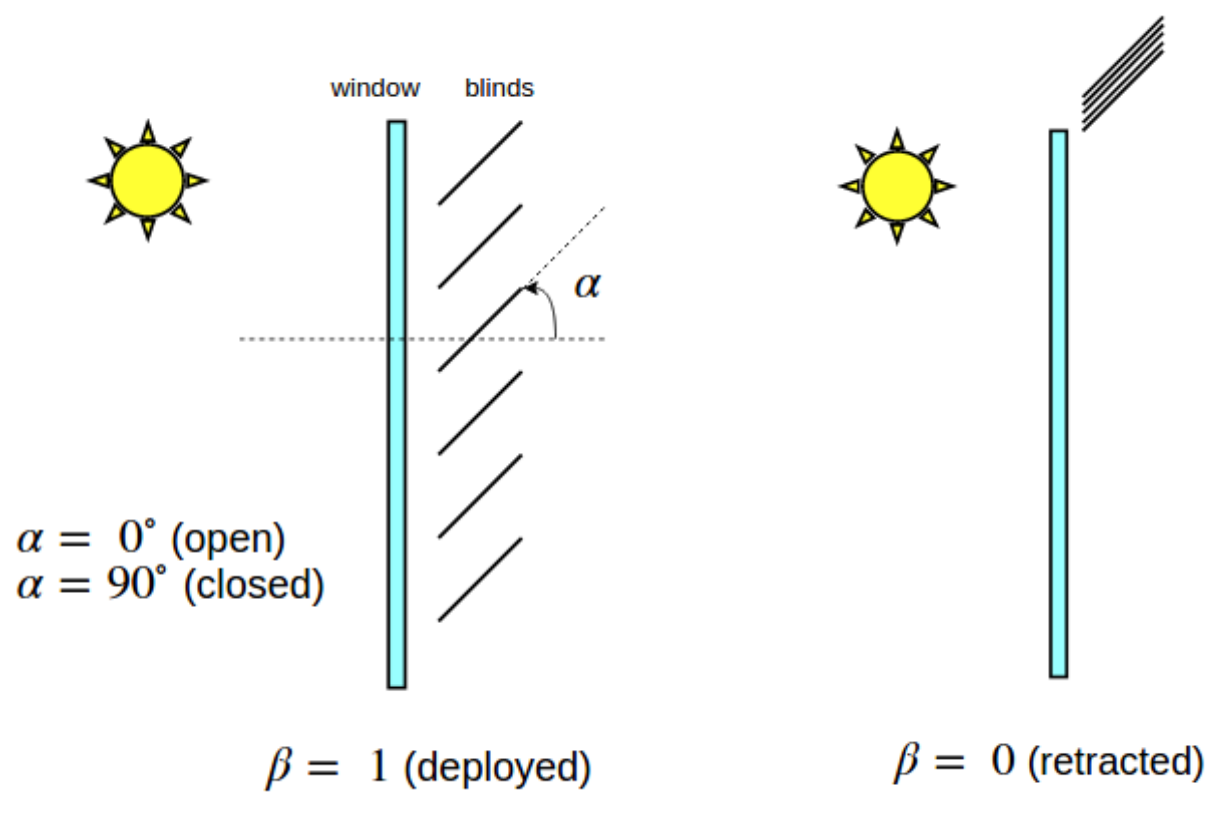

Figure 2.6: Representation of slat control configuration

\section{Solar Radiation}

Calculations of the solar-optical properties of the venetian blinds are based on a model developed by Kotey and Wright [35]. The slats are assumed to only reflect (and transmit, if they are translucent) solar radiation diffusely, such that the slat material's optical properties are independent of the angle of incidence. The model also assumes that reflected and transmitted solar radiation within the glazing/shading system is specular and/or isotropically diffuse. In specular reflection, the angle of incidence is equal to the angle of reflection. Isotropically diffuse means that the diffuse radiation 
is identical in all directions.

Under these assumptions, solar radiation paths can be characterized as: (1) beambeam (incident beam radiation that passes through the slat openings and remains beam radiation), (2) beam-diffuse (incident beam radiation that passes through the slat openings and becomes diffuse), (3) diffuse-diffuse (incident diffuse radiation that passes through the slat openings and leaves diffused). The solar-optical properties of radiation that fall within each of these categories are resolved using the view factors and geometric relationships of the incident radiation and slat surfaces.

In ESP-r, solar processing begins by determining angle geometry. For glass layers, optical properties are based on the angle of incidence of solar radiation. For blinds, optical properties are dependent on the angle of the incident solar radiation and the slat angle. Furthermore, the CFC facility allows active control of the slat angle. As such, solar-optical properties must be calculated before simulations and whenever there is a change in geometry, in order to account for the new slat positions.

Next, the solar-optical properties of each layer are calculated. The inputs required by the CFC facility are the normal incident transmittance and reflectances of the front and back surfaces of all glazing/shading layers. For glass layers, because glass is specular, these values correspond to the beam-beam solar radiation within a slat enclosure. Off-normal properties of glazing layers are calculated by normalizing the angular dependency to a reference glass type and thickness. Diffuse-diffuse properties are calculated similarly to beam-beam properties for solar radiation incident at an equivalent angle of $51^{\circ}$. As a result, only the beam-diffuse solar-optical properties of the blinds are required. These properties are supplied by the user.

Using the obtained solar-optical properties, the fraction of the solar flux absorbed within each layer and the fraction transmitted into the zone are calculated during each time step. The absorbed quantities at each construction layer serve as energy sources for the heat balance equations of containing nodes.

\section{Longwave Radiation}

The exchange factor method, described in [36] is used as a basis for calculating the longwave radiation coefficients between each pair of relevant surfaces. This method assumes that all surface temperatures within the glazing/shading construction lie within a small range, such that the spectral longwave absorptivity and longwave emmisivity of each surface are equal. 
Exchange factors are similar to view factors. However, view factors are solely concerned with the fraction of radiation leaving one surface that directly strikes another surface within an enclosure. Exchange factors consider direct radiation, as well as all possible reflections. As such, they are applicable for diffuse radiation exchanges that may undergo further reflections. Exchange factors are especially beneficial for tracking individual longwave radiation exchanges involving diathermanous layers, which have multiple paths of radiant exchange with other surfaces. Like with solar processing, exchange factors are calculated at the start of simulations or whenever there is a change in blind/slat positions.

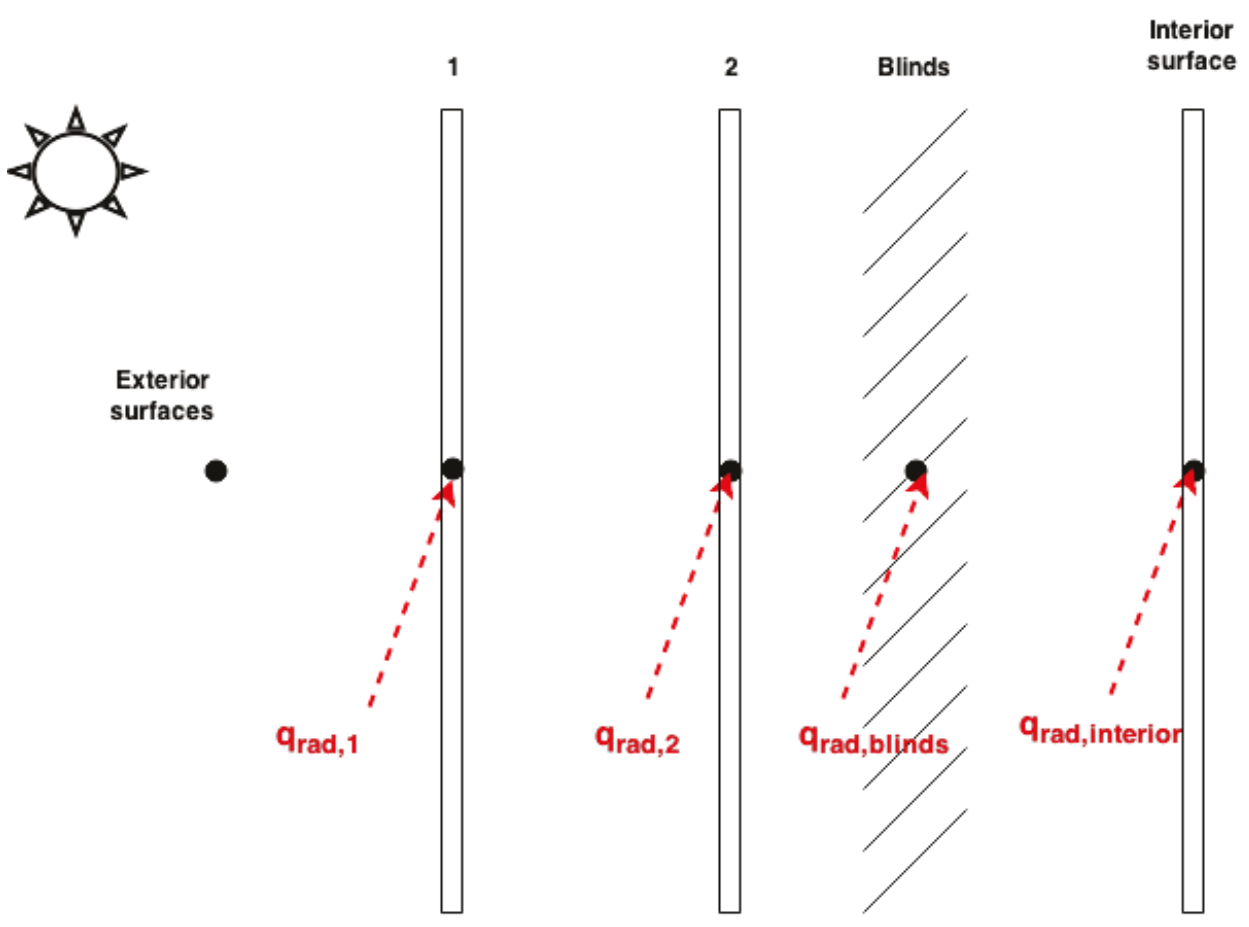

Figure 2.7: Injection/extraction radiant fluxes to represent all longwave exchanges between layers

The CFC facility resolves the longwave thermal exchanges by treating the net flux at each surface as an injection or extraction term at each node. This is shown in Figure 2.7. Heat fluxes between each pair of surfaces are calculated using the obtained exchange factors. The longwave transfer coefficients are subsequently determined, and node temperatures are solved iteratively. 


\section{Convection}

The presence of window blinds on the interior surface of a window influences the surrounding, convective flow. Convective exchanges around interior blinds are modelled using findings reported by Shahid and Naylor [37]. This model is an empirical formulation, and may not be applicable to non-conventional glazing/shading systems. Their findings showed that the convective exchanges around window blinds are dependent on the distance of the slat tip from the window surface. When the blinds are positioned near the window, the convective exchanges between the glass and blind surfaces to the indoor air decrease, while the convective exchanges between the blinds and the glass surface increase. As the blinds are positioned further away from the window, the converse is true.

These observations were adapted to an empirical formula using Wright et al.'s [36] equivalent resistance network for a shaded, double-glazed window. The convective flow from the glass to the blinds is assumed to be laminar, and mostly parallel to the window surface. The convection coefficients within the glazing/shading system are expressed as exponential functions of the distance of the blinds from the window and the slat angle.

The jump resistors are expressed in terms of the convection coefficients and resolved as injection/extraction flux terms, as shown in Figure 2.8.

\subsection{Urbandale CHEeR House Model}

As stated in Chapter 1, the goal of this thesis is to develop an MPC scheme for automated blind control, and apply it to the Urbandale CHEeR house. An existing ESP-r model of the Urbandale CHEeR house from [38] was used as a basis for creating the model used for this work. The existing model presents a detailed representation of the thermal processes within the house. As part of this work, venetian blinds were added to the existing ESP-r model. A control 'schedule' that complements MPC of the blinds was also created in ESP-r. This section describes the existing model and the modifications made for this work. 


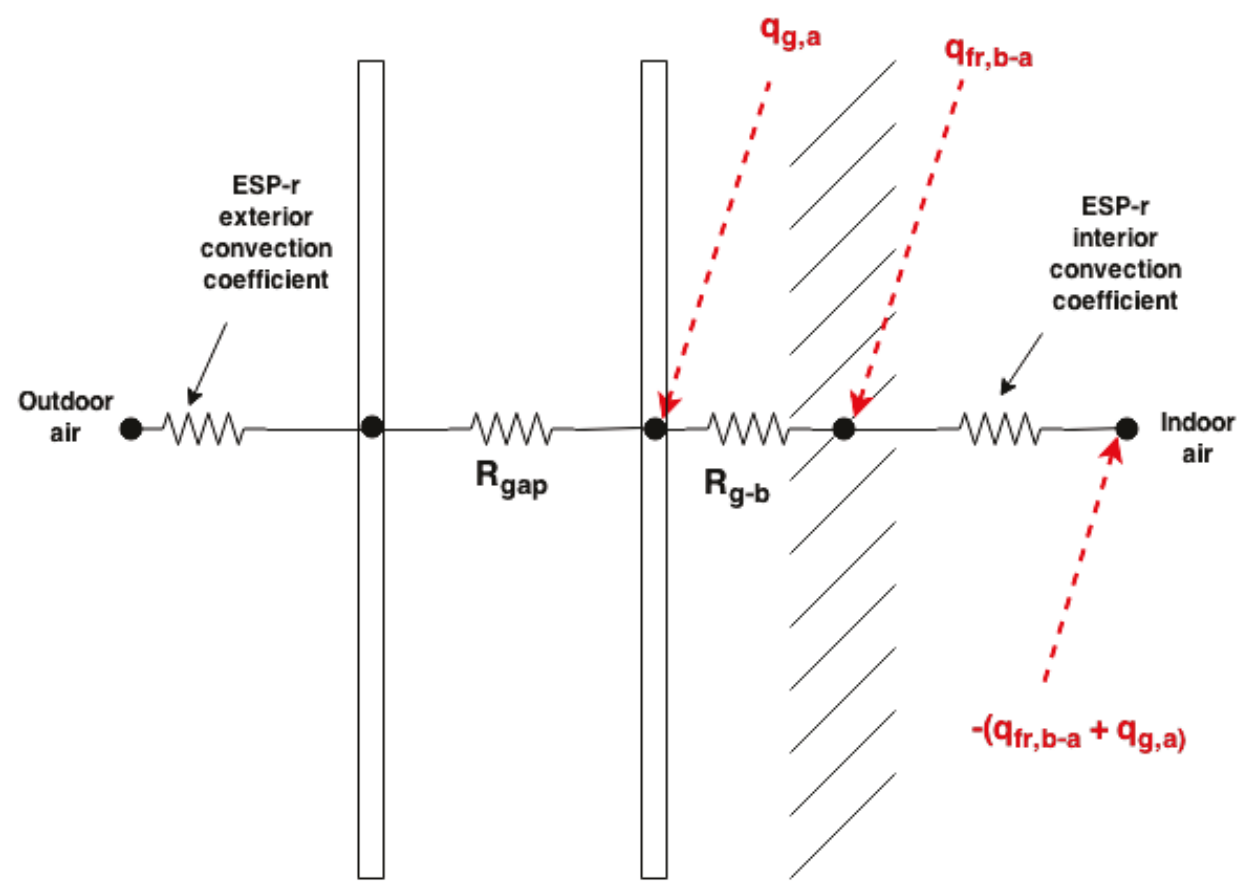

Figure 2.8: Injection/extraction convective fluxes to represent jump resistors

\subsubsection{Building Description}

The Urbandale CHEeR house is a $74.3 \mathrm{~m}^{2}$, single-family detached home with two storeys, a basement and an attic-space. It is located in Ottawa, Canada $\left(45.4214^{\circ} \mathrm{N}\right.$, $\left.75.6919^{\circ} \mathrm{W}\right)$. Summers in Ottawa are hot and humid, and winters are cold with an abundance of snow. This wide variation in the ambient temperature makes shading buildings within this climate complicated, as shading practices which are favourable in the winter may be detrimental in the summer, and vice-versa.

Windows are distributed along the east, west and south faces of the house, with the majority on the south face to promote passive heating, (see Figure 2.9).

\subsubsection{Existing Model Details}

The Urbandale CHEeR project covers a wide range of energy saving designs and techniques, and the existing ESP-r model is reflective of this. This section summarizes only the aspects of the existing model, which are relevant to this work. A wireframe illustration of the model is shown in Figure 2.11. 


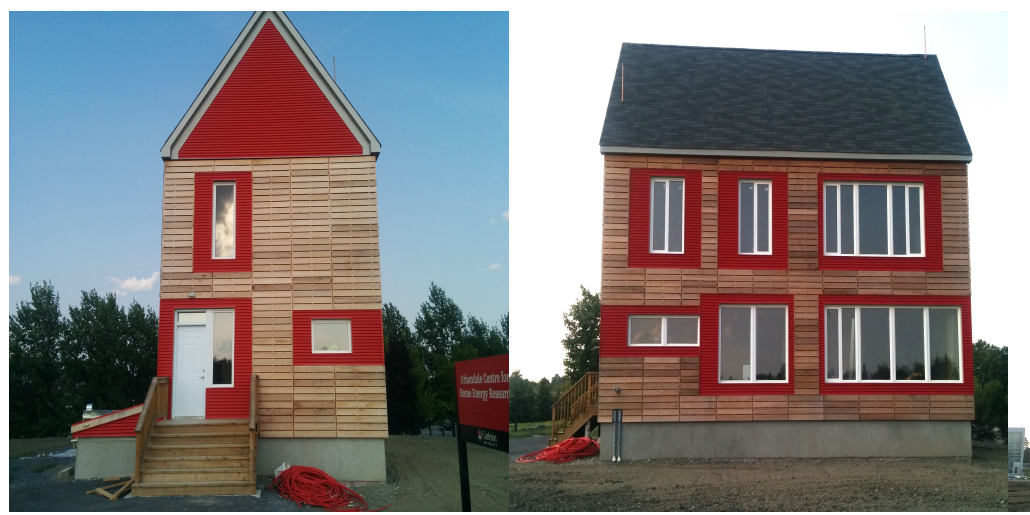

(a) East view

(b) South view

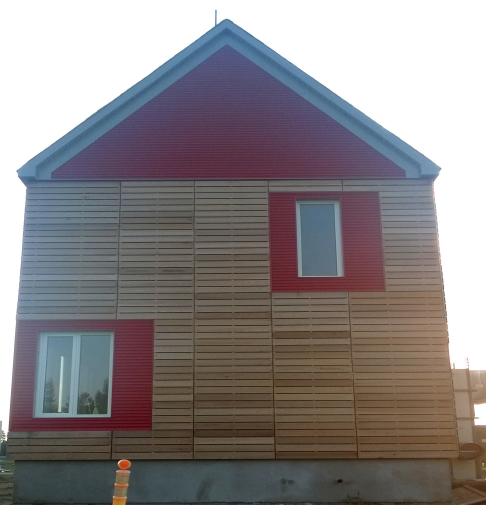

(c) West view

Figure 2.9: Urbandale CHEeR house, showing window positions

The existing model uses weather data from the Canadian Weather year for Energy Calculation (CWEC) [39]. The house is divided into seven thermal zones. The conditioned spaces (the two storeys and basement) and the attic were each assigned a thermal zone. The joist spaces between each floor were also treated as separate thermal zones. In addition, explicit surfaces were defined to represent the window frames and structural thermal bridging. Infiltration through the envelope was modelled using the Alberta Air Infiltration Model (AIM-2) [40]. The building's leakage was described using blower-door test data. The inputs for this model are air tightness, given in air-changes per hour at $50 \mathrm{~Pa}$ pressure differential $[\mathrm{ACH}]$, and estimated leakage area $\left[\mathrm{cm}^{2}\right]$. Also, the first and second storey of the CHEeR house are each prescribed $400 \mathrm{~W}$ of internal sensible heat gains and $0 \mathrm{~W}$ of latent heat gains daily.

The thermal resistance (R-value) of each exterior wall is $5.6 \mathrm{~m}^{2} \mathrm{~K} / \mathrm{W}$. For simplicity, interior walls were omitted from the model. Also, the ESP-r model of the Urbandale CHEeR house has thirteen triple glazed windows in total - eight on the south face, two on the east face, and three on the west. The glazing units are a combination of picture and casement windows. It is worth mentioning that this study was conducted using the windows from design phase of the Urbandale CHEeR house, which differ from the currently installed windows. The glazing construction for a casement window from the design phase is illustrated in Figure 2.10, and material properties are given in Table 2.1. The front surface corresponds to the side of the construction facing the outside. The casement windows have a centre of glass U-value of 0.89 and solar heat gain coefficient of 0.57 respectively. The picture windows have 


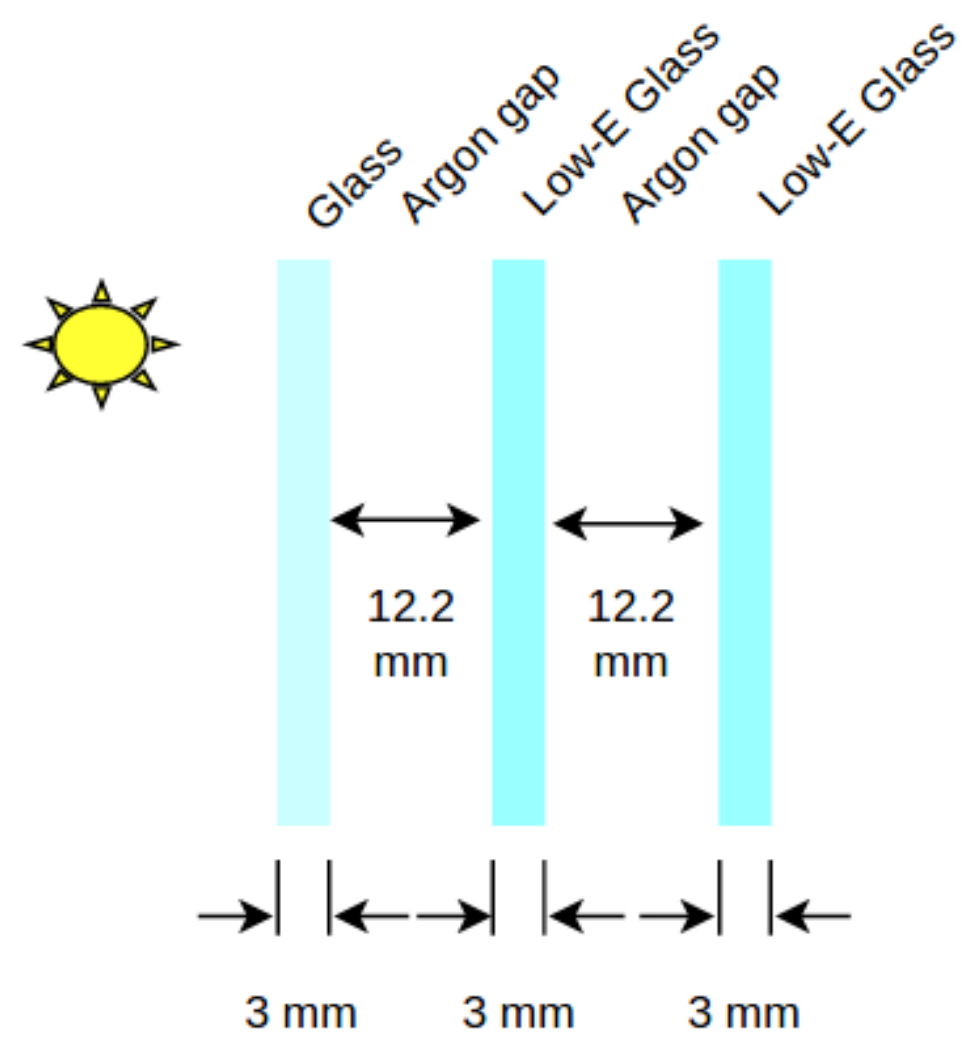

Figure 2.10: Glazing construction for casement windows

a similar construction, but with $15.3 \mathrm{~mm}$ thick gas gaps.

The Urbandale CHEeR house has three conditioned zones, with a total floor area of $217 \mathrm{~m}^{2}$. The HVAC system is modelled using a plant network in ESP-r. The plant components are provided in the ESP-r plant file in Appendix C.2. Heating and cooling is provided by a heat pump with a heating capacity of $7 \mathrm{~kW}$ and cooling capacity of $3.5 \mathrm{~kW}$. In the existing model, the heat pump is simulated using the ESP-r/TRNSYS co-simulator [41]. Heating or cooling is injected using an ON/OFF controller, which senses the air temperature of the $1^{\text {st }}$ storey and reacts accordingly. The ON/OFF set-points are given in Table 2.2. 


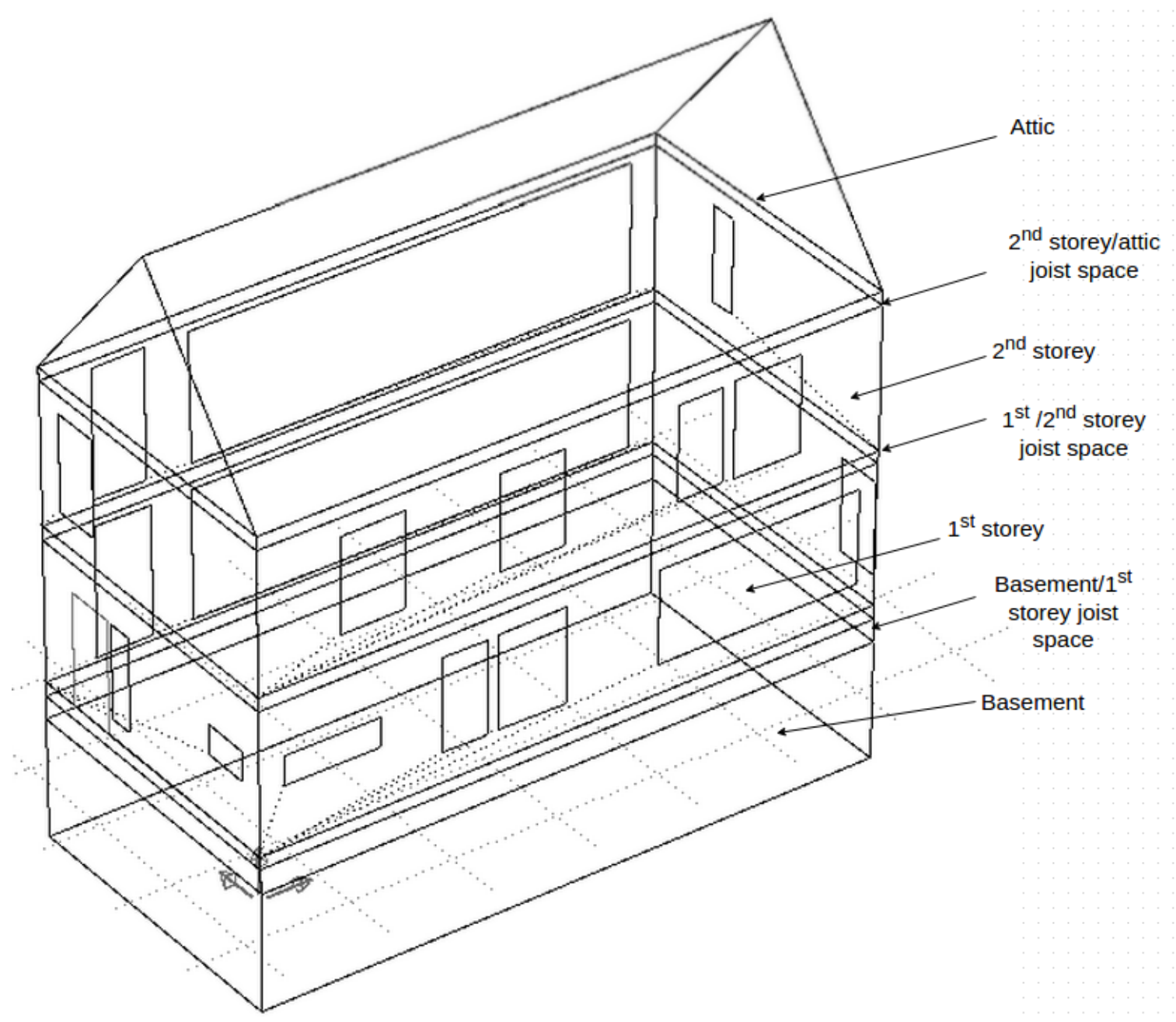

Figure 2.11: Wireframe representation of the Urbandale CHEeR house model in ESP-r 


\begin{tabular}{ccc}
\hline Property & Glass & Low-E Glass \\
\hline$\rho_{\text {solar,front }}$ & 0.122 & 0.122 \\
$\rho_{\text {solar,back }}$ & 0.117 & 0.112 \\
$\tau_{\text {solar,front }}$ & 0.801 & 0.692 \\
$\tau_{\text {solar,back }}$ & 0.801 & 0.692 \\
$\epsilon_{\text {lw,front }}$ & 0.833 & 0.156 \\
$\epsilon_{\text {lw,back }}$ & 0.840 & 0.840 \\
Conductivity $(\mathrm{W} / \mathrm{mK})$ & 1 & 1 \\
\hline
\end{tabular}

Table 2.1: Glazing optical properties at normal incidence

\begin{tabular}{lcc}
\hline & ON set-point $\left({ }^{\circ} \mathrm{C}\right)$ & OFF set-point $\left({ }^{\circ} \mathrm{C}\right)$ \\
\hline Heating & 20.5 & 21.5 \\
Cooling & 25.5 & 24.5 \\
\hline
\end{tabular}

Table 2.2: Temperature set-points for heating and cooling

\subsubsection{Modifications to Existing Model and Introduction of Venetian Blinds}

The modifications made to the existing model are described in this subsection.

First, the heat pump is substituted for an equivalent cooling and heating coil connected in series in ESP-r. This substitution eliminates the need for the ESP-r/TRNSYS co-simulator, therefore simplifying the model and reducing the simulation time. The cooling and heating coils were modelled to replicate the cooling and heating output of the heat pump, according to the prescribed temperature set-points.

Second, venetian blinds were introduced to the interior sides of all thirteen windows of the Urbandale CHEeR house. The blinds used for this work are $1 / 2$ inch, light, aluminum venetian blinds. This configuration was chosen based on results from [11], which concluded that this configuration provides the largest energy savings for Canadian climates in comparison to other common window shading devices. The 
Table 2.3 shows the solar and longwave optical properties of the blinds.

\begin{tabular}{|c||c|}
\hline Thickness $(\mathrm{mm})$ & 12.7 \\
\hline Conductivity $(\mathrm{W} / \mathrm{mK})$ & 170 \\
\hline$\rho_{\text {solar,back }}$ & 0.85 \\
\hline$\rho_{\text {solar, front }}$ & 0.85 \\
\hline$\tau_{\text {solar,back }}$ & 0.00 \\
\hline$\tau_{\text {solar, front }}$ & 0.00 \\
\hline$\tau_{\text {lw,back }}$ & 0.00 \\
\hline$\tau_{\text {lw,front }}$ & 0.00 \\
\hline$\epsilon_{\text {lw,back }}$ & 0.85 \\
\hline$\epsilon_{\text {lw, front }}$ & 0.85 \\
\hline
\end{tabular}

Table 2.3: Blind solar and longwave optical properties at normal incidence

In addition, a control 'schedule' that supports MPC of the blinds was created in ESP-r. Generally, under a schedule-type control, the blinds do not react to any of the building's conditions, but simply assume a user-declared position. However, for this work, the 'schedule' is updated hourly with the calculated optimization results instead of using user-declared blind positions.

Furthermore, the set of blinds on each face of the house were assigned a common 'schedule' control. Each 'schedule' is divided into fourteen control periods over the day (see Figure 2.12). The first and last control periods, 12 a.m. -7 a.m. and 7 p.m.12 a.m. respectively, represent the early hours and late hours of the day, when the solar radiation is minimal. The blind positions are not optimized during these hours. The remaining twelve control periods from 7 a.m. -7 p.m represent the hourly daytime periods, which are optimized. The choice of hourly control periods are based on MPC applications within the literature [3].

The blinds can be retracted or deployed, and the blind slat angles can be controlled when the blinds are deployed. Hence, each period has two control parameters - $\alpha$, which represents the slat angle on the window blinds, and $\beta$, which indicates whether the blinds are retracted or deployed. Since the windows are only distributed along 


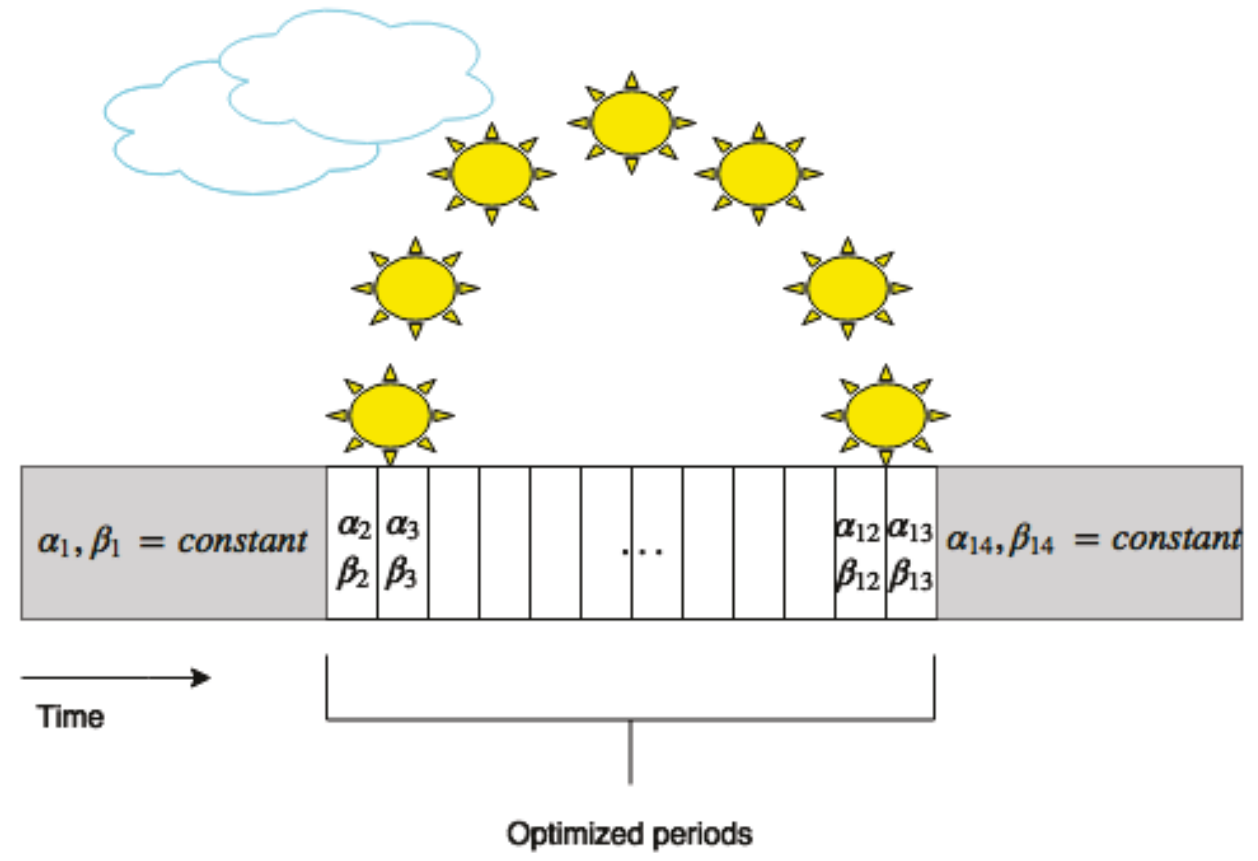

Figure 2.12: Outline of control schedule, showing blind control periods and variables for a single day

three faces of the building, and there are twelve sub-periods in the daytime and two control parameters, the optimization problem will be characterized by 72 variables $(3 \times 12 \times 2=72)$. Chapter 3 explains the optimization problem in greater detail.

This control schedule outline allows each hour within the optimization period to be assigned the optimized blind position ahead of the simulation. A warm-up period of 7 days was chosen as further increases in the number of warm-up days showed no significant differences in the simulation results. Also, a 5 minute time-step was used, as it is small enough to capture the dynamic performance of the plant components while keeping computation costs manageable.

\subsection{Closing Remarks}

An accurate representation of the relationship between blind control and building energy demand is required for proper implementation of model predictive control of window blinds. ESP-r, a rigorous building performance simulation tool, was used to model this relationship. This chapter discussed the methodologies and models used within ESP-r, which are relevant to this thesis. Emphasis is placed on the complex 
fenestration construction functionality within ESP-r, which facilitates the modelling of window blinds. This chapter also provides a summary of the ESP-r simulation model used for this work. The following chapter explores the optimization tool and methods featured in this thesis. 


\section{Chapter 3}

\section{Solving the Optimization Problem}

Solutions that optimally utilize available resources are useful due to the finite nature of most resources. In building design and operation, optimization is generally geared towards minimizing parameters such as energy demand or costs, and maximizing others like efficiency, output or performance. Optimization is an essential aspect of $\mathrm{MPC}$, and the choice of the optimization algorithm is critical to accuracy. GenOpt was chosen as the optimizer for this work due to its compatibility with ESP-r. In addition, GenOpt's library contains optimization algorithms that are relevant to this thesis. This chapter describes the MPC optimization problem, explains the choice of optimization algorithm, and briefly discusses the process of setting up optimizations in GenOpt.

\subsection{Optimization Problem}

Any optimization problem can be described by a set of potential inputs, feasible states, and an objective function. The input is the control action that is taken to realize the solution to the optimization problem. The state describes the current conditions, and the objective function is the property that is either minimized or maximized. A general minimization formulation for MPC was expressed in Equation 1.1 .

In the optimization problem featured in this work, the control inputs are the variable blind and slat positions at each hour, the state is represented by the hourly interior temperatures, and the objective function is the sum of the heating and cooling loads. As the amount of heating and cooling supplied to the house is dependent on temperature (the state), the focus is placed on the relationship between the thermal 
loads and the blind and slat positions in order to perform optimizations.

For optimization purposes, the combined thermal load (the objective function, and $L(x, u)$ from Equation 1.1) is simplified as a function of the blind and slat positions only. Although the thermal loads are dependent on other factors (for example, the exterior temperature), the goal of this work is to optimize the contribution (or lack) of exterior solar gains to the building's heating and cooling demand. To maintain conformity within this thesis, the objective function is now denoted by $E_{\text {total }}$, the control variables are the blind slat angle $\alpha$ and the blind position (retracted or deployed), $\beta$. Therefore, at time $t$, the optimization problem over a prediction horizon $T$ may be expressed as:

$$
\begin{gathered}
\min \sum_{t}^{t+T} E_{\text {total }}^{t}\left(\alpha_{t}, \beta_{t}\right) \\
\left\{\alpha_{t}, \beta_{t}\right\} \in \boldsymbol{A}_{t}
\end{gathered}
$$

As stated in Chapter 2, ESP-r's capabilities allow the slats to assume any angle from $0^{\circ}$ to $90^{\circ}$ while the blinds are fully deployed $(\beta=1)$, or the blinds may be fully retracted $(\beta=0)$. This simplification makes the optimization problem more tractable and therefore easier to solve.

Now, the function of the optimizer is to solve the optimization problem given in Equation 3.1, for each optimization time step. The optimal solution can be found by applying a suitable algorithm for this problem. The choice of algorithm is dependent on the system's dynamics and constraints, in addition to time constraints. The algorithm chosen for this work is a hybrid of particle swarm optimization and the Hooke-Jeeves algorithm, which is discussed in the following section.

\subsection{Optimization Algorithm}

\subsubsection{Factors Influencing the Choice of Algorithm}

Real-time simulation of MPC requires quick computation. A full factorial experiment to solve each optimization problem within this MPC scheme would involve over 60 million simulations ${ }^{1}$, which may be completed at great computational cost.

\footnotetext{
${ }^{1}$ There are twelve $\alpha$ and twelve $\beta$ variables that represent the blind positions on each of the three faces of the house. Since $\alpha$ has three possible values: $0^{\circ}, 45^{\circ}$, or $90^{\circ}$ and $\beta$ has two possible values: 0 or 1 , the number of possible combinations $=(12 \times 3)^{3} \times(12 \times 3)^{2}=60,466,176$
} 
Conversely, an optimization algorithm may be chosen such that convergence to the optimal point occurs quickly, but without sacrificing the accuracy of optimizations.

Furthermore, system dynamics described by building simulation tools like ESP$\mathrm{r}$ are often non-linear and discontinuous in time. Continuous systems provide the advantage of using the gradient of the objective function to find the optimal point. The gradient of a function is a vector whose components are the partial derivatives of the function with respect to its variables. However, the derivative of a discontinuous function cannot be calculated. For such problems, derivative-free optimization algorithms should be used.

The algorithm used in this work is a hybrid of the derivative-free particle swarm optimization (PSO) and Hooke-Jeeves (HJ) generalized pattern search algorithm. Both algorithms are derivative-free optimization methods, which are useful for this work. The PSO algorithm generally performs better, especially when applied to large search spaces, but is slow to converge. Conversely, the HJ algorithm converges quickly, but is susceptible to premature convergence. Hybridization of these algorithms allows the user to exploit the benefits of both algorithms, while lessening their individual shortcomings.

The hybrid algorithm begins with the particle swarm optimization for a given number of iterations. Then, the HJ algorithm is initiated using the best solution found by the particle swarm optimization. Both algorithms are discussed extensively in the following sections.

\subsubsection{Particle Swarm Optimization}

The particle swarm optimization (PSO) algorithm is a population-based optimization method that was motivated by the collective behaviour of natural biological systems, such as bird flocking or fish schooling. Under such collective behaviour, each individual agent interacts with its neighbours and the environment based on simple rules. In the case of bird flocking, each bird flies in the same direction as its neighbours. This local tendency results in a cohesive movement of the entire flock in the same direction.

The PSO algorithm begins by generating a population of candidate solutions (particles) randomly distributed throughout the search space. The objective function at each particle's position is evaluated. Then, the algorithm updates the velocities and positions of each individual particle in each generation, such that they are attracted 
to the current best position within a given range. The particle's position refers to its location within the search space, and its velocity dictates how fast it moves at the end of each generation. The traditional PSO model is the global best (gBest) model, where all particles are attracted to the best position found by the swarm. Alternatively, the local best (lBest) model may be used, in which each particle is attracted to the best position found within its neighbourhood.

The lBest model was used for this work, and each particle's neighbourhood is defined using the von Neumann topology (see Figure 3.1). In the von Neumann topology, each particle is only connected to its immediate neighbours in all dimensions of the search space. For a two-dimensional optimization problem, the neighbours lie in the north, south, east and west directions. This version of the algorithm allows the particles to explore more areas in the search space in order to avoid premature convergence. Hence, it converges slower than other PSO versions, but generally performs better. GenOpt's implementation of this algorithm is illustrated in Figure 3.2, and the equations used to update each particle's position and velocity are given in Equation 3.2.

$$
\begin{aligned}
v_{i}(k+1)=v_{i}(k)+c_{i} \operatorname{rand}[] & \left(p \text { Best }_{i}(k)-x_{i}(k)\right) \\
& +c_{2} \operatorname{rand}[]\left(\text { lBest }(k)-x_{i}(k)\right) \\
x_{i}(k+1)= & x_{i}(k)+v_{i}(k+1)
\end{aligned}
$$

where $k$ is the generation number, $n_{p}$ is the number of particles in each generation, $x_{i}(k)$ denotes the $i$ th particle of the $k$ th generation, where $1 \leq i \leq n_{p}$, and $v_{i}(k)$ represents its velocity. lBest and $p B e s t_{i}$ are the current lBest position and the $i$ th particle's best position respectively. $c_{1}$ and $c_{2}$ are the cognitive and social acceleration. rand[ ] is a random number uniformly distributed between 0 and $1 . c_{1}$ and $c_{2}$ are set as 2.8 and 1.3 respectively, based on suggestions given in the GenOpt manual [42].

\subsubsection{Hooke-Jeeves Algorithm}

Generalized pattern search (GPS) algorithms are a collection of heuristic optimization methods that do not require a derivative to determine the optimal solution. 


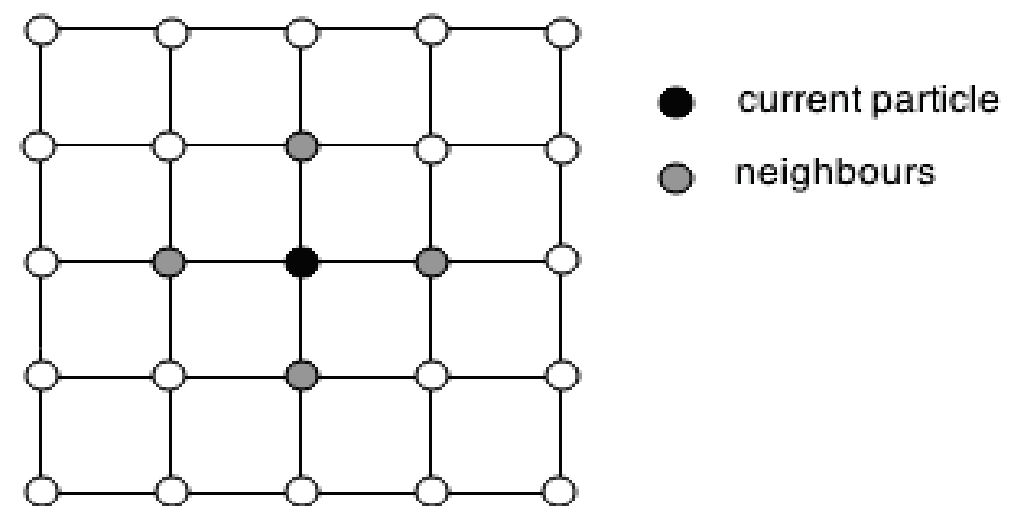

Figure 3.1: Von Neumann neighbourhood topology for two-dimensional search space

They simply emulate the 'gradient' of a discontinuous function by evaluating the objective function of a point and its neighbours, and move towards the direction of improvement. The neighbouring positions are perturbations of the original point in all directions of the search space, but only one variable is altered at at time. This is called an exploratory search. The Hooke-Jeeves (HJ) variation of GPS uses an exploratory search as well as a pattern move, whereby the algorithm makes larger moves in the direction of improvement. As a result, the HJ variant is quick to converge.

The HJ algorithm is most suitable for problems with continuous variable parameters, meaning that the variables can assume any value within the set of constraints. This is because each particle uses its neighbouring positions to move towards the optimal position. Depending on its implementation, if no neighbouring position falls within the set of constraints, the algorithm may fail (as in GenOpt) or optimize the wrong problem. Since both $\alpha$ and $\beta$ are continuous variables by definition ${ }^{2}$, the HJ algorithm is suitable for this optimization problem.

The HJ algorithm is explained using only $\alpha$ for simplicity. A thorough explanation of the algorithm is included in the appendices (Appendix B).

First, the HJ algorithm describes the search space as a multi-dimensional grid.

\footnotetext{
${ }^{2}$ The definition of $\beta$ within the ESP-r source files is a piece-wise function such that the blinds are:

$$
\begin{cases}\text { retracted } & \text { if } 0 \leq \beta<1 \\ \text { deployed } & \text { if } \beta>1\end{cases}
$$

Hence $\beta$ can be treated as a continuous variable between 0 and 1 , which allows $\beta$ to be varied during the HJ phase.
} 


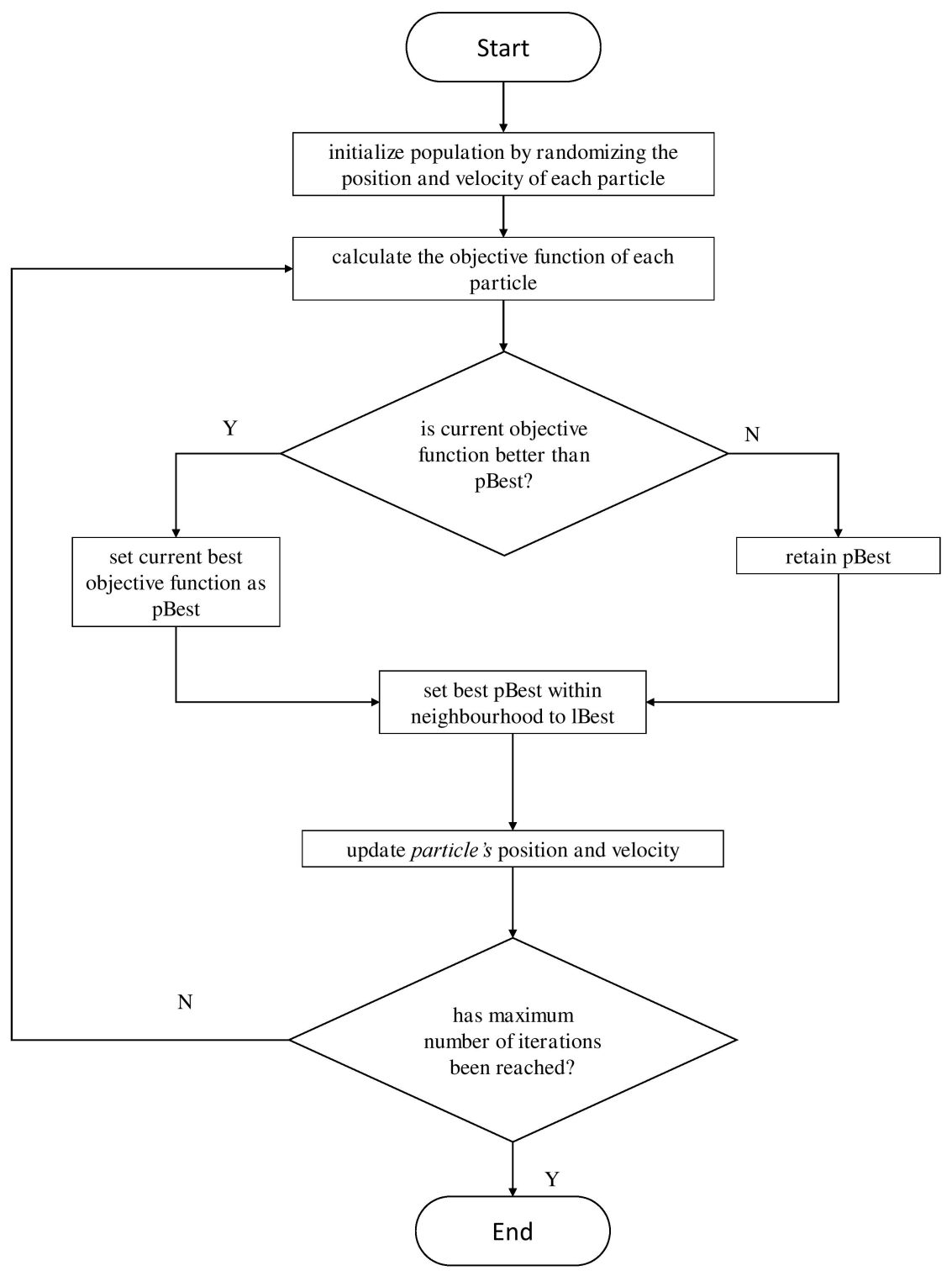

Figure 3.2: Flow chart of a sample PSO algorithm

Each dimension corresponds to each varied parameter, $\left\{\boldsymbol{\alpha}_{1}, \ldots, \boldsymbol{\alpha}_{n}\right\}$, for $n$ variables. For example, the search space for a problem with two variables is represented in two dimensions. The initial perturbation in each direction is supplied by the user. For this work, initial perturbations for $\alpha$ and $\beta$ were given as $90^{\circ}$ and 1 respectively. However, perturbations in all directions do not need to be equal. The algorithm evaluates the objective function at a user-defined starting point and assigns this value as the current, 
best iterate, $L_{\text {best }}$ (as it is the only iterate thus far).

Next, an exploratory search is initiated. The algorithm searches the neighbouring positions for an improvement in the objective function, based on the specified perturbations. Each variable is perturbed one at a time. If a perturbation shows an improvement in the objective function, this perturbation is retained and the search continues until all variables are exhausted. If the exploratory search is successful, the algorithm initiates a pattern move which makes larger steps in the direction of improvement. Otherwise, the perturbations are made smaller and another exploratory search is repeated. A suggested step reduction variable of 2 was used for this work [43].

The HJ algorithm searches the space until the required tolerance or the maximum number of iterations is reached. In GenOpt, the tolerance is given by the number of step reductions. For this work, the number of step reductions was set to 1 and the initial perturbations of $\alpha$ were set to $90^{\circ}$. Therefore, iterations are terminated when the perturbation vector becomes $\left\{\frac{\Delta \alpha_{1}}{2}, \ldots, \frac{\Delta \alpha_{n}}{2}\right\}$ (since $2^{1}=2$ ). For this work, this value provides a $45^{\circ}$ resolution for the optimizations, which is sufficient, as a finer resolution introduces redundancy. Figure 3.3 shows the routine of the HJ algorithm.

\subsection{Solving the Optimization Problem in GenOpt}

The interested reader is directed to [42] for a more detailed discussion of GenOpt.

GenOpt is an optimization software that can be used with any text-based simulation program that calculates the objective function without having to recompile the program. Also, the simulation program must be capable of being initiated by a command, and the simulation program must terminate automatically after completion. GenOpt contains a library of optimization algorithms including the hybrid PSO-HJ algorithm. The user can also create a custom algorithm within GenOpt's environment. This section describes the process of setting up an optimization problem in GenOpt.

\subsubsection{Objective Function}

First, the objective function is defined. The objective function is a numerical value calculated from the simulation program, which is to be minimized through optimization. For this work, the objective function at a time $t$ is the sum of the heating and 


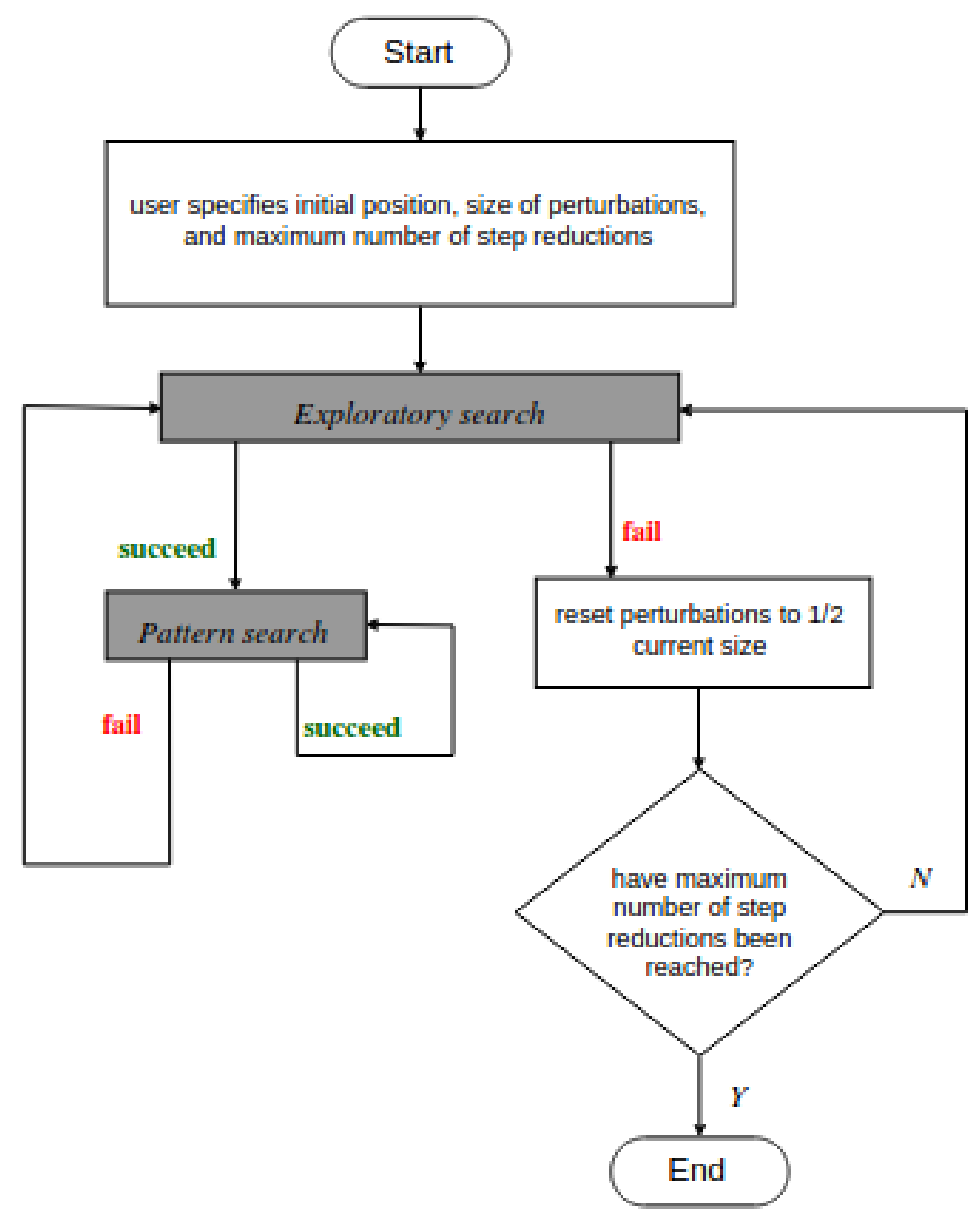

Figure 3.3: Routine of Hooke Jeeves algorithm with a step reduction of 2

cooling loads over the prediction horizon $[t, t+T]$, given by $E_{\text {total }}^{t}$ :

$$
E_{\text {total }}^{t}(\boldsymbol{\alpha}, \boldsymbol{\beta})=\sum_{j=t}^{t+T}\left(E_{\text {heating }}^{t}\left(\alpha_{j}, \beta_{j}\right)+E_{\text {cooling }}^{t}\left(\alpha_{j}, \beta_{j}\right)\right)
$$

$E_{\text {heating }}$ and $E_{\text {cooling }}$ denote the heating and cooling load requirements of the house during the simulation period $[\mathrm{kWh}]$, respectively. These quantities are obtained from ESP-r's simulation outputs. 


\subsubsection{Variable Parameters}

In order to minimize $E_{\text {total }}$, the blind and slat positions are varied. As noted in 2.5.3, the blinds on each face of the house share a common control. Each control period is assigned a variable for the blind position, $\beta$ (retracted or deployed) and the slat angle $\alpha$. This configuration results in a total of 72 variable parameters. Each $\alpha$ is a continuous variable, ranging from $0^{\circ}$ to $90^{\circ}$, while $\beta$ ranges from 0 to 1 . The declarations of these variables in GenOpt are given in Appendix C.1.

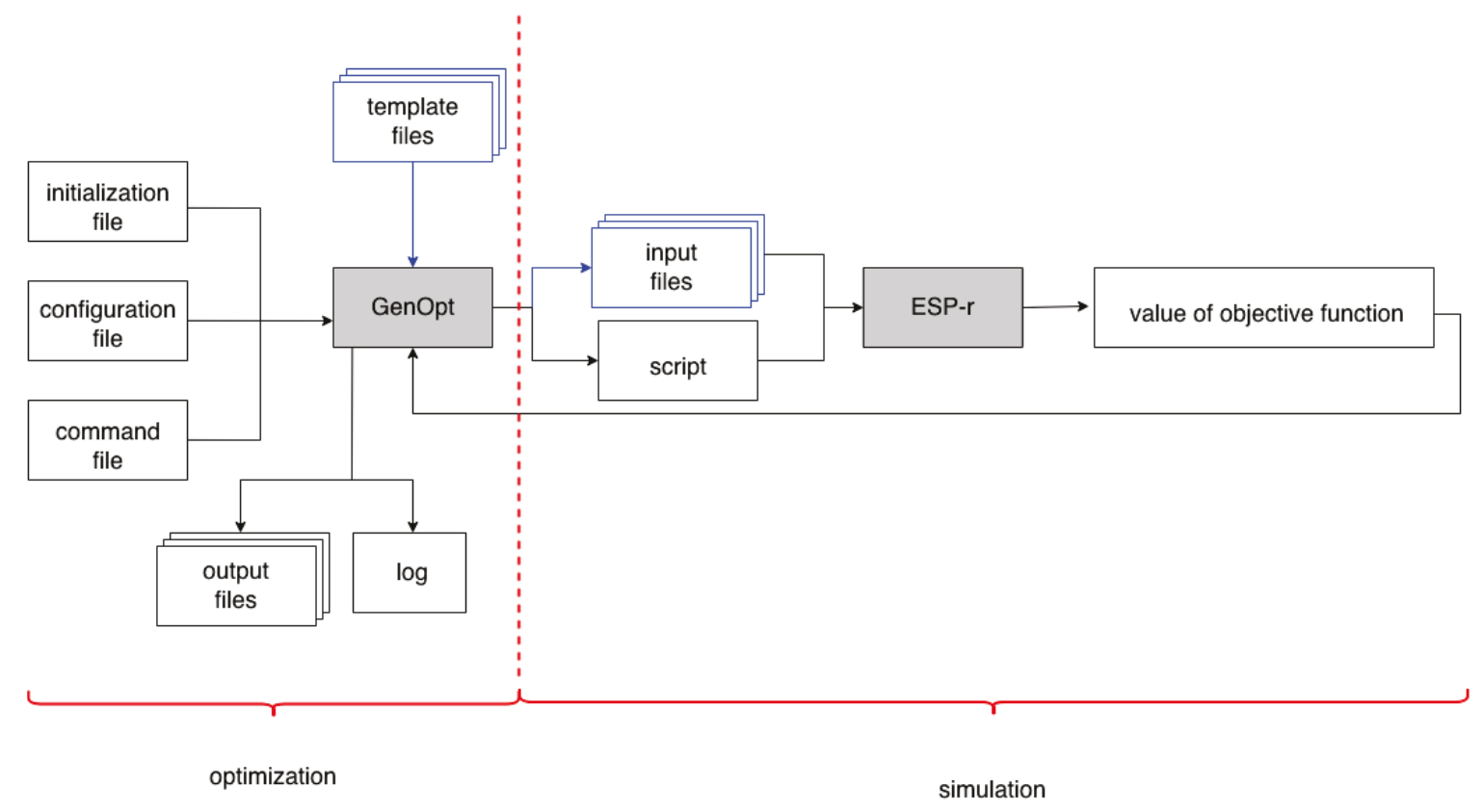

Figure 3.4: Data flow of GenOpt/ESP-r coupling. Adapted from [26]

\subsubsection{Software Coupling}

Several files must be prepared to facilitate communication between GenOpt and the simulation program, ESP-r (see Figure 3.4). These are: (i) a configuration file that specifies how to start ESP-r, (ii) a command file stating the optimization algorithm, settings, and user-defined starting points, (iii) template files of the simulation input files, (iv) an initialization file containing the location of files (i)-(iii), a log file, and the location of the objective function calculated from ESP-r. The interested user is directed to [26] and [42] for detailed directions on how to prepare these files. The prepared files for this work are also included in the appendices (see Appendix C.1). 
An overview of the information flow for one iteration (shown in Figure 3.5) is given as follows:

- Step 1: GenOpt creates ESP-r input files from the template files, using the optimization algorithm and settings

- Step 2: GenOpt calls the shell script, StartPawnSimulations.sh

- Step 3: StartPawnSimulations.sh initiates ESP-r's bps module, which commences simulations

- Step 4: Once simulation is complete, StartPawnSimulation.sh interacts with ESP-r res module to write heating and cooling loads over the simulation period to text file

- Step 5: StartPawnSimulations.sh combines the heating and cooling loads and Step 1 is repeated

In the first iteration, Step 1 is carried out using the initial values declared within the command file. Steps 1 and 2 are internal to GenOpt, while Steps 3-5 are specific to the MPC scheme discussed in Chapter 4. The shell script, StartPawnSimulations.sh (see Appendix C.1), was created to initiate simulations through ESP-r's bps module, interact with ESP-r's results module (res), and perform post-processing of the results to obtain the objective function. Through interactions with res, this script obtains and combines the output power of the heating and cooling coils [W] and converts it to the thermal load requirements $[\mathrm{kWh}]$ over a specified time frame. This time frame corresponds to the prediction horizon of the Pawn simulations, which is discussed later in Chapter 4. The conversion from $\mathrm{W}$ to $\mathrm{kWh}$ for cooling is shown in Equation 3.4. The heating loads are converted similarly. Also, the PSO component of the optimizations is performed in parallel in order to decrease optimization time.

$$
E_{\text {cooling }}^{t}=\frac{P_{\text {cooling }}^{t} \Delta t}{1000}
$$

where $E_{\text {cooling }}^{t}$ is the cooling demand $\left[\mathrm{kWh}\right.$ ] at time $t, P_{\text {cooling }}^{t}$ is the cooling power output $[\mathrm{W}]$, and $\Delta t$ is the simulation time-step $[\mathrm{h}]$. 


\subsection{Closing Remarks}

Like the accuracy of the building model, the choice of the optimization algorithm is important for MPC applications. The building simulation tool and the optimizer should support interactions with each other. For this reason, GenOpt was used as the optimizer for this work. GenOpt's library of optimization algorithms contains a variety of algorithms that are suitable for building simulation applications. The optimization chosen for this thesis is a hybrid of the particle swarm optimization and Hooke-Jeeves algorithms. This chapter discussed both algorithms and the factors influencing the choice of algorithm. The methods of preparing optimizations in GenOpt are also discussed. The following chapter focuses on the development of the MPC scheme.

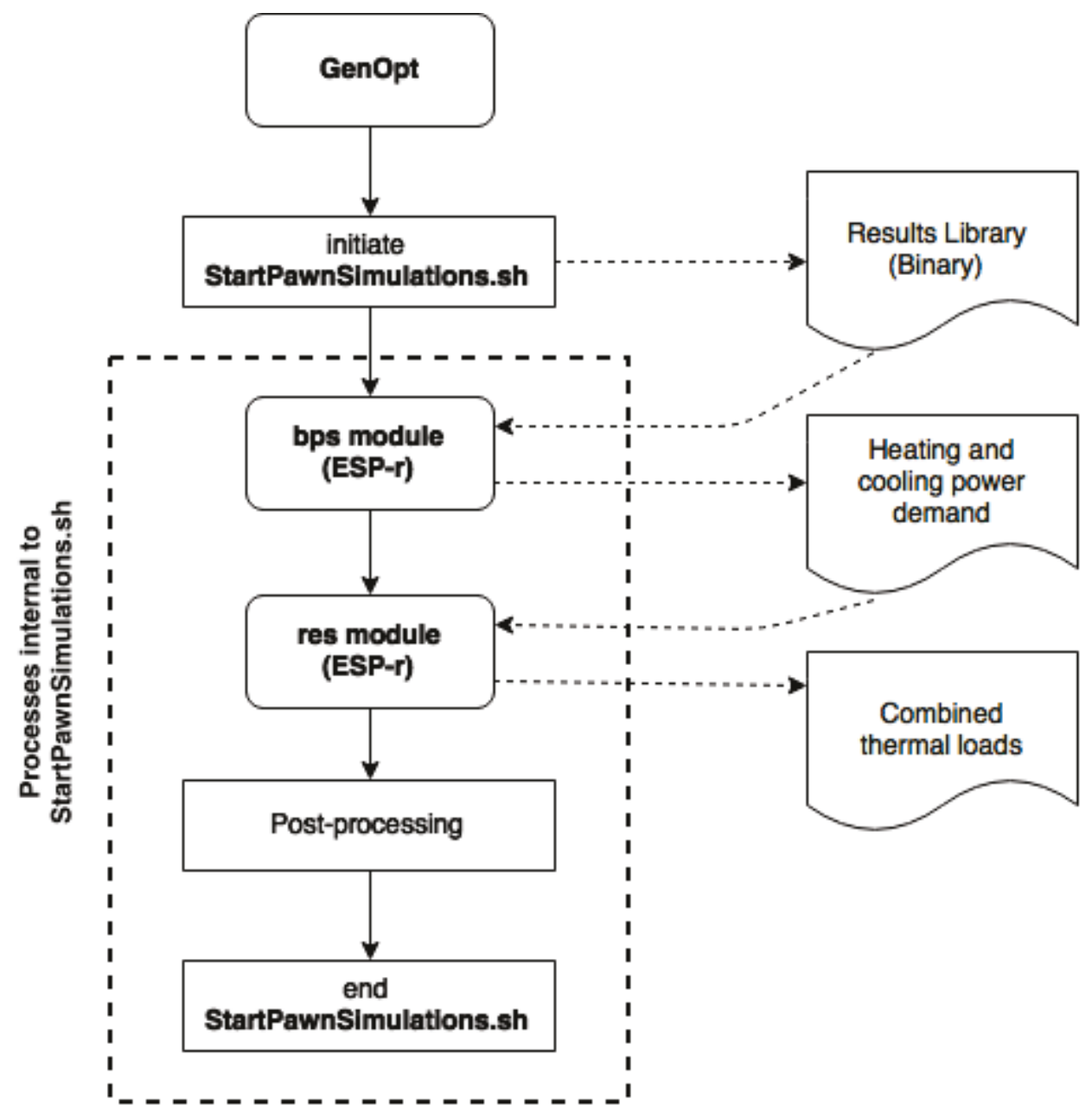

Figure 3.5: Transfer of information between ESP-r and GenOpt for a single iteration 


\section{Chapter 4}

\section{MPC Scheme}

This study involves developing an MPC scheme for controlling window blinds, aimed at minimizing the heating and cooling demand in the Urbandale CHEeR house. The performance of this scheme is evaluated using ESP-r simulations. This chapter focuses on the development of the underlying MPC framework used in this thesis.

As discussed in previous chapters, MPC in buildings relies on an optimizer and a dynamic model of the building. GenOpt and an ESP-r model of the Urbandale CHEeR house were used for computations. The actual building is also represented by an ESP-r model. Interaction between each of the building, the optimizer and the model is also necessary for MPC. In order to facilitate these interactions, both ESP-r compilations are modified and information is passed between the components using shell scripts and text files. The following sections describe the components of the MPC scheme and their interactions.

\subsection{Prediction Horizon}

The length of the prediction horizon is an important aspect of MPC. The prediction horizon is the length of future time the MPC controller must evaluate during each optimization. In general, a heavyweight building would require a longer prediction horizon than a lightweight one. At the end of each optimization, the prediction horizon is shifted forward. In other words, the prediction horizon recedes with time.

The choice of prediction horizon was found to be an under-discussed topic within the literature on predictive controls. Ideally, the prediction horizon should contain the entire thermal response of the system to a control decision such as retracting or deploying the blinds. However, the thermal response of the Urbandale CHEeR house 
is also influenced by heat injection/extraction by the HVAC system. As a result, the system's dynamics are prolonged by the input of the HVAC system over an infinite amount of time. This observation was exemplified by simulating four different cases where the house is: (1a) thermally conditioned and the blinds are closed throughout the simulation; (1b) thermally conditioned and the blinds are retracted for only one hour; (2a) free-floating and the blinds are closed throughout the simulation; and (2b) free-floating and the blinds are retracted for only one hour. The temperature differences between cases $1 \mathrm{a}$ and $1 \mathrm{~b}$, and $2 \mathrm{a}$ and $2 \mathrm{~b}$ are indicative of the building's thermal response when it is thermally conditioned and free-floating respectively. The prolonged thermal response of the house in the conditioned case is illustrated in Figure 4.1, which compares the thermal responses in both cases. The spikes in the conditioned case are due to heat injection/extraction at each time-step.

A 24-hour prediction horizon was used for this work, based on research by [44], which showed that 24 hours is sufficient for MPC of passive buildings to deviate by at most $5 \%$ from the results of controlling the building optimally using perfect knowledge of the building's present and future dynamics. Moreover, the value of the prediction horizon remains an open question that should be answered by future research, as a thermally massive house may require a longer prediction horizon.

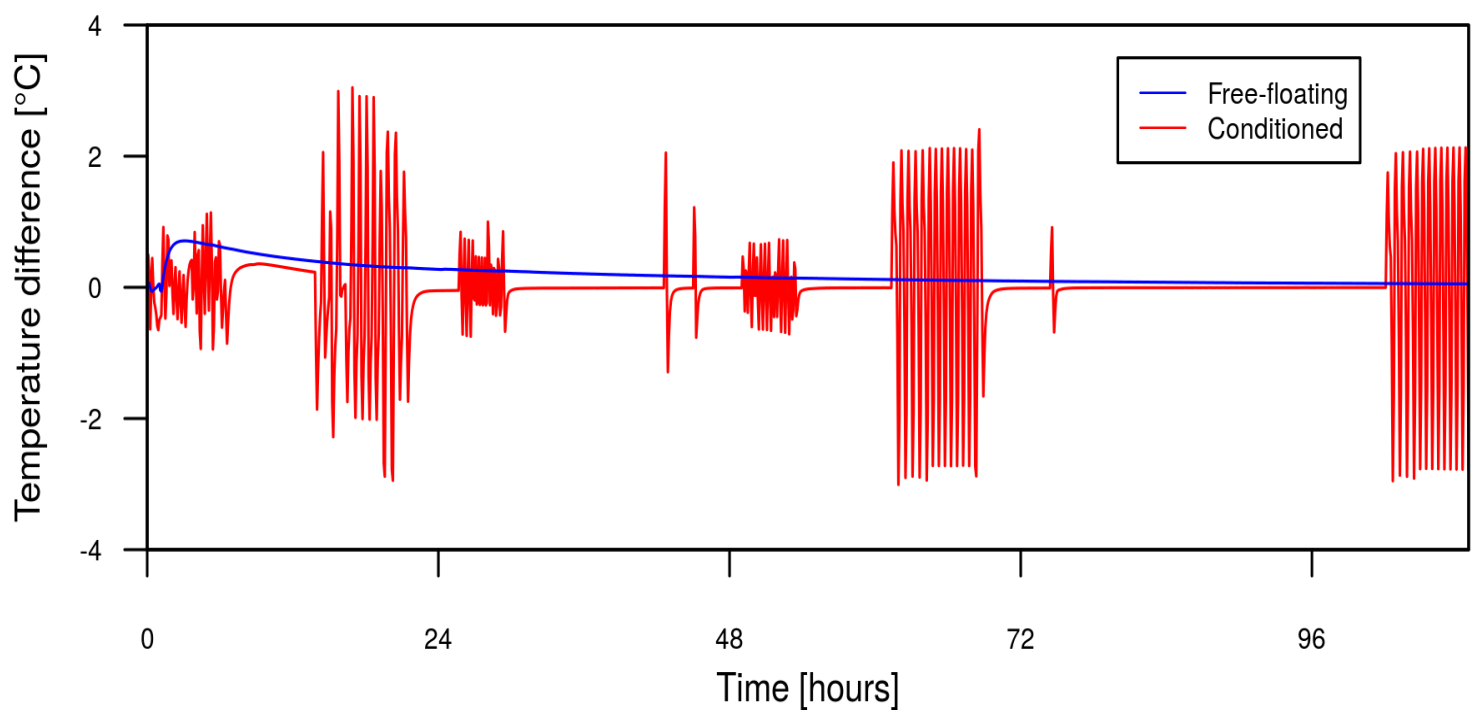

Figure 4.1: Thermal response of the Urbandale CHEeR house 


\subsection{Modifications to ESP-r source files}

The MPC scheme in this work features interactions between two ESP-r compilations (termed Queen and Pawn) and GenOpt. Queen ESP-r represents the actual building, while Pawn ESP-r represents the model used for computations. Representing the Urbandale CHEeR house by an ESP-r model allows for the development of the MPC scheme in a simulated and controlled environment, which if managed correctly can be migrated to the actual building.

In a real-world MPC implementation, the computation model would use the building's current thermal state and weather information to calculate predictions. However, since this study is simulation-based, the weather is represented by past weather data. One implication of this is that the Queen experiences identical weather as the Pawn. In other words, the performance of this MPC scheme is contingent on the assumption that the predictions and weather forecasting are perfect, which is unlikely to occur in practice. Hence, the MPC's performance in this thesis provides an upper limit of its potential. The substitutions made to the typical MPC setup discussed in Chapter 1 are illustrated in Figure 4.2.

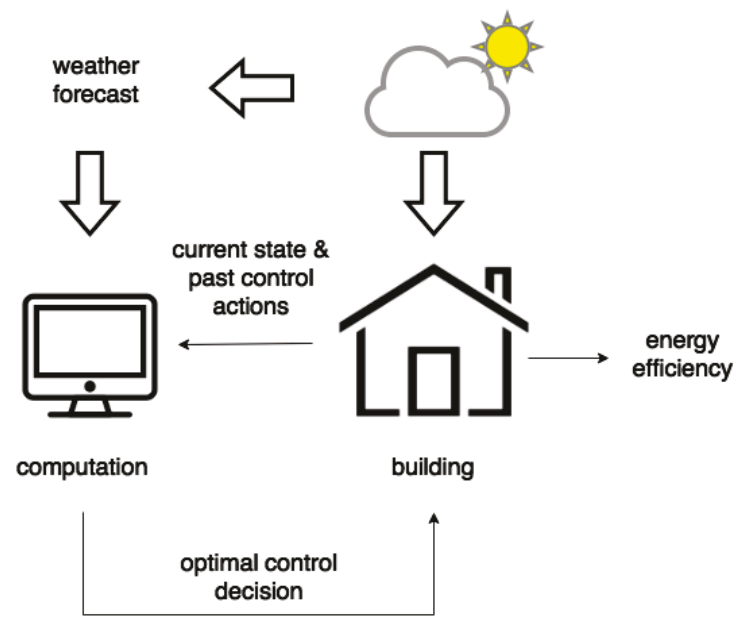

(a) Typical setup for MPC implementation

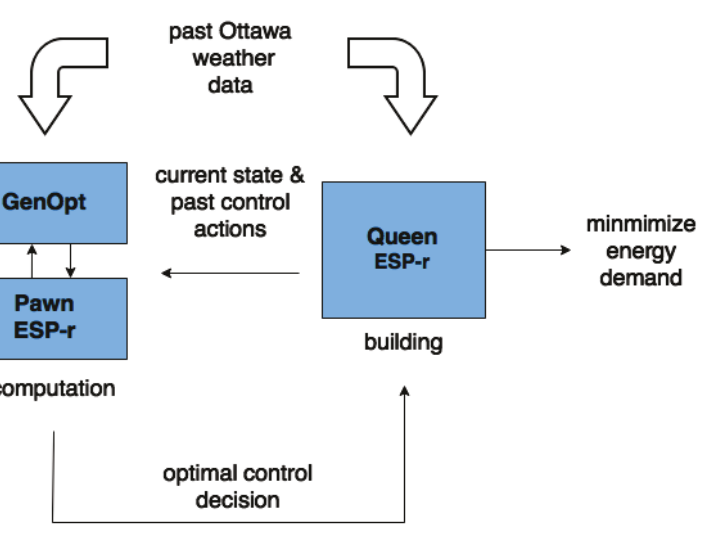

(b) MPC setup used for this work

Figure 4.2: Adaptation of typical MPC setup for this work

In addition, the optimal results are applied to the building at the end of the calculations. This information transfer is facilitated by modifying the standard ESP$\mathrm{r}$ source code, and using shell scripts and text files. 
The standard ESP-r source code was modified to create the Queen and Pawn, in order to permit interactions between the components of the MPC scheme. The modifications are discussed in this section. ESP-r's source files are written in Fortran 90, and these modifications have been made accordingly. The source code is recompiled after making modifications.

\subsubsection{Queen compilation}

The Queen ESP-r simulations represent the behaviour of the actual building. Here, the standard ESP-r code is modified to perform three tasks:

- Initiate hourly optimizations during daytime

- Export building's current thermal state and hour-of-year number to text files

- Import optimization results at the start of the hour

These modifications are illustrated in Figure 4.3 and explained subsequently.

\section{Initiate hourly optimizations during daytime}

As discussed in Section 2.1, only the twelve hourly periods in the daytime are optimized in this study. The hours from 7 a.m.- 7 p.m. (standard time) experience the majority of the solar radiation daily, over the year. This is also when solar gains have a significant impact on the thermal loads. Although winter experiences fewer daytime hours than the other seasons, the 12-hour time frame is used for the entire year for easier organization of data. Additionally, optimizations are carried out at the start of the hour. In Queen ESP-r, these changes are made to the 'MZNUMA' subroutine within the 'bmatsv.F' source file, which acts as the simulation clock. Within this

subroutine, the simulation start and finish days are set, and the simulation time step is updated. The changes made to this subroutine use the existing variables to track the simulation time.

Within ESP-r, a variable NSINC reflects the number of the current time step (including time steps within the warm-up period). At the start of the warm-up period, $N S I N C=0$. Using $N S I N C$, another variable $H O Y$ was created to provide a standard, hourly measure of the simulation time. $H O Y$ is a real variable that tracks 


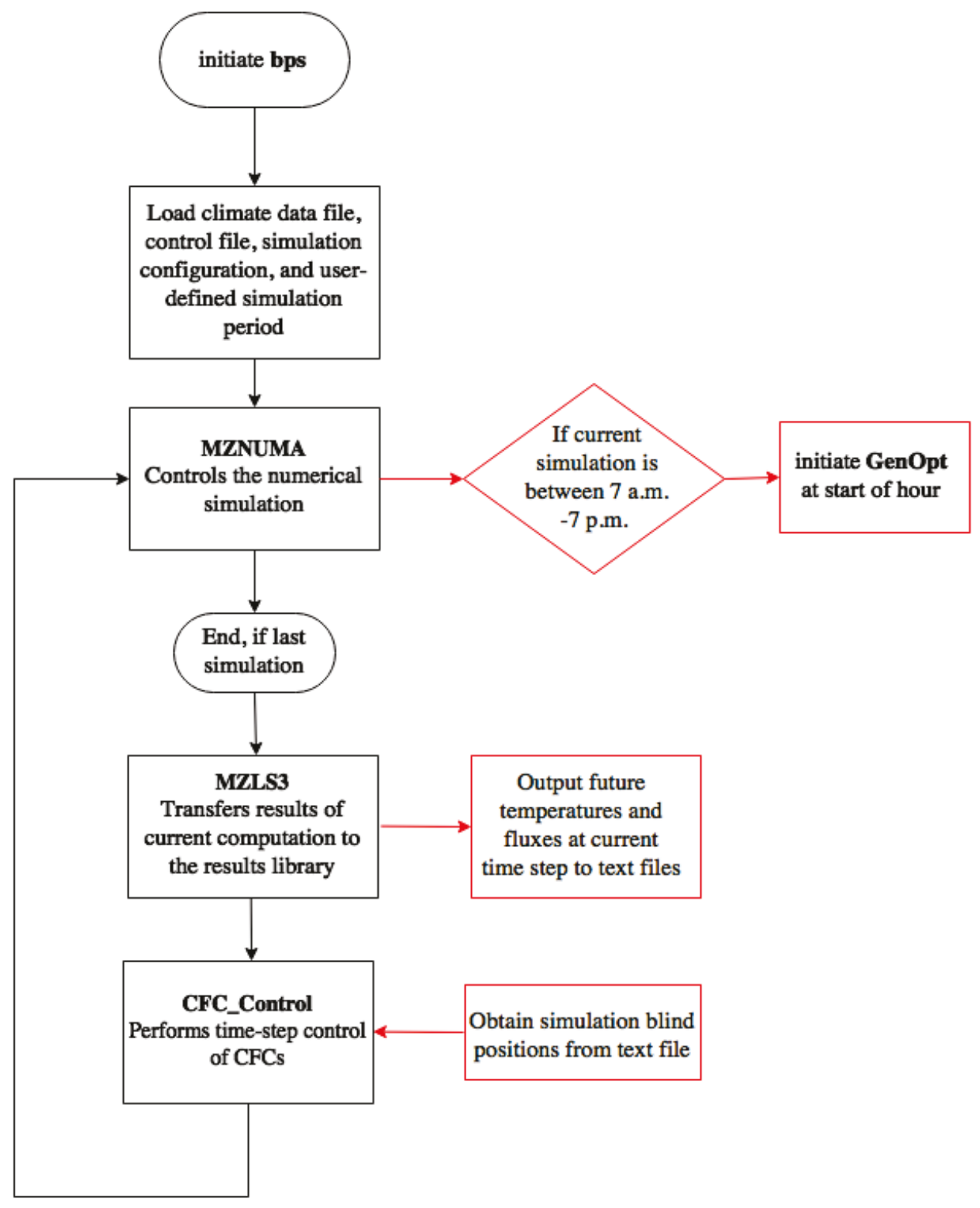

Figure 4.3: Simplified flowchart of Queen showing modifications to relevant subroutines (modifications are shown in red)

the hour-of-year number of the current simulation. For example, if 9 a.m. on January 1 is currently undergoing simulations, $H O Y=9$. $H O Y$ is expressed as:

$$
H O Y=24\left(I S D S-N_{\text {warm-up }}-1\right)+N S I N C \Delta t
$$

where ISDS is the day-of-year number for the simulation start day, NSINC is the simulation number, $\Delta t$ is the simulation time step [hours], and $N_{\text {warm-up }}$ is the number 
of simulation warm-up days.

The above variables are used to set the optimization conditions. For the optimizations to begin, the current simulation must be at the start of an hour between $7 \mathrm{am}-7 \mathrm{pm}$. Hence:

$$
\begin{gathered}
H O Y \geq \text { hour-of-year at simulation start } \\
\bmod \left(N S I N C, \frac{1}{\Delta t}\right)=0 \\
\frac{6}{\Delta t} \leq \bmod \left(N S I N C, \frac{24}{\Delta t}\right)<\frac{18}{\Delta t}
\end{gathered}
$$

The modulo $(\mathrm{mod})$ operation finds the remainder after the division of the first number by the second number.

The first condition states that the current hour-of-year number must be equal or greater than the corresponding value at the simulation start. This restriction enforces that for the optimizations to be initiated, the current time step must fall within the specified simulation period. This condition avoids unnecessary optimization during the warm-up period. ESP-r automatically terminates at the end of the simulation, so no upper bound was required on $H O Y$.

The second condition ensures that optimizations are only performed at the start of the hour, instead of at each time step. Recall that NSINC is updated during each time step, $\Delta t$. As $\Delta t$ is given in hours, the inverse of $\Delta t$ is the frequency at which $N S I N C$ is updated per hour. Therefore, the remainder of dividing NSINC by $\frac{1}{\Delta t}$ will be zero at the start of an hour during simulations. Hence, this condition confines the optimizations to an hourly resolution.

The third condition restricts optimizations to the 7 a.m. -7 p.m time frame. Over the span of a single day, the variable $N S I N C$ will be updated $\frac{24}{\Delta t}$ times. At the start of 7 a.m. NSINC would have been updated $\frac{6}{\Delta t}$ times since the start of the day, as only six hours of simulations have been completed at this point. Likewise, NSINC is updated $\frac{18}{\Delta t}$ times before 7 p.m.

If all three conditions are met, the Queen simulation initiates optimizations in GenOpt through the RunGenOpt.sh shell script, which is discussed later in this chapter. See Appendix C.2 for the modifications to the ESP-r source code. 


\section{Export building's current thermal state and hour-of-year number to text files}

The Queen's source files were also modified to output the hour-of-year number and the building's current temperatures and heat fluxes to text files. This modification plays a role in the transfer of information on the building's current thermal state from the Queen to the Pawn. The Pawn compilation uses these values for its simulations, which is discussed later in this section.

The changes to the source code are made in the 'MZLS3' subroutine within the 'blibsv.F' source file, which transfers the results of current computations to the results library. The variables TFA, TFC and TFS represent the calculated temperatures of the air, constructions and surfaces of the house for the next time step (future). QFA, QFC and QFS are the corresponding heat fluxes. These variables, and the HOY number are exported after the energy balance for each time step is completed (see Appendix C.2).

\section{Import optimization results at the start of the hour}

Finally, the Queen's source files were modified to import blind control information from text files. In the standard ESP-r, the control data is imported from the ESP-r control files before the simulations are initiated. However, real-time updates of the blind positions are necessary for MPC. The MPC scheme applies the optimization results to the Queen at the start of the hour. This action is equivalent to implementing the calculated optimal control action in the 'actual' building. The blind positions during each control period are represented by two sets of variables, therefore two text files are used. These text files are updated with the optimal blind positions at the start of each hour. These will henceforth be called the Queen's blind control files.

The modifications are made to the 'CFC_control' subroutine within the 'CFC_thermal_and_aux.F' source file, which carries out time step control of the blinds. The ESP-r multi-dimensional variable, 'CFCmiscdata' stores all control information regarding the blinds. The entries within 'CFCmiscdata' corresponding to the blind positions for a given hour are overwritten with the optimization results for that hour (see Appendix C.2). 


\subsubsection{Pawn compilation}

The purpose of the Pawn is to replicate the present thermal state of the Queen and use this information to make future predictions. The Pawn is also coupled with GenOpt for the optimization calculations. Only one major modification is made to the Pawn's ESP-r source files (see Figure 4.4). This modification imports the Queen's current thermal conditions, which are used to calculate future predictions of the building.

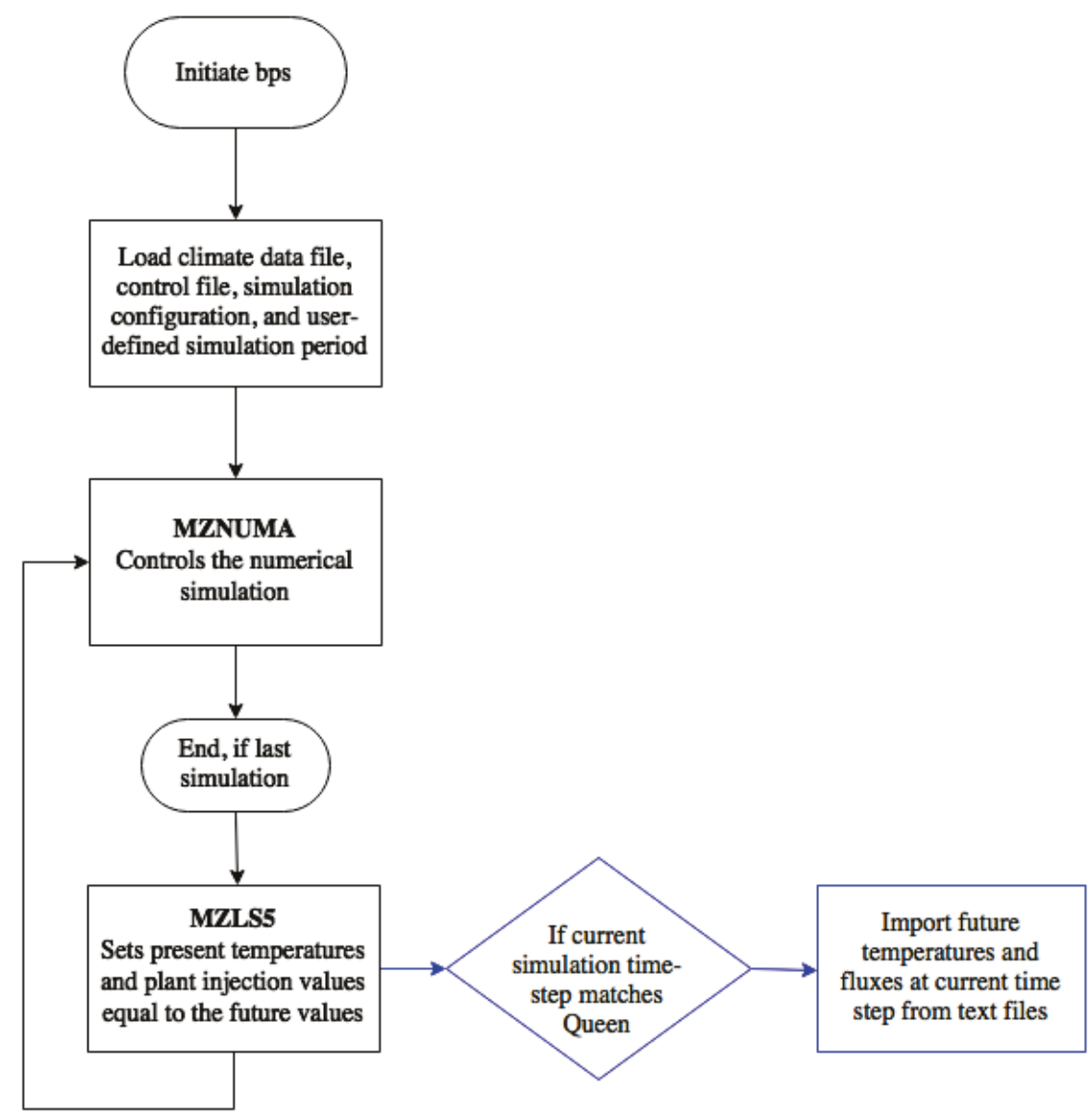

Figure 4.4: Simplified flowchart of Pawn showing modifications to relevant subroutines (modifications are shown in blue)

\section{Modifications to Pawn}

As discussed earlier in this chapter, the Queen's thermal conditions and HOY number are exported to text files during each simulation. This information is imported from these text files into the Pawn simulations. These modifications are made to the 
'MZLS5' subroutine in the 'blibsv.F' source file, which sets the present temperatures and plant injection fluxes to the corresponding future values. Recall from 4.2.1 that TFA, TFC and TFS are the temperatures for the next time step (future). The variables, TPA, TPC and TPS represent the current temperatures (present). The same naming convention applies to the heat fluxes.

As discussed in Section 2.1, ESP-r uses the Crank Nicolson formulation to calculate the energy balance at each time step. The energy balance is given in terms of the present (known) and future (unknown) temperatures and heat fluxes. Therefore, in order to replicate the thermal conditions of the Queen for a future time step, only the present temperatures and heat injection fluxes are required. Note that the calculated, future temperatures and heat fluxes at a time $t-\Delta t$ will be the present values at time $t$. Hence, the Queen's current thermal conditions can be replicated in the Pawn by feeding the Queen's future temperatures and heat fluxes to the Pawn at a matching time step. Refer to Figure 4.5 for an illustration of this information transfer.

The modification imports the Queen's HOY value from the text file into a new variable called 'HOY_Queen'. Another variable 'HOY' tracks the hour-of-year number of the Pawn simulations. If HOY_Queen = HOY, this means that the Queen and Pawn are simulating the same time step. When this condition is fulfilled, the contents of the text files are imported into the corresponding temperature and flux variables in the Pawn's source file.

For example, at the start of 2:00 p.m. in the Queen, 'HOY_Queen' and the future temperatures calculated at the last time step (1:55 p.m., using a 5-minute time step) would be the last values exported from the Queen. These temperatures correspond to the Queen's current temperatures at 2:00 p.m. These values are imported into the Pawn at the end of the 1:55 p.m. calculations, and are used to replace the present temperature values at 2:00 p.m. in the Pawn.

\subsection{Managing optimizations and results}

The interactions between GenOpt and the ESP-r compilations are managed using shell scripts and text files (see Figure 4.6). All shell scripts and text files were written for this thesis, but can be adapted to other MPC applications.

As discussed in the previous section, the Queen initiates optimizations in GenOpt at the start of the hour. This process is executed using a shell script, RunGenOpt.sh. 
The interactions between GenOpt and the Pawn are carried out using another shell script, StartPawnSimulations.sh, which was discussed in Section 3.3.3.

At the end of each optimization, GenOpt prints the optimal results to text files. However, in accordance with MPC, only the blind positions for the current hour are implemented (refer to Section 1.3.2). This process is facilitated using a shell script, UpdateFiles.sh and a text file, counter.txt.

Finally, StartQueenSimulations.sh is used to initiate the Queen simulations and set the simulation period. These files are discussed in the following sections.

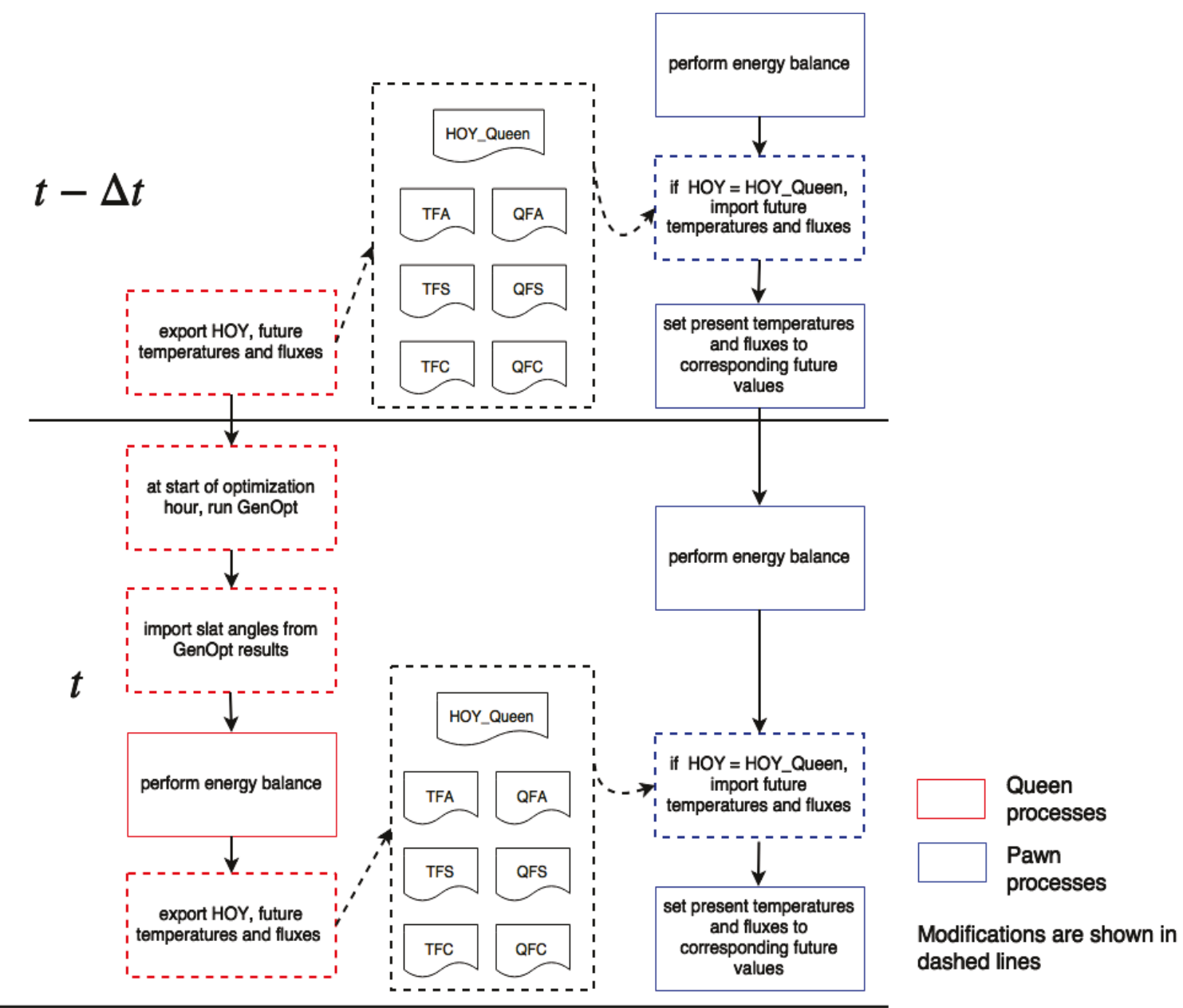

Figure 4.5: Transfer of current thermal state from Queen to Pawn at each time step 


\section{StartQueenSimulations.sh}

The main function of this shell script is to initiate the Queen simulations. In addition, this script is used to set the initial conditions of the MPC implementation.

First, the ESP-r simulation periods are declared within this file. The Pawn's simulation period exceeds the Queen by a minimum of one day, in order to accommodate future predictions. This information is used to update the Queen and Pawn ESP-r configuration files.

Second, this script sets the initial blind positions of the Queen, and the initial contents of the counter (which will be discussed shortly). For this work, the blinds are assumed to be retracted before the simulation period. This information is relayed to the Queen's blind control files.

Once the simulation conditions have been defined, the Queen simulations are initiated. See Appendix C.2 for the StartQueenSimulations.sh script.

\section{RunGenOpt.sh}

This script starts optimizations in GenOpt. GenOpt was used without the graphical user interface for easy management. It is necessary to identify the moment of completion of optimizations in order to direct the current optimal blind positions obtained from GenOpt to the Queen.

As discussed in Chapter 3, GenOpt outputs a log file stating whether optimizations are successful or not. This log file is only created at the end of a successful optimization or if the optimization fails. The contents of the log file are used to determine the completion of a successful optimization, in order for the current optimal result to be implemented. When the log file states that a successful optimization has been performed, UpdateFiles.sh is initiated and RunGenOpt.sh exits.

\section{Counter and UpdateFiles.sh}

GenOpt calculates the optimal blind positions over the prediction horizon and lists the optimization results to a text file, OutputListingMain.txt. However, in accordance with MPC, only the optimal blind positions at the current hour are implemented. Also, as the prediction horizon moves forward in time, the location of the plant power output in the ESP-r results file changes. This change is reflected in the StartPawnSimulations.sh script, which is used for GenOpt/Pawn ESP-r coupling 
(see Section 3.3.3). The receding prediction horizon and the current optimal blind positions are tracked using the counter and UpdateFiles.sh.

The first six entries of the counter text file correspond to the locations of the current blind positions ( $\alpha$ and $\beta$ for the east, west and south faces) within GenOpt's output file, OutputListingMain.txt (refer to Section 1.3.2 for the definitions of $\alpha$ and $\beta$ ). The next six entries track the start and end times of the prediction period. The final four entries are used to identify the power demand over the prediction horizon from the Pawn ESP-r results file. These entries are updated at the end of each optimization to match the receded prediction horizon.

The shell script, UpdateFiles.sh is initiated at the end of each optimization. This script copies the current optimal blind positions from GenOpt's output file to the Queen's blind control files; this action is equivalent to implementing the optimization results in the Queen. In addition, UpdateFiles.sh shifts the prediction horizon forward in time. The shift is reflected in the counter and within StartPawnSimulations.sh.

Another function of the UpdateFiles.sh script is to initiate optimizations using the results from the last optimization as the algorithm's starting point. In MPC, there exists an overlap between the prediction horizons of successive optimizations. For a problem with several minima, more than one combination of values may produce the same minimum objective function. As a result, even though an optimal solution may be applicable for two consecutive hours, the algorithm may converge to different solutions (that produce the same minimum objective function) for each hour. As only the current blind positions are selected from both optimizations, this new combination of solutions may result in a non-optimal solution overall. Using the previous optimal solution as the starting point for the following optimization ensures that the previous optimal solution is first re-evaluated over the new prediction horizon. This action establishes consistency over the entire simulation.

\subsection{Closing Remarks}

This chapter discussed the processes within the MPC scheme featured in this thesis. The choice of the prediction horizon was explained. The MPC scheme features two compilations of ESP-r- Queen and Pawn. The Queen represents the actual house, and the Pawn represents the model used to compute future predictions. The ESP-r source files for the Queen and Pawn have been modified to permit information transfer 
between each other, but both models are thermally identical. GenOpt was coupled with the Pawn for optimizations. Furthermore, shell scripts and text files were used to manage this scheme and the information transfer. The following chapter presents and analyzes the results obtained from the MPC scheme. 


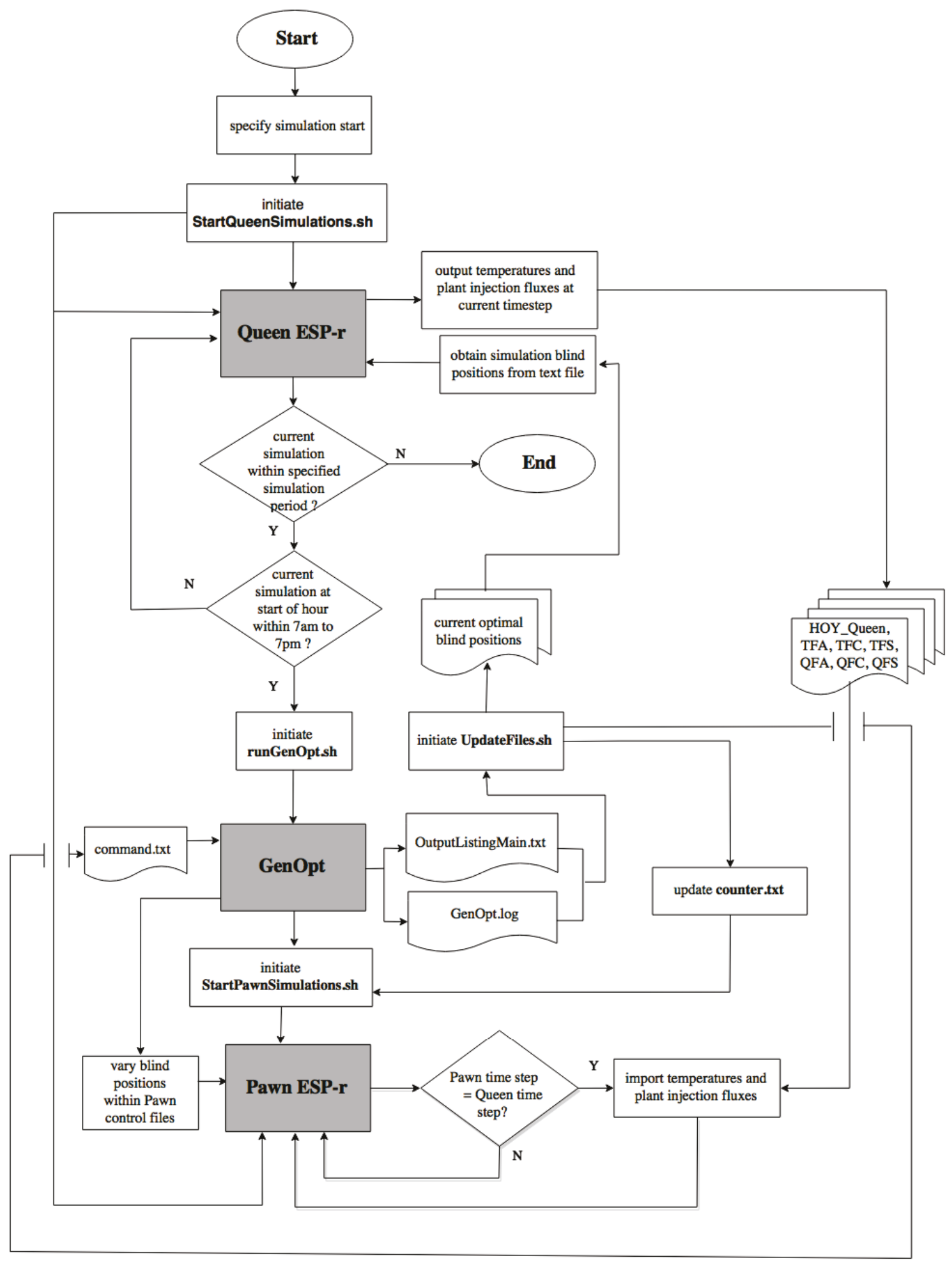

Figure 4.6: Flowchart of the MPC scheme 


\section{Chapter 5}

\section{Results and Analysis}

This chapter presents the results obtained from applying the MPC scheme to a model of the Urbandale CHEeR house in order to minimize the thermal loads required for heating and cooling. The MPC controller was evaluated using simulations of the ESP-r model described in Chapter 2. The MPC's performance was compared to three cases:

i ) A reactive Rule-Based Controller (RBC), which senses the air temperature of the first storey and reacts by retracting the blinds for temperatures below $21.5^{\circ} \mathrm{C}$, and deploying them for temperatures exceeding $24.5^{\circ} \mathrm{C}\left(1^{\circ} \mathrm{C}\right.$ higher than the heating set-point and $1^{\circ} \mathrm{C}$ lower than the cooling set-point respectively). The blinds are always closed in the deployed state.

ii ) Retracted blinds, where the blinds are fully retracted throughout the simulation period

iii ) Closed blinds, where the blinds are fully deployed and closed throughout the simulation period.

The computation time of optimizations in this work poses a challenge to acquiring performance results for the entire year. As a result, the MPC controller is evaluated over weekly periods that are representative of the seasons of the year. The winter season was assessed during a week in December when the building undergoes heating primarily. Summer was represented by a week in June during which the building is strictly cooled. Spring and fall are represented by a week in March and October respectively, when the building experiences days when both heating and cooling are required. 
Section 5.1 discusses the computational cost of optimizations. Sections 5.2, 5.3, 5.4, and 5.5 discuss the MPC controller's performance in the spring, fall, winter and summer seasons respectively. Section 5.6 addresses the controller's performance regarding the east and west-facing blinds. Finally, Section 5.7 summarizes and concludes this chapter.

\subsection{Computational Cost of Optimizations}

Optimizations were performed at the start of each hour on a $2.4 \mathrm{GHz}$ processor with four CPUs. A single optimization generally converged to a solution after about 515 iterations. Figure 5.1 shows a sample optimization and the switch from the PSO to the HJ algorithm.

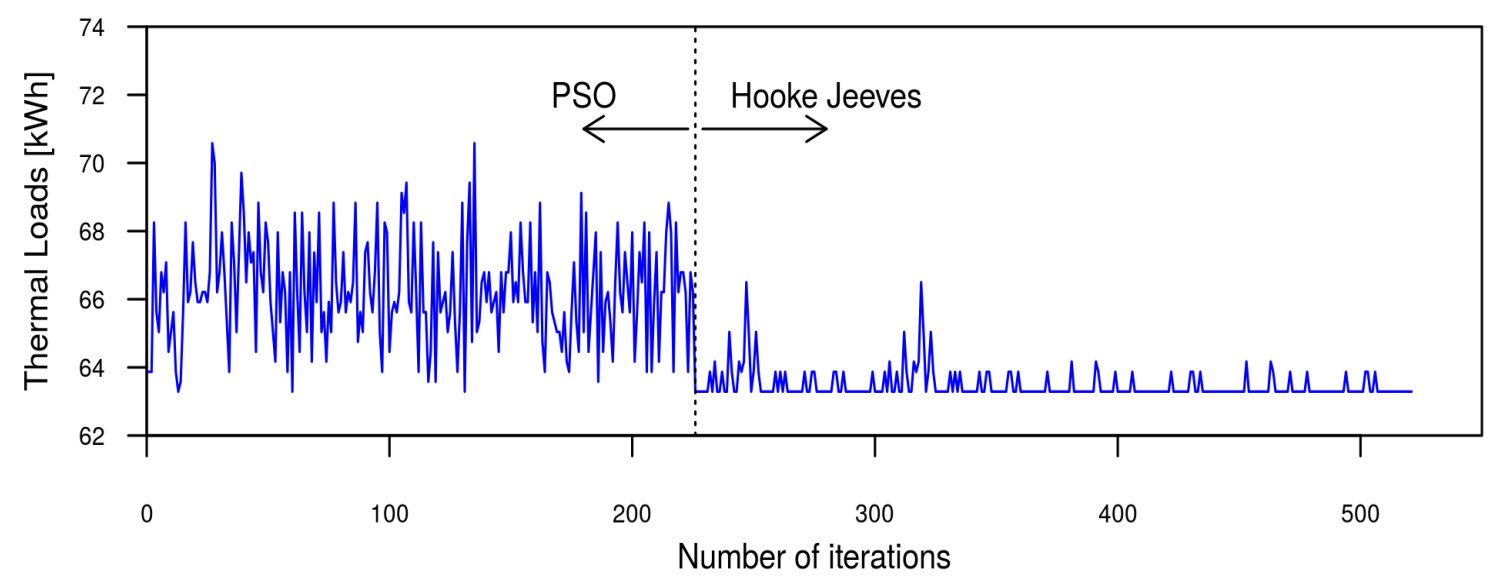

Figure 5.1: Optimization iterations for a single hour

Each optimization was executed in approximately 3.15 hours, which is impractical for an hourly, real-time implementation of MPC since the predictions must be completed very early in the hour. The complexity of the ESP-r model was a major contributor to the cost of computations. The ESP-r representation of the house consists of seven zones, and included explicit surfaces to capture thermal bridging effects and heat transfer through the window frames, which are not mandatory for this work. Simplifications to this model, such as using fewer zones and surfaces, would reduce the computation time.

Also, the large number of variables, the number of step reductions of the HJ algorithm, and the speed of the computer's processor contributed to the length of 
optimizations. Recall from Chapter 3 that the number of step reductions dictates the number of intermediate positions the blinds can assume during optimizations. Strategies to improve the computational cost of optimizations are discussed later in Chapter 6.

\subsection{Spring Performance}

Spring is represented by March 18 to 24, around the Spring Equinox - a day of equal lengths of day and night. The Urbandale CHEeR house experiences heating and cooling during this week. Heating is more dominant during this period due to low ambient temperatures experienced during this week. Optimization is carried out hourly from 7 a.m. to 7 p.m. Outside of this time frame, exterior solar radiation is negligible and the blinds are fully closed to minimize the longwave heat transfer to the building's exterior. The total heating and cooling loads are presented in Figure 5.2 .

Overall, the MPC controller performs best during the week in the spring. The total energy savings with MPC are approximately $12.3 \%$ compared to the retracted

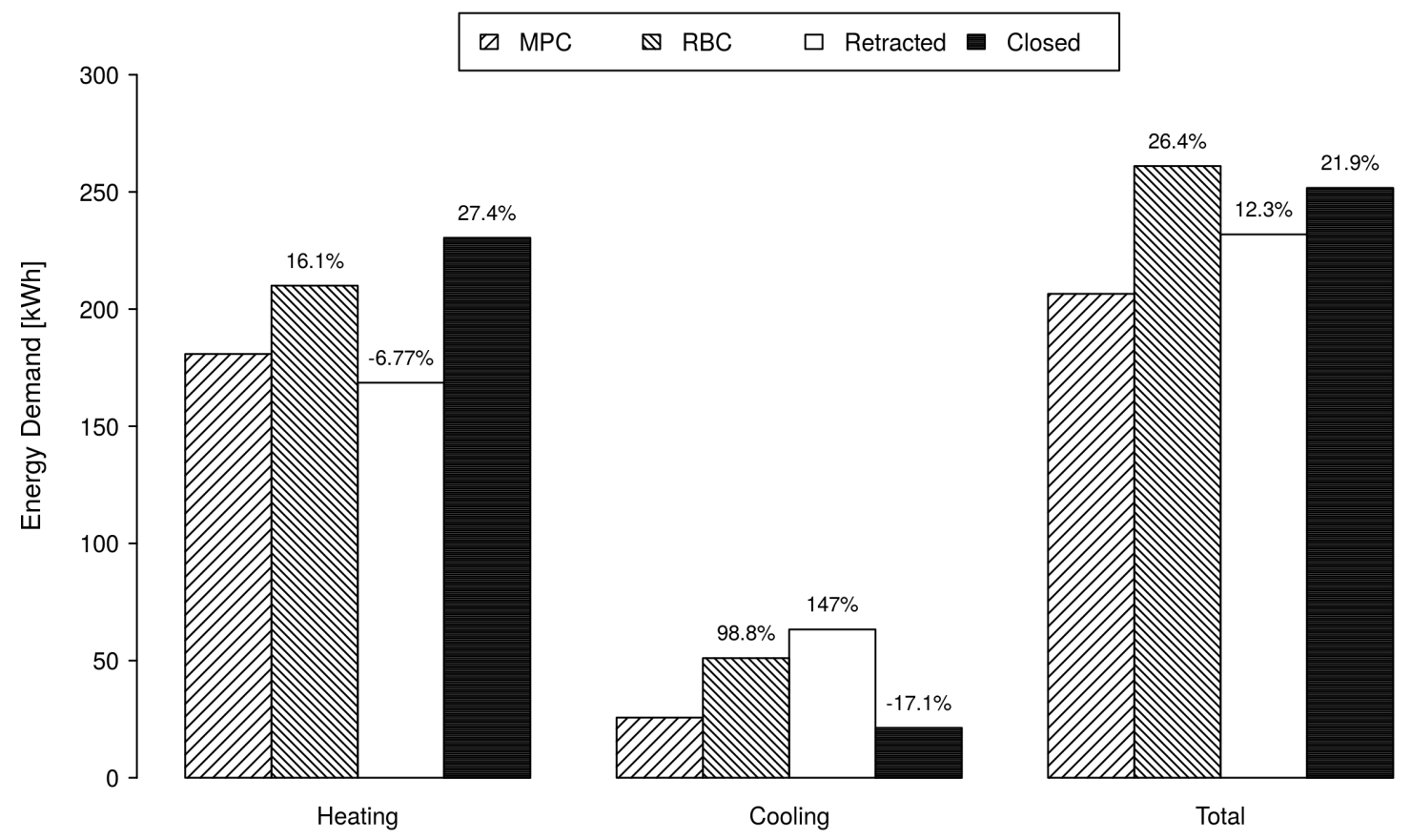

Figure 5.2: Total heating and cooling demand for a week in March, comparing performance to the MPC 
case. Here, the majority of the savings comes from cooling reductions on the days that experience overheating. As shown in Figure 5.3, the MPC closes the blinds on the south face early in the day in anticipation of the overheating that occurs in the afternoon. The MPC's reduction of the cooling loads also occurs at the expense of increasing the heating loads. Furthermore, the retracted case ranks $2^{\text {nd }}$ in terms of performance. This is most likely due to the larger need for heating over cooling during the week in March. Hence, retracting the blinds more often in the spring reduces the heating demand, which ultimately has a large impact on reducing the overall thermal loads.

In comparison to the case with closed blinds, the MPC reduced the thermal loads by $21.9 \%$. These savings are attributed to heating reductions, as the majority of the useful solar gains are rejected when the blinds are fully closed. The heating reductions from the MPC are also accompanied by an increase in the cooling demand. Moreover, it is evident from the results the MPC provides a trade-off between heating and cooling in order to minimize the combined thermal loads.

In addition, the results show that the MPC outperforms the RBC chosen for this work. The MPC implementation provides energy savings of $26.4 \%$, when compared to the RBC. Figure 5.3 shows that the MPC begins to shade the south-facing windows earlier than the RBC for a typical day in the week. Consequently, the adverse solar gains that contribute to increasing the cooling loads are admitted into the space before the RBC activates shading. Also, the MPC retracts the blinds later in the day in anticipation for the temperature drop that will occur overnight, therefore reducing the heating loads in the night time. Conversely, the RBC continues to shade the house until the late evening as the indoor air temperature remains high. This behaviour diminishes its effectiveness at reducing the heating loads. The improved performance of the MPC over the $\mathrm{RBC}$ is also evident in the temperature graphs, as the air temperature in the first storey lies outside the heating and cooling set-points (illustrated with dashed lines) more frequently using the RBC. The spikes in the air temperature are due to heat injection and extraction at each time step.

The RBC also performs worse than the other cases in the spring. From Figure 5.2 , it is apparent that the RBC has a lower heating demand than the closed blinds, and also lower cooling demand than the retracted blinds. However, the combined heating and cooling loads are greater than in the other cases. Hence, the RBC may be detrimental to reducing the building's thermal loads during the spring season. 
Blind positions for south face using MPC
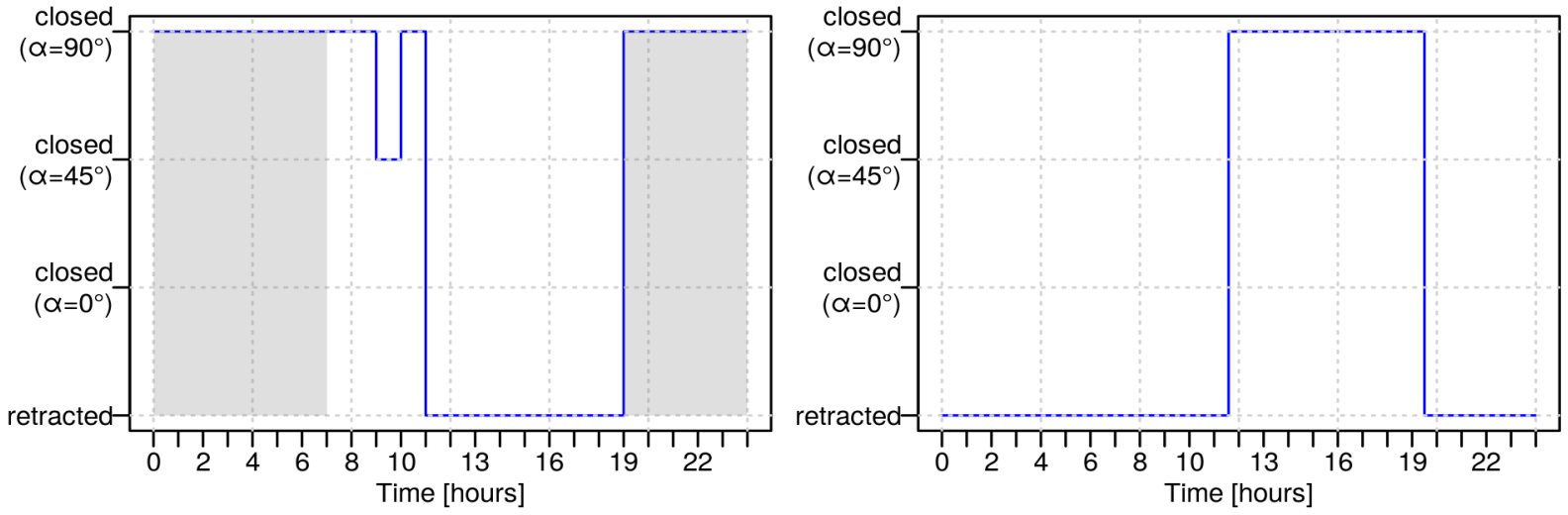

Temperature in first storey using $\mathrm{MPC}\left[{ }^{\circ} \mathrm{C}\right]$ Temperature in first storey using $\mathrm{RBC}\left[{ }^{\circ} \mathrm{C}\right]$
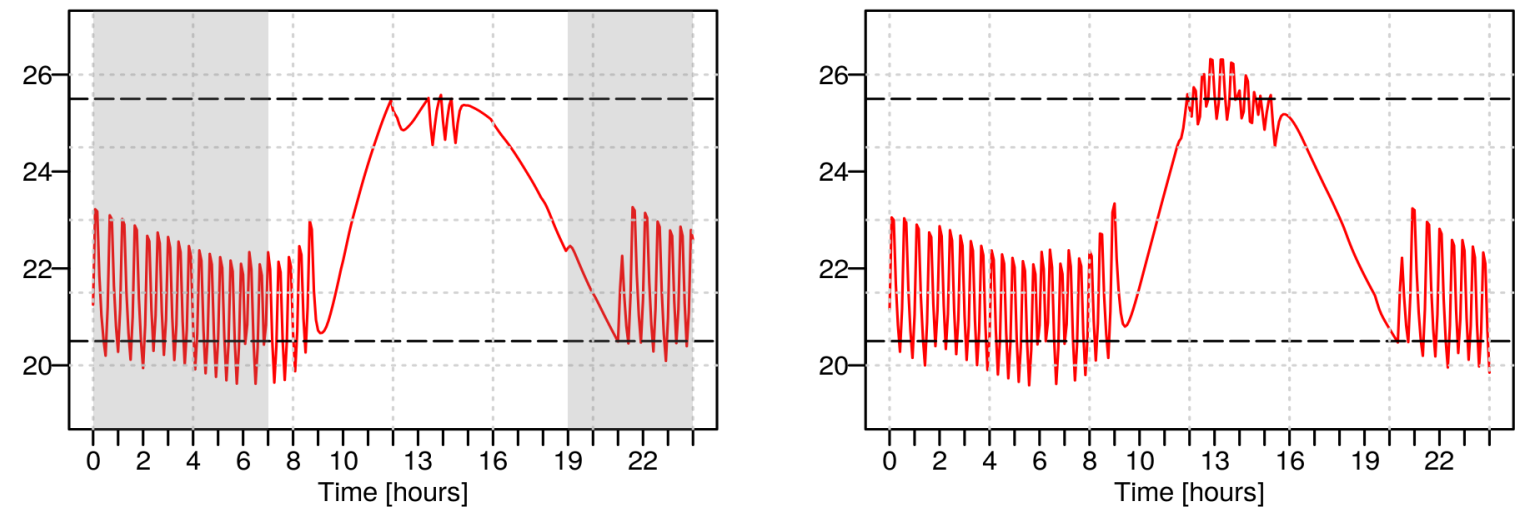

Incident solar flux on south face $\left[\mathrm{W} / \mathrm{m}^{2}\right]$

Ambient temperature $\left[{ }^{\circ} \mathrm{C}\right]$
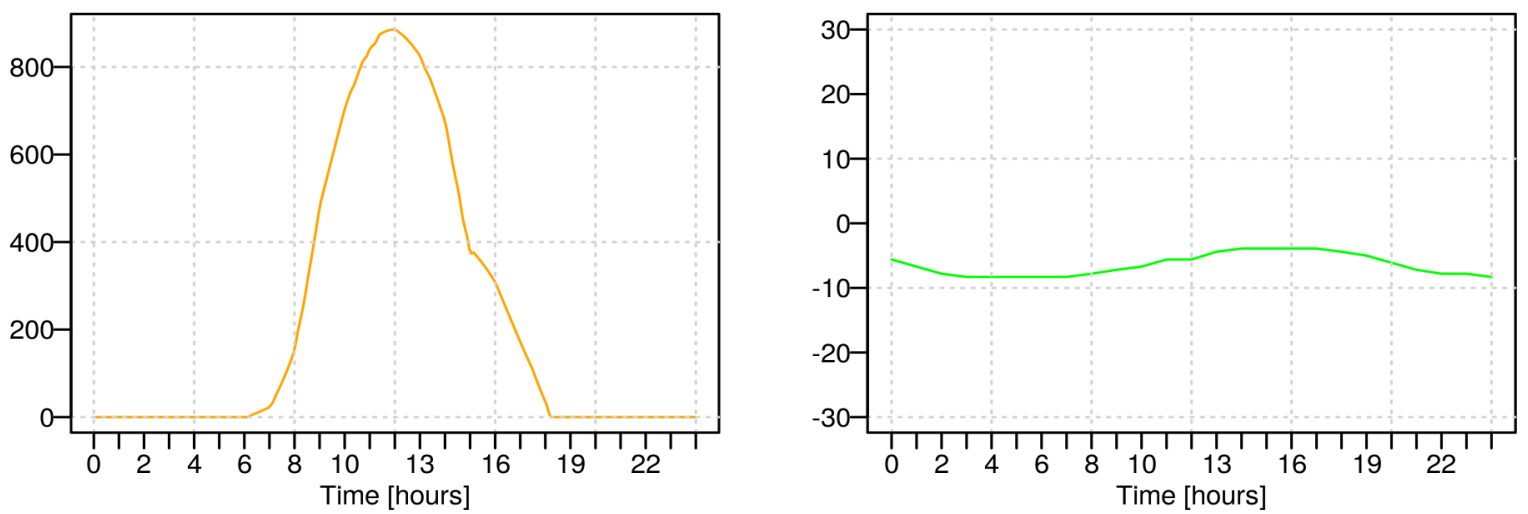

Figure 5.3: Blind positions and thermal conditions for a single day in March. The shaded regions represent the non-optimized periods using MPC, dashed lines represent heating and cooling set points 
Another observation from the spring performance is that the optimization results rarely converge to any of the intermediate positions. The blinds were mostly fully retracted or fully closed, with the exception of 9 a.m. on the day featured in Figure 5.3 when the slats assume a $45^{\circ}$ angle. This indicates that the intermediate positions generally do not offer significant improvements to the objective function. This observation introduces an avenue for better management of the computational costs of optimizations, which will be discussed further in Chapter 6 .

\subsection{Summer Performance}

Summer is represented by June 18 to 24, around the Summer Solstice - the longest day of the year. The Urbandale CHEeR house has no heating requirements during this week. Optimizations are carried out hourly from 7 a.m. to 7 p.m. in which the majority of solar irradiation is experienced. Outside of this time frame, the external solar radiation is minimal and the blinds are fully closed to minimize the longwave heat transfer to the outside. The total heating and cooling loads are presented in Figure 5.4.

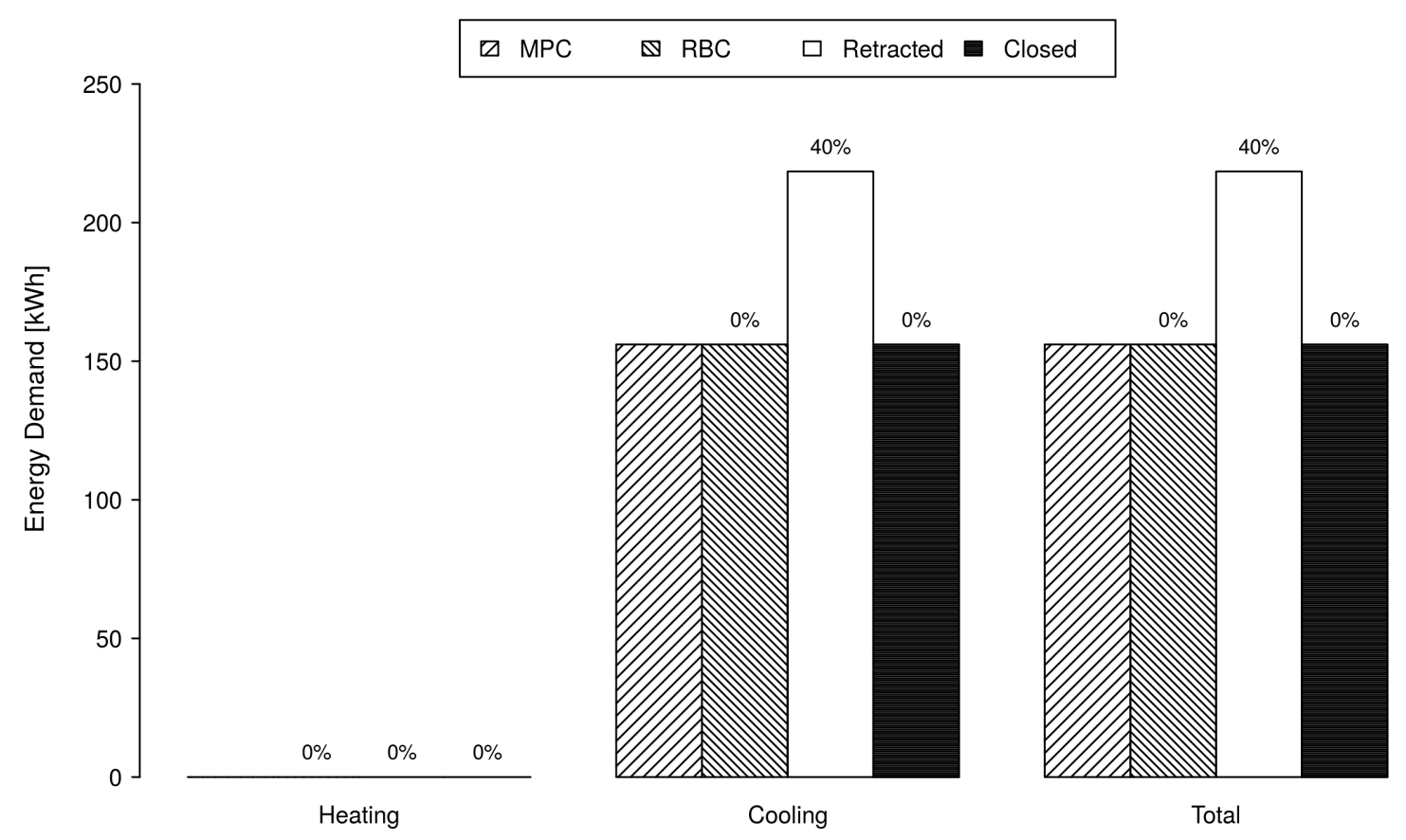

Figure 5.4: Total heating and cooling demand during a week in June, comparing performance to the MPC 
Blind positions for south face using MPC
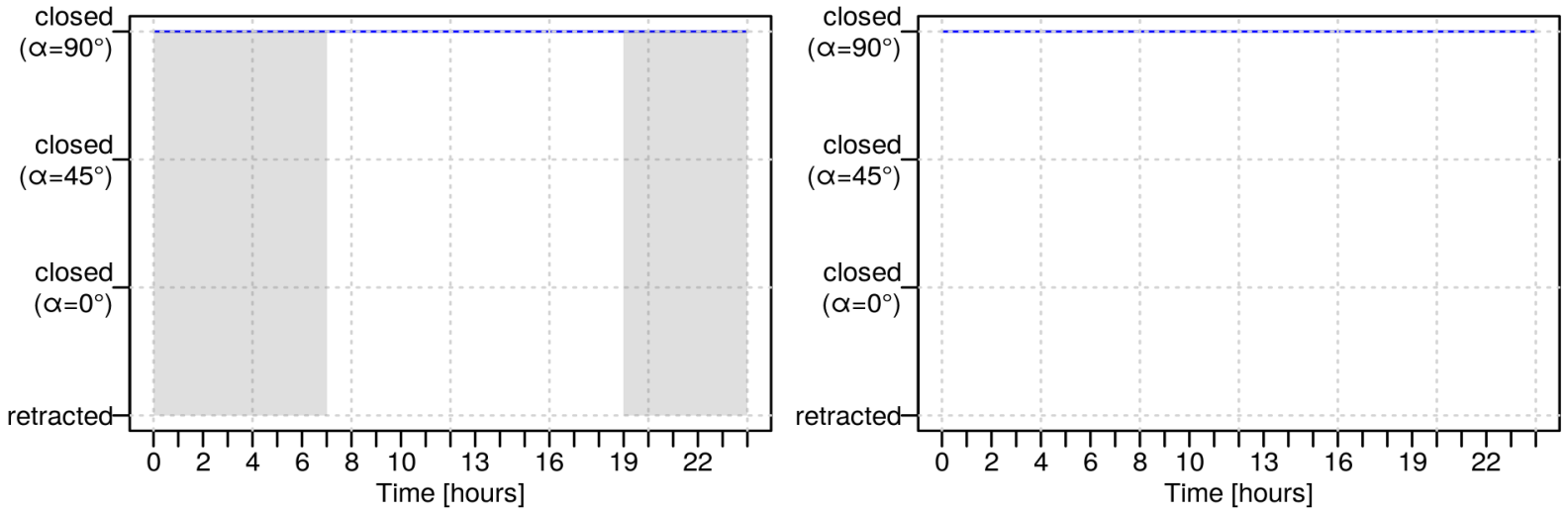

Temperature in first storey using $\mathrm{MPC}\left[{ }^{\circ} \mathrm{C}\right]$ Temperature in first storey using $\mathrm{RBC}\left[{ }^{\circ} \mathrm{C}\right]$
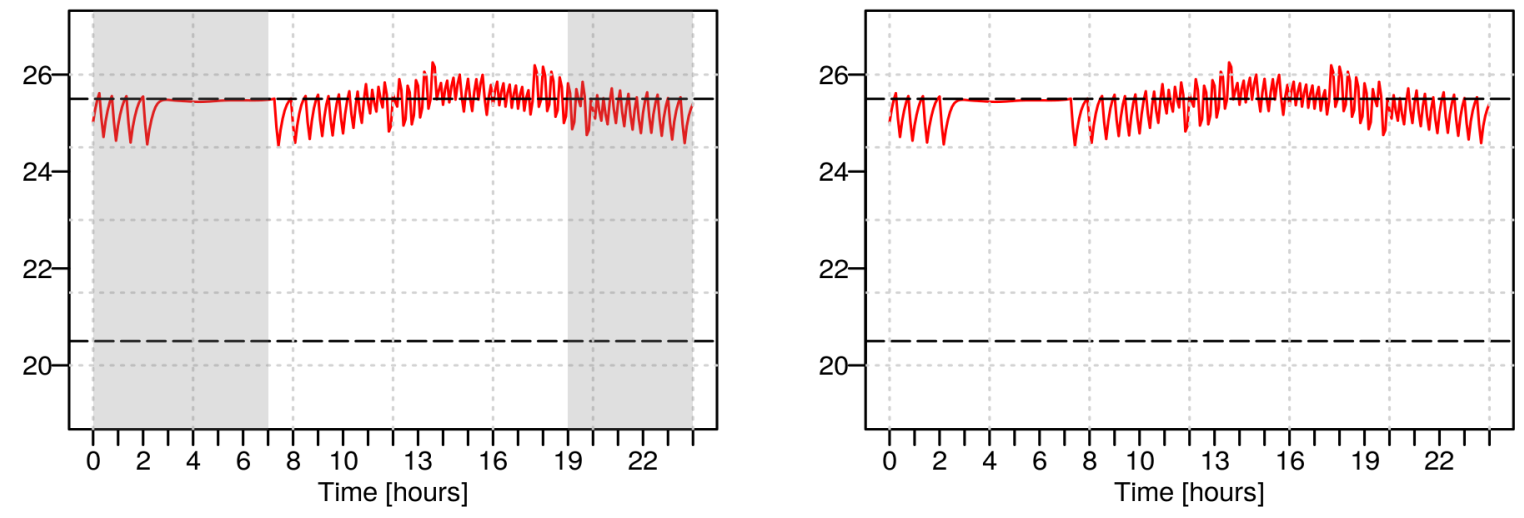

Incident solar flux on south face $\left[\mathrm{W} / \mathrm{m}^{2}\right]$

Ambient temperature $\left[{ }^{\circ} \mathrm{C}\right]$
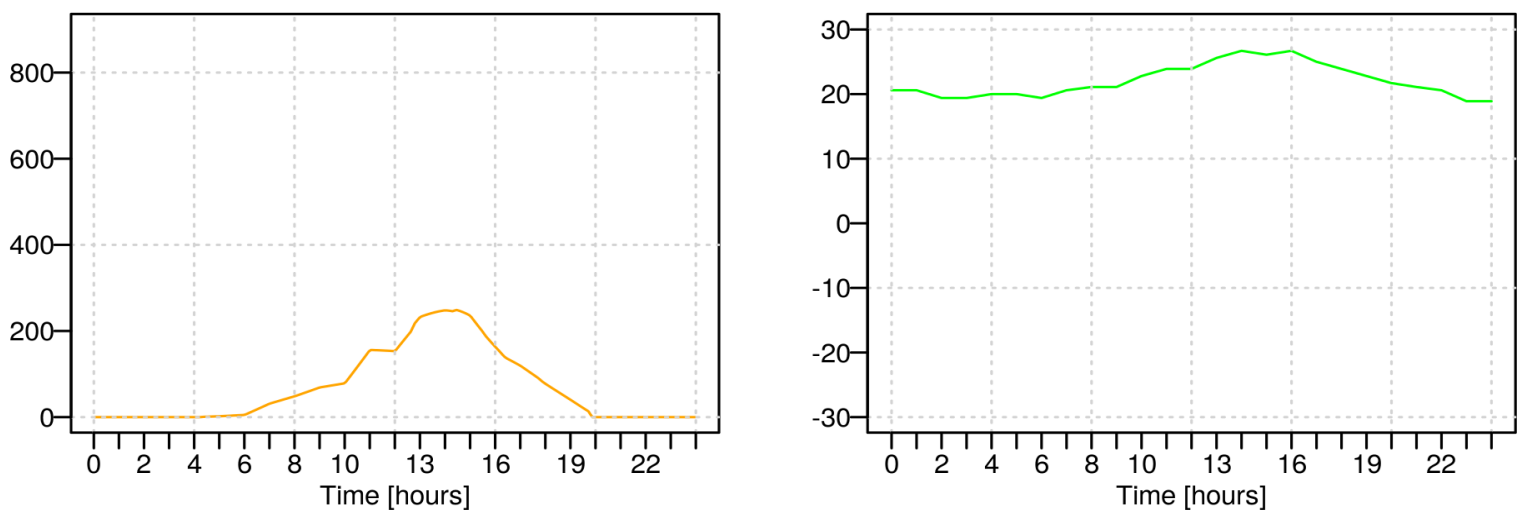

Figure 5.5: Blind positions and thermal conditions for a single day in June. The shaded regions represent the non-optimized periods using MPC, dashed lines represent heating and cooling set points 
The Urbandale CHEeR house requires no heating in all four cases during this week. Hence, it is expected that closing the blinds throughout the simulation period should minimize the total thermal loads. The MPC application predicts that allowing solar radiation into the zone at any moment during the optimization period would be detrimental to the cooling loads, and closes the blinds for the entire duration (see Figure 5.5). In the case of the RBC, the temperature always exceeds the upper temperature set-point, $23.5^{\circ} \mathrm{C}$, and the blinds are closed throughout the week. As such, the MPC, RBC and the closed blinds perform equally during the summer, and reduce the thermal loads by $40 \%$ compared to the retracted case.

\subsection{Fall Performance}

Fall is represented by the week from October 13 to 19, during which the Urbandale CHEeR house is heated and cooled, but with a smaller disparity between the heating and cooling components than in the spring. This is most likely due to the higher ambient temperatures experienced in fall (compare Figures 5.3 and 5.7). Optimizations are carried out hourly in the day time from 7 a.m. to 7 p.m. Outside of this time frame, the blinds are closed and fully deployed to reduce the longwave heat transfer to the surroundings. The thermal loads during this week are presented in Figure 5.6.

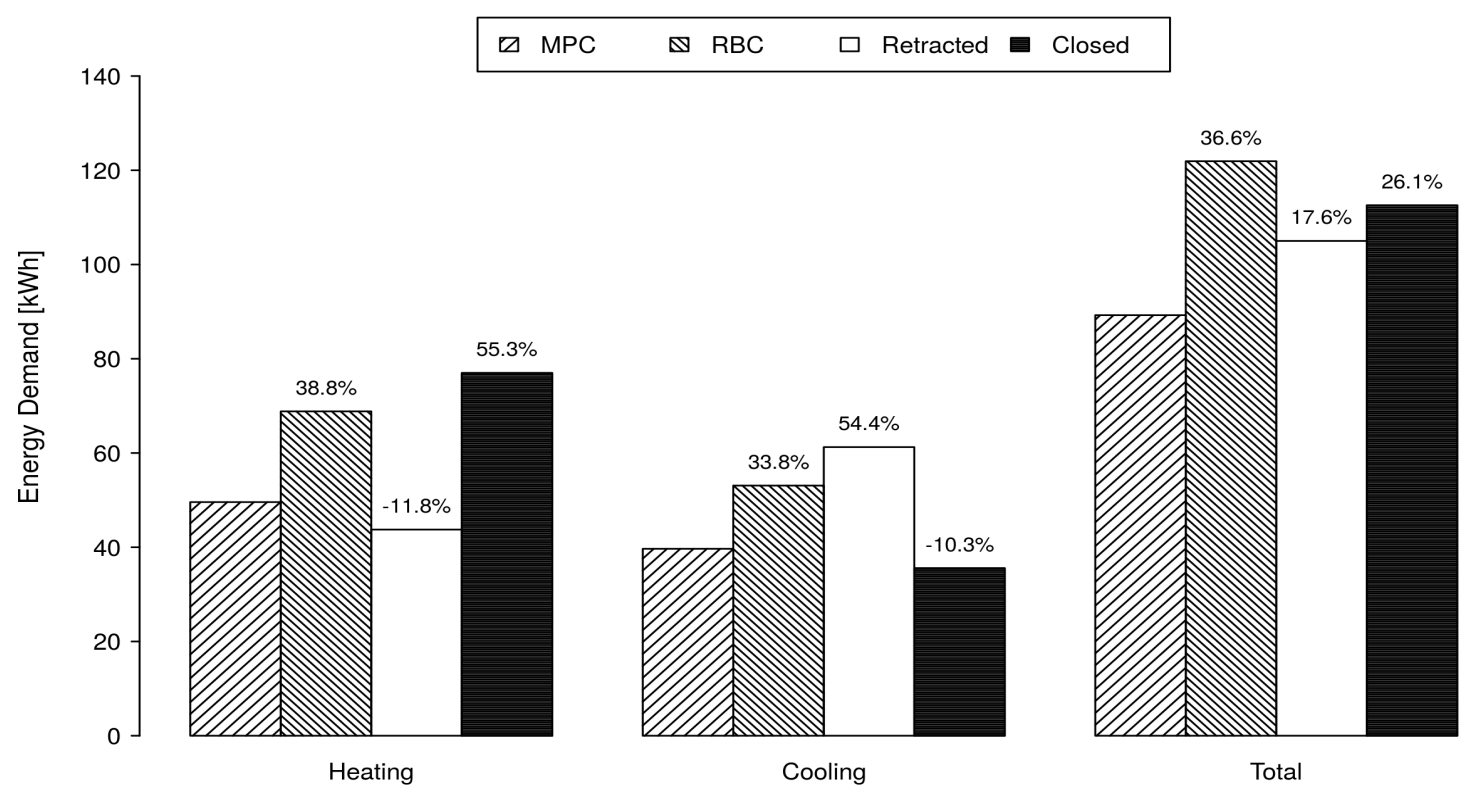

Figure 5.6: Total heating and cooling demand for a week in October, comparing performance to MPC 
Here, the MPC outperforms the other cases. The total energy savings are 17.6\% and $26.1 \%$ compared to the retracted blinds and closed blinds respectively. As in the spring, the individual heating and cooling loads show that the MPC compromises between heating and cooling to minimize the combined thermal loads.

Figure 5.7 shows the MPC blind positions over a single day during this week. As in the spring, the blinds on the south face are fully closed earlier in the day in anticipation of overheating in the afternoon, and retracted later to reduce the heating loads at night. However, the blinds are deployed again at 6 p.m. This occurs because the optimization algorithm determines the optimal solution by evaluating the objective function at several points within the space and moving in the direction of improvement. Hence, the algorithm has no preference for one position over another if they result in the same objective function; it simply converges to the first one it finds. At 6 p.m. there are no exterior solar gains incident on the south face (see Figure 5.7), hence retracting or deploying the blinds may have no significant impact on the building's thermal state and the optimization algorithm simply settles for the fully closed state in this case.

The MPC outperforms the RBC with savings of $36.6 \%$. As in the spring, the MPC rejects the adverse solar gains that contribute to increasing the cooling loads and admits the useful solar gains. Conversely, the RBC closes the blinds only when the building already begins to overheat. In addition, the $\mathrm{RBC}$ is also unable to effectively manage the useful solar gains in the late afternoon that contribute to heating reductions. The improved performance of the MPC is also illustrated in the indoor air temperature graphs, which show that the temperature in the RBC falls outside of the comfort range more frequently than the MPC. Also, when the building switches from heating to cooling and vice-versa, the temperature in the MPC rises or descends much slower than the RBC, implying that the MPC does a better job of maintaining the air temperature within the comfort range.

The results also show that the RBC has the lowest performance in the fall. From Figure 5.6, the individual heating and cooling components show that the $\mathrm{RBC}$ reduces heating compared to the fully closed state, and reduces cooling compared to the retracted state individually. However, these individual reductions do not provide a reduction in the combined thermal loads in the building in comparison with the other strategies. 
Blind positions for south face using MPC
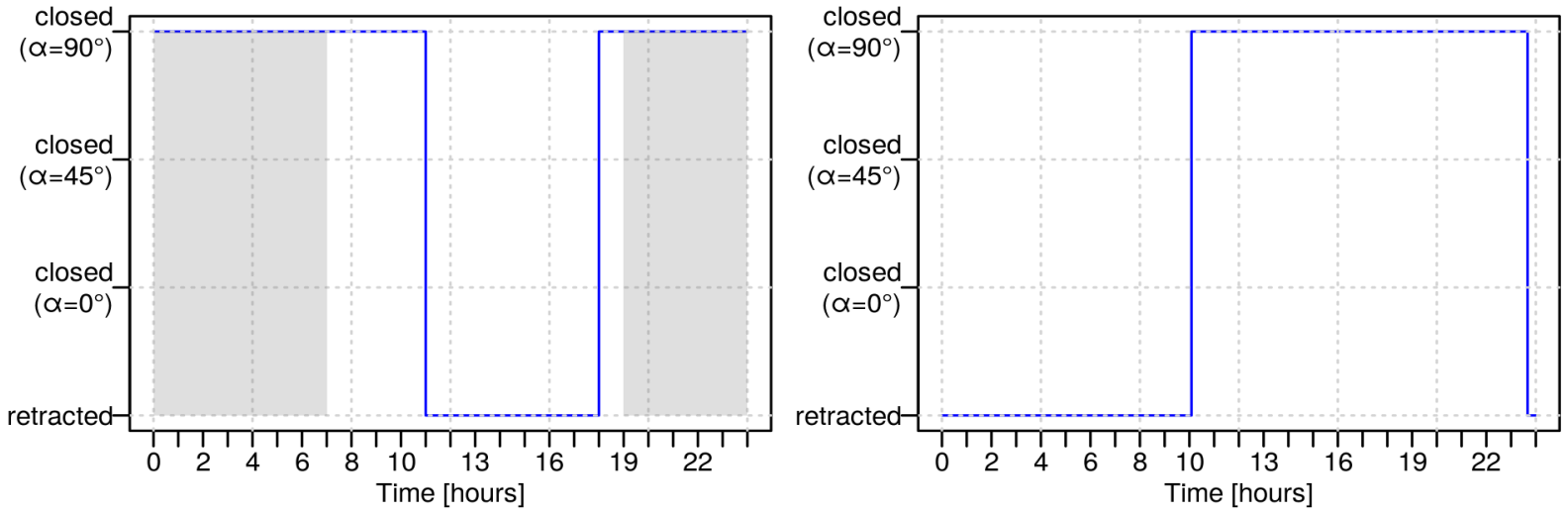

Temperature in first storey using MPC $\left[{ }^{\circ} \mathrm{C}\right]$ Temperature in first storey using $\mathrm{RBC}\left[{ }^{\circ} \mathrm{C}\right]$
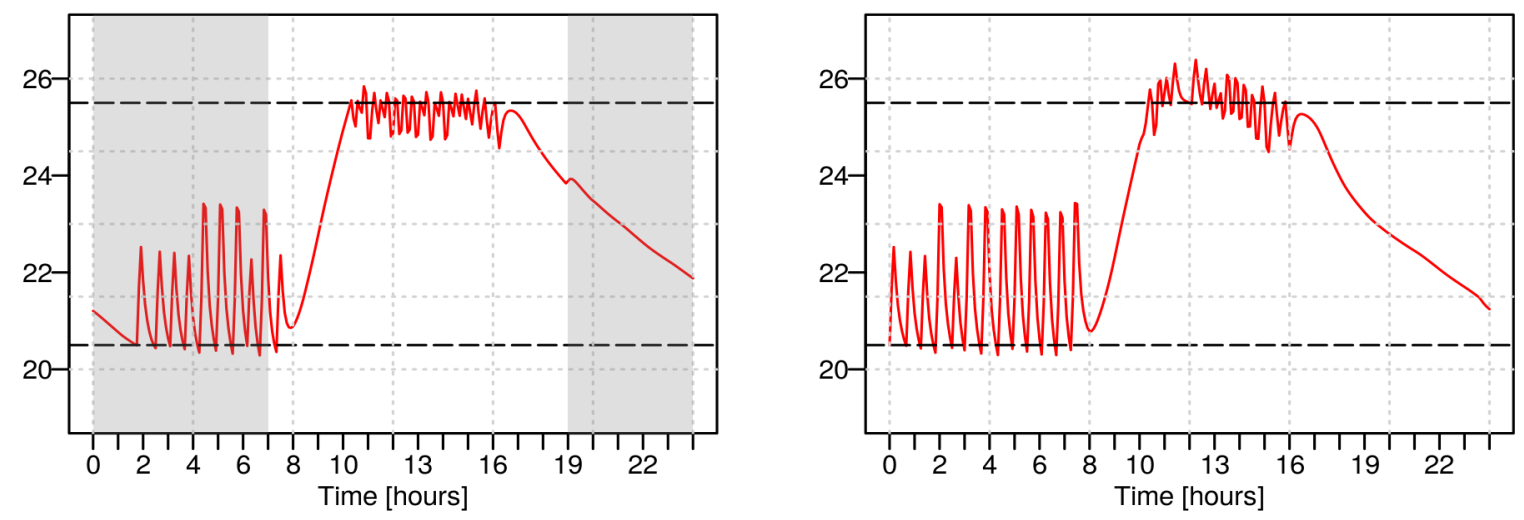

Incident solar flux on south face $\left[\mathrm{W} / \mathrm{m}^{2}\right]$

Ambient temperature $\left[{ }^{\circ} \mathrm{C}\right]$
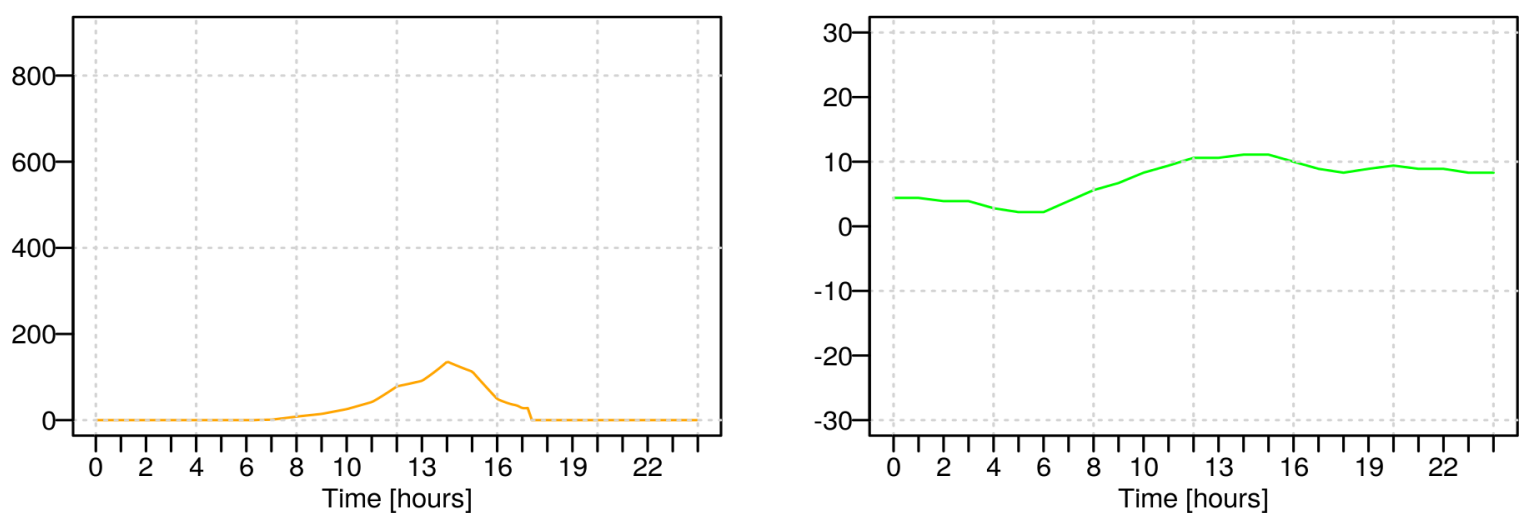

Figure 5.7: Blind positions and thermal conditions for a single day in October. The shaded regions represent the non-optimized periods using MPC, dashed lines represent heating and cooling set points 


\subsection{Winter Performance}

Winter is represented by the week from December 19 to 25, which contains the Winter Solstice - the shortest day of the year. The Urbandale CHEeR house undergoes primarily heating during this week. Optimizations are carried out hourly from 7 a.m. to 7 p.m. in the daytime. Outside of this time frame, the blinds are fully deployed. The total heating and cooling loads are presented in Figure 5.8.

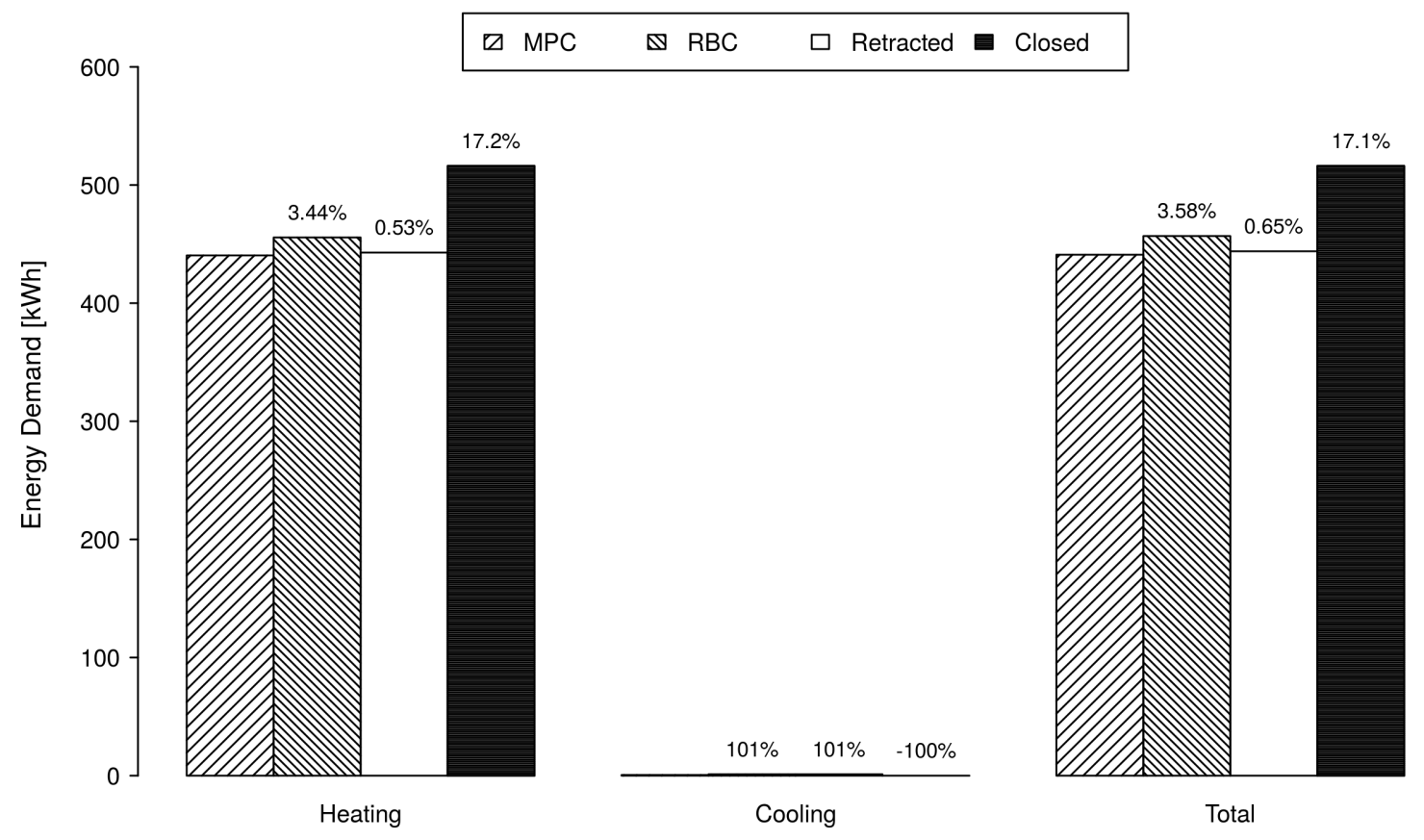

Figure 5.8: Total heating and cooling demand for a week in December, comparing performance to MPC

The Urbandale CHEeR house experiences a few instances of cooling on a single day during the selected week in the winter, but the heating loads are more dominant. Hence, retracting the blinds to allow solar gains during the daytime is generally favourable. The results show that energy savings of $17.1 \%$ are attributed to retracting the blinds, compared to deploying them for the duration of the week.

The MPC application keeps the blinds retracted throughout the optimization period. However, the contribution of closing the blinds during the night time is observable. By closing the blinds during the night time, the longwave heat transfer to the building's surroundings is minimized, resulting in a slight $0.5 \%$ decrease in the heating energy demand in comparison to the retracted case. 
Blind positions for south face using MPC
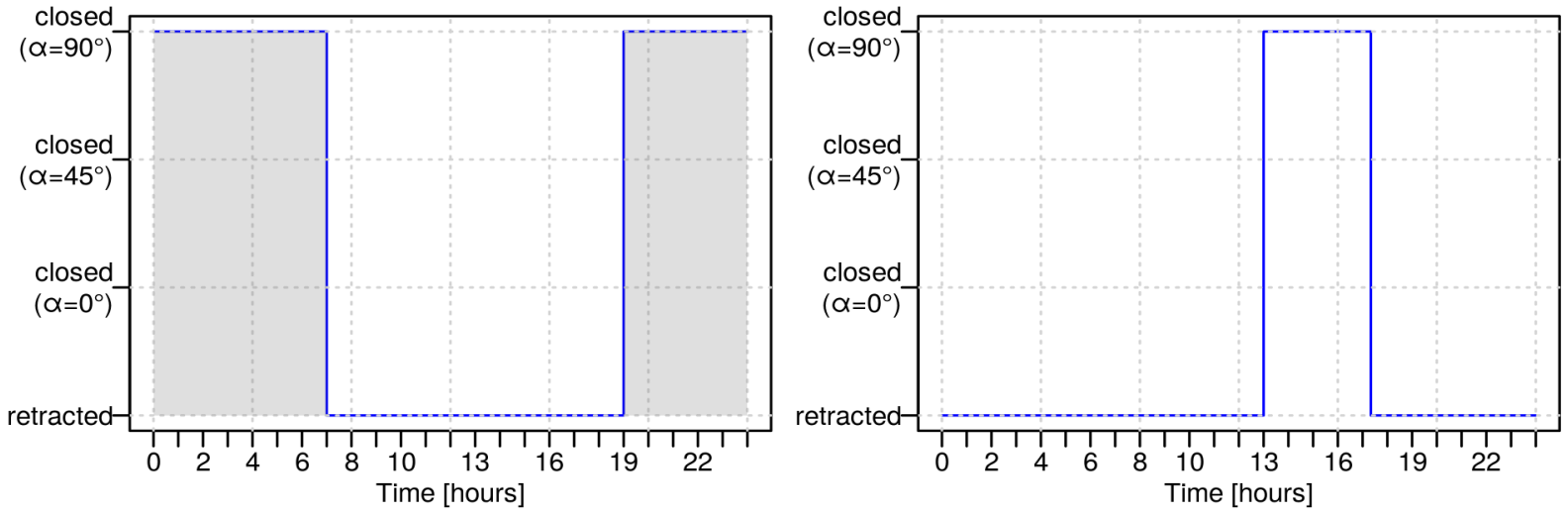

Temperature in first storey using $\mathrm{MPC}\left[{ }^{\circ} \mathrm{C}\right]$ Temperature in first storey using $\mathrm{RBC}\left[{ }^{\circ} \mathrm{C}\right]$
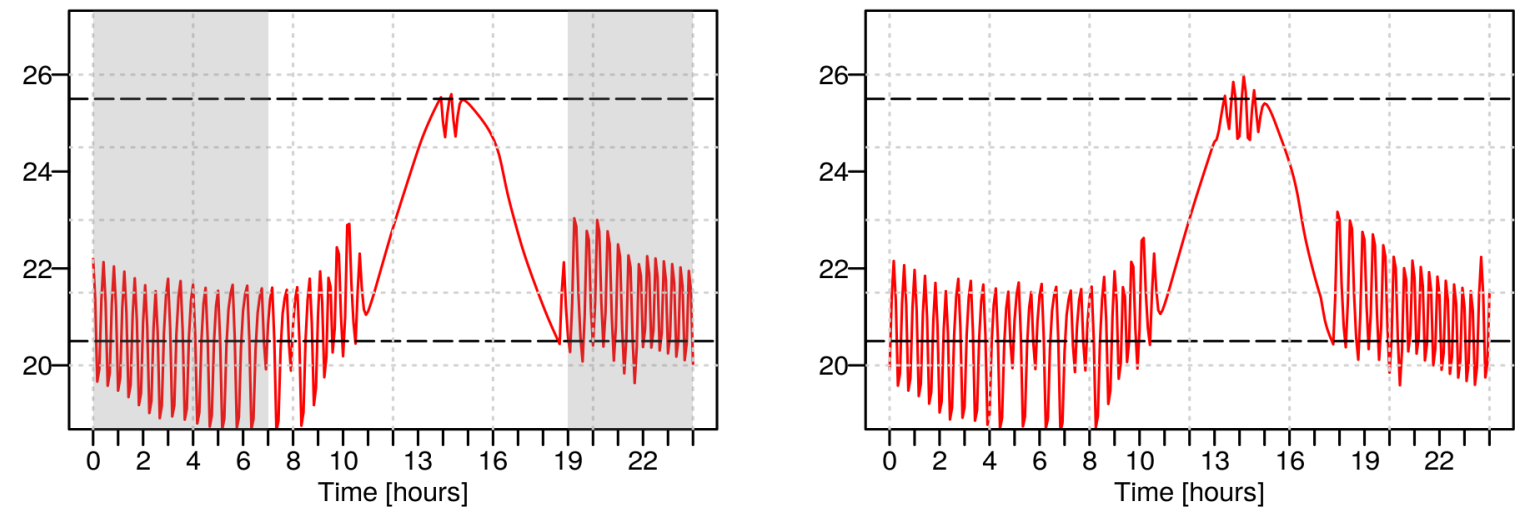

Incident solar flux on south face $\left[\mathrm{W} / \mathrm{m}^{2}\right]$

Ambient temperature $\left[{ }^{\circ} \mathrm{C}\right]$
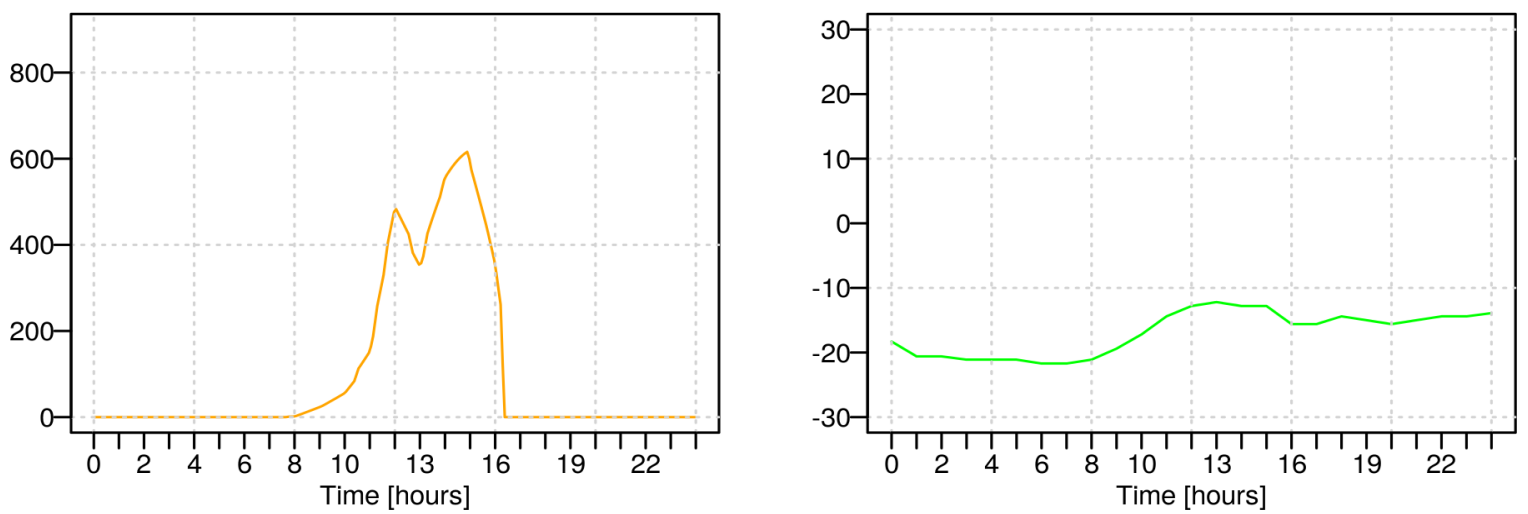

Figure 5.9: Blind positions and thermal conditions for a single day in December. The shaded regions represent the non-optimized periods using MPC, dashed lines represent heating and cooling set points 
The instances of overheating are also halved. In the case of the $\mathrm{RBC}$, the blinds are closed for a portion of the test period, causing an increase in the heating loads. Also,

as the building already starts to overheat before the blinds are closed, the RBC does not improve the cooling loads in comparison to when the blinds are retracted.

\subsection{MPC of Blinds on East and West Faces}

So far, the discussion has been centred around the blinds on the south face of the house. The sun rises in the East and sets in the West, and only the south face of a building in the Northern Hemisphere is constantly irradiated in the daytime. Thus, the incident solar radiation on the south face of the Urbandale CHEeR house is more important than other orientations. Nevertheless, the MPC controller was also applied to the east and west-facing blinds. The contribution of including the blinds on the east and west faces in this MPC application is discussed in this section.

In general, the MPC blind positions on the east and west facing windows did not show a discernible pattern (see Appendix A). This is because controlling these blinds at certain hours of the day may have no significant impact on the heating and cooling loads due to their orientation. Also, there are fewer windows on the east and west faces compared to the south face. The sensitivity of the building's energy combined thermal loads to the blind positions on each orientation is summarized in Table 5.1.

The thermal loads were most impacted in the cases where the south-facing blind positions were kept constant. The highest increase of $30 \%$ occurs when the southfacing blinds are retracted during the summer. In some scenarios, the position of the south-facing blinds has only a slight influence on the thermal loads. Such is the case when the south-facing blinds are retracted in the summer and fully closed in the winter. This observation is due to the homogeneous composition of the combined thermal loads in the summer and winter that causes the MPC to either fully retract or close the blinds for the majority of the week. However, the combined energy requirements for the entire year is not homogeneous, and keeping the blind positions on the south face constant is unlikely to result in such a small increase.

The maximum increase in the thermal loads due to keeping the west-facing blind positions constant is $6.9 \%$, which occurs when the blinds are retracted in the summer, when all solar gains are detrimental. Likewise, the maximum energy increase from the east-facing blinds occurs when the blinds are retracted in the summer. The results 
show that including the east and west-facing blinds in the MPC application improves energy savings, but their contributions are not as significant as the south-facing blinds. Including the east and west-facing blinds in this MPC application triples the number of variables required for optimization(refer to Section 2.5.3). Hence, the influence of the east and west-facing blinds on the combined heating and cooling loads may be useful for further study of this topic, especially for reducing the computational costs of the optimizations. This subject is discussed further in Chapter 6 .

\subsection{Closing Remarks}

The results of this thesis show that the MPC requires the lowest thermal loads in all seasons. The MPC's performance in the summer, where the combined thermal loads consist mostly of cooling, supports the conclusion that rejecting heat for the entirety of the week provides the best energy savings. Similarly, allowing solar radiation into the house in the winter is most advantageous for reducing heating requirements. The MPC scheme is most applicable to the spring and fall swing seasons since the building requires significant amounts of both heating and cooling, and simply retracting or fully closing the blinds for the entire duration is not ideal. During the spring and fall seasons, the MPC provides an excellent trade-off between reducing the heating and cooling loads individually, in order to minimize the combined thermal loads in the building.

In contrast, the RBC performed poorly during the fall and spring swing seasons. It is important to note that the RBC used for comparisons in this work is a typical, broadly applied reactive strategy, which is not optimal for controlling the blinds in the Urbandale CHEeR house. Moreover, the RBC was one of the best performers in the summer, as the building experiences high indoor temperatures that exceed the upper RBC set-point for the entire week. This causes the blinds to stay closed throughout and reject all external solar gains, which is best during the summer. A similar reasoning applies to the acceptable performance of the RBC winter season, where the blinds stay open for the majority of the week. The spring and fall swing seasons highlight the poor performance of the RBC. In general, the RBC admits the adverse solar gains and rejects the useful portion that is incident on the south face during these seasons. The results show that the RBC does a fine job of reducing the heating and cooling loads individually, but fails to minimize the combined loads. 
The computational cost of optimizations was also discussed in this chapter. The length of optimizations currently makes this MPC scheme unfeasible for real-time implementation. The complexity of the ESP-r model used for this work was identified as major contributor to the computation time. The results also highlighted that some of the other factors affecting computation time, such as including intermediate blind positions or involving the east and west-facing blinds in the optimization calculations could be forgone. The blinds on the south face rarely converged to the intermediate blind positions, and the contributions of the east and west-facing blinds are minimal in comparison to the south face. The following chapter builds on this idea and offers recommendations for future work, in addition to concluding this thesis. 


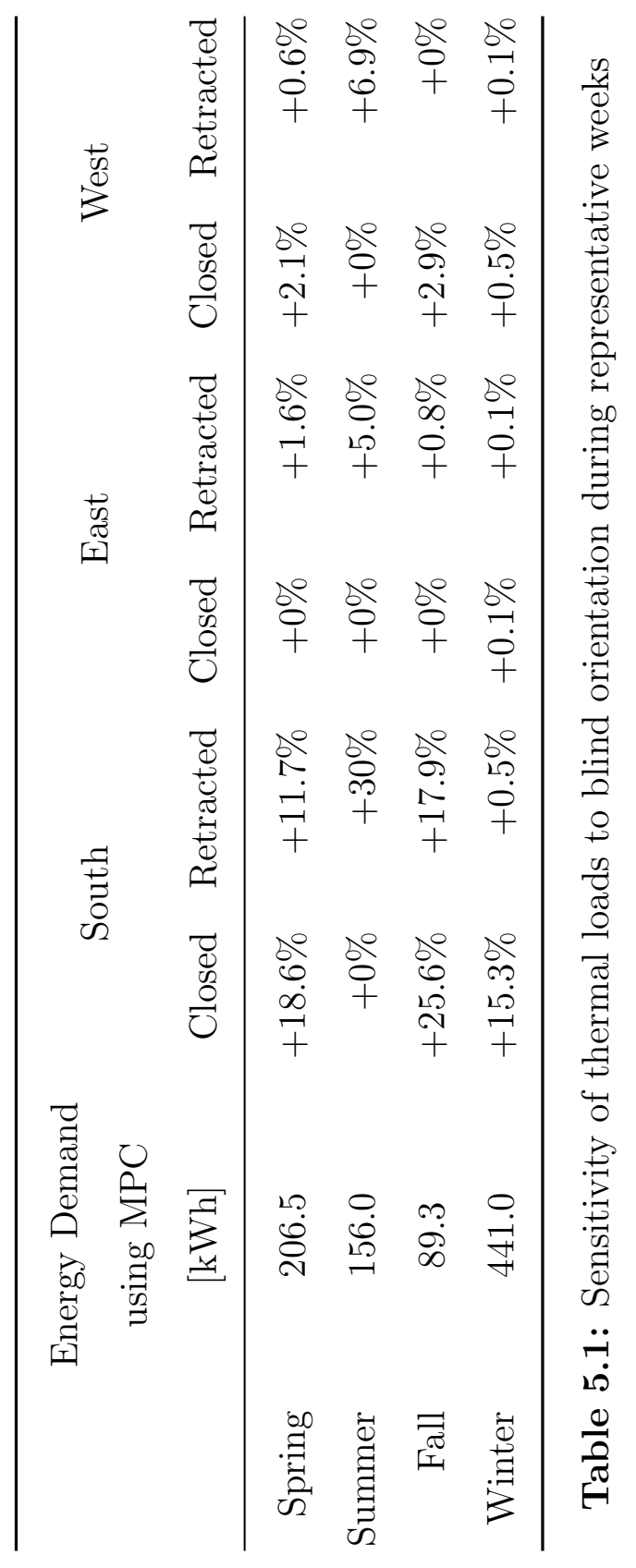




\section{Chapter 6}

\section{Conclusions and Recommendations}

As stated in Chapter 1, the goals of this thesis were to :

- Develop and study an MPC scheme for controlling window blinds to minimize the heating and cooling energy demand in the Urbandale CHEeR house

- Evaluate performance of the MPC scheme by comparing it to other blind control strategies

These goals have been met using the methodology described in Chapter 4, which utilizes building performance simulation software to model the Urbandale CHEeR house and an optimization software. Section 6.1 summarizes the work and the main results of this thesis. Section 6.2 gives recommendations for future research in this area.

\subsection{Conclusions}

\section{ESP-r Model}

This thesis used a building simulation program, ESP-r, to model the thermal behaviour of the Urbandale CHEeR house and its plant components. The heat pump featured in the original model of the Urbandale CHEeR house developed by [38] was replaced by an equivalent heating and cooling system to meet the comfort requirements of the space. This modification eliminated the need for co-simulation between ESP-r and TRNSYS, in order to reduce computational time of simulations. The heating and cooling plant components are actuated based on the air temperature in the 
first storey. Heating is switched on for temperatures below $20.5^{\circ} \mathrm{C}$ until the temperature exceeds $21.5^{\circ} \mathrm{C}$, and cooling is operational for temperatures exceeding $25.5^{\circ} \mathrm{C}$, until the temperature falls to $24.5^{\circ} \mathrm{C}$.

$1 / 2$ inch wide aluminum venetian blinds were added to the original model. The blinds can either be retracted or deployed, and when deployed the slats can assume any position from $0^{\circ}$ to $90^{\circ}$. The blinds were controlled according to a 'schedule' that is determined from the optimization calculations. The daily 'schedule' of the blinds is divided into fourteen periods - one from 12:00 a.m.-7:00 a.m., another from 7:00 p.m.-12:00 a.m., and twelve hourly periods from 7:00 a.m.-7:00 p.m. The hourly periods from 7:00 a.m.-7:00 p.m. experience significant amounts of solar radiation and are optimized. Outside of this time frame, the blinds are fully closed for the entire duration of the simulations.

\section{Optimization Methodology}

MPC involves solving an optimization problem repeatedly, over a finite, receding period of time. The objective function of the optimization problem in this thesis was the energy demand in the Urbandale CHEeR house, and the control variables are the hourly blind positions, $\boldsymbol{\beta}$ (retracted or deployed) and slat positions, $\boldsymbol{\alpha}\left(0^{\circ}\right.$ to $\left.90^{\circ}\right)$ from 7:00 a.m.-7:00 p.m. The windows on each orientation of the house were controlled together.

GenOpt was chosen for the optimizations in this thesis because of its ability to couple externally with ESP-r, and also for its library of algorithms. GenOpt was configured to exchange information with ESP-r using text files and shell scripting. A hybrid of the Hooke-Jeeves (HJ) algorithm and the particle swarm optimization (PSO) was used for this work. The PSO is first initiated to narrow down the search space and provide an approximate location of the minimum objective function. Then, the HJ algorithm uses the termination point of the PSO as its starting point to perform a localized search for the global minimum. This hybrid algorithm utilizes the strengths of both algorithms in order to converge to an accurate solution quickly.

\section{MPC Scheme}

The MPC scheme was designed to predict the buildings thermal response to changing blind positions over a finite time horizon, and automate the blind positions in a 
manner that reduces the energy demand of the building. These design goals were met using ESP-r and GenOpt.

In a real world MPC application, information is exchanged between the building and a computation system. Here, the Urbandale CHEeR house was represented by an ESP-r model (Queen). Another ESP-r model (Pawn) is used in conjunction with GenOpt for virtual optimizations. The Queen and Pawn are assumed to operate under identical conditions, using perfect weather predictions. This configuration is equivalent to the MPC having a perfect forecast. Hence, this places an upper bound on the energy savings that could be realized by MPC. The information transfer between the Queen, Pawn and GenOpt was managed using text files, shell scripting and modifications to the standard ESP-r source codes.

For a single day application, the MPC scheme is summarized as follows: First, the Queen's simulations are initiated. At 7 a.m., the first optimization in GenOpt begins. The Queen's current thermal state is replicated in the Pawn and used to make predictions of the energy demand over a 24 hour period, under various blind positions. The optimization process involves running simulations of the Pawn several times, using the hybrid algorithm, until the algorithm's termination point is reached. Once the optimizations are complete, the blind positions for the current hour are implemented in the Queen, and the process is repeated until after 7 p.m. Simulations of the Queen and Pawn are performed using a 5 minute time step and a 7 day warm-up period.

\section{MPC Performance}

The limitations associated with the computational time of the MPC application were explored. Each hour was optimized in approximately 3.15 hours, rendering this MPC scheme inapplicable for real-time application using a similar computer as the one used for this work. The major contributors to computation time were found to be the number of optimization variables, the inclusion of intermediate blind positions and the speed of the computer. Possible actions for improvement in this area are discussed in Section 6.2.

In the simulated building, the performance of the implemented MPC scheme was compared to a reactive rule-based controller (RBC), a case with fully retracted blinds, 
and a case with fully closed blinds. Due to the large computation costs, the comparisons were studied over representative weeks of the entire year. The MPC outperformed the other cases in all weeks, except for the summer where it performed equally as the RBC and the fully closed blinds. In comparison to the RBC, energy savings of $26.4 \%$ were recorded in the spring, $36.6 \%$ in the fall, and $3.6 \%$ in the winter. These results support the premise that predictive control strategies generally offer additional energy savings over reactive control strategies, especially in the fall and spring shoulder seasons.

Furthermore, a sensitivity study of the blind positions of the different orientations of the house on the energy demand showed that the blinds on the east and west faces are not critical to minimizing the energy demand in the house. This observation shows that eliminating the east and west blinds from the MPC application is a possible area to cut back on computational costs without considerably sacrificing accuracy.

\section{Closing Remarks}

Overall, the results of this thesis indicate that MPC shows promise for controlling automated blinds in homes. Over the four representative weeks, the MPC scheme improved energy savings by $10 \%$ compared to a broadly-applied, reactive RBC. However, the performance of a practical application of this MPC scheme is contingent on the validity of the model of the house and the accuracy of the weather forecasts. It is expected that future work on this topic will address how much the MPC scheme's practical performance will differ from the theoretical savings predicted in this thesis due to variations in the model. Recommendations for improving the MPC scheme and future work on this topic are discussed in the following section.

\subsection{Recommendations for Future Work}

The design and construction of passive houses is gaining prevalence, and with this comes the issue of proper management of solar gains in order to improve the building's operation. The MPC approach in this thesis shows substantial potential in regard to addressing this issue, but its performance in the actual house using an as-built model must be studied before conclusions can be drawn. By implementing the MPC scheme in the actual house, prediction errors from discrepancies in the building model and weather forecasts can be studied and accommodated for accordingly. 
Another area of further study on this topic would be to compare the performance of the MPC to an optimal RBC. The RBC used for this work is simply a broadly applied, reactive strategy that may not be optimal for controlling the blinds in the Urbandale CHEeR house. Hence, further work on this topic should investigate the performance of the MPC in comparison to a RBC that is better tailored to the Urbandale CHEeR house. Some RBCs that may be useful for performance comparison purposes are described in [45].

In addition, the MPC scheme used for this work requires large computational costs, which poses a limitation to implementation in the actual house. This limitation could be addressed by using fewer zones and surfaces for the model. Along with simplifying the ESP-r model, maintaining a better compromise between the accuracy and speed of optimizations within the MPC scheme could lower the computational costs. One alternative is to forego the intermediate blind positions, which did not seem to significantly improve the optimization results, and either keep the blinds fully retracted or fully closed. Computations may also be executed on a computer with a faster processor to improve the overall speed. A third option is to optimize the blind positions on the south face of the house only, and predetermine the less critical east and west-facing blinds prior to optimizations. For example, if overheating is predicted to occur in the house over the prediction horizon, the blinds on the east and west faces can be fully closed; the opposite would apply when only heating is required. Another avenue to improve computational costs may be to perform optimizations over longer time intervals, for example every 2-3 hours instead of hourly.

Furthermore, the choice of the prediction horizon in this work was based on a study by [44], which was geared towards buildings in a Swiss climate. The Urbandale CHEeR house is located in Ottawa, thus this begets the question: What is an appropriate length of prediction horizon for this application? This question could be examined by simulating the performance of the MPC scheme using various prediction horizon lengths. It is possible that a prediction horizon shorter than 24 hours may yield adequate results, while also reducing the computation cost.

It was also concluded that the MPC scheme was most applicable to the spring and fall swing seasons. Further work on this topic could involve creating a method of quantifying the start and end of the swing seasons.

Finally, as shading systems highly influence the visual comfort of occupants, creating a comfortable environment for occupants is also essential. Ideally, the MPC 
scheme must be adaptable to occupants' requests and overrides. Introductory work by [46] on adaptive modelling of occupants preferences and behavioural patterns for lighting and shading systems may be useful for further work on this topic. 


\section{List of References}

[1] Natural Resources Canada, "Energy efficiency trends in Canada, 1990 to 2009." http://oee.nrcan.gc.ca/publications/statistics/trends11/, 2012. Accessed: 2013-10-17.

[2] U.S. Department of Energy, "Energy efficient window treatments." http://energy.gov/energysaver/articles/ energy-efficient-window-treatments, 2012. Accessed: 2015-03-20.

[3] Automatic control laboratory, "Simulation-based potential assessment of MPC." http://http://control.ee.ethz.ch/ building/research.php, 2014. Accessed: 2015-04-07.

[4] H. Akbari, D. M. Kurn, S. E. Bretz, and J. W. Hanford, "Peak power and cooling energy savings of shade trees," Energy and Buildings, vol. 25, no. 2, pp. 139-148, 1997.

[5] T. Inoue, M. Ichinose, and N. Ichikawa, "Thermotropic glass with active dimming control for solar shading and daylighting," Energy and Buildings, vol. 40, no. 3, pp. 385-393, 2008.

[6] L. Bellia, F. D. Falco, and F. Minichiello, "Effects of solar shading devices on energy requirements of standalone office buildings for Italian climates," Applied Thermal Engineering, vol. 54, pp. 190-201, 5/14 2013.

[7] M. Manzan, "Genetic optimization of external fixed shading devices," Energy and Buildings, vol. 72, pp. 431-440, 42014.

[8] L. G. Caldas and L. K. Norford, "A design optimization tool based on a genetic algorithm," Automation in Construction, vol. 11, pp. 173-184, 22002.

[9] S. Raeissi and M. Taheri, "Optimum overhang dimensions for energy saving," Building and Environment, vol. 33, pp. 293-302, 91998.

[10] B. A. Lomanowski and J. L. Wright, "The Complex Fenestration Construction: a practical approach for modelling windows with shading devices in ESP-r," Journal of Building Performance Simulation, vol. 5, no. 3, pp. 185-198, 2012.

[11] S. Nikoofard, V. I. Ugursal, and I. Beausoleil-Morrison, "Technoeconomic assessment of the impact of window shading retrofits on the heating and cooling energy consumption and GHG emissions of the Canadian housing stock," Energy and Buildings, vol. 69, pp. 354-366, 22014. 
[12] G. van Moeseke, I. Bruyre, and A. D. Herde, "Impact of control rules on the efficiency of shading devices and free cooling for office buildings," Building and Environment, vol. 42, pp. 784-793, 22007.

[13] P. Littlefair, J. Ortiz, and C. D. Bhaumik, "A simulation of solar shading control on UK office energy use," Building Research $\&$ Information, vol. 38, no. 6 , pp. 638-646, 2010.

[14] F. Oldewurtel, A. Parisio, C. Jones, M. Morari, D. Gyalistras, M. Gwerder, V. Stauch, B. Lehmann, and K. Wirth, "Energy efficient building climate control using Stochastic Model Predictive Control and weather predictions," in American Control Conference (ACC), 2010, pp. 5100-5105, June 2010.

[15] F. Oldewurtel, D. Gyalistras, M. Gwerder, C. Jones, A. Parisio, V. Stauch, B. Lehmann, and M. Morari, "Increasing energy efficiency in building climate control using weather forecasts and model predictive control," in Clima - RHEVA World Congress, 2010.

[16] M. J. Jimenez and H. Madsen, "Models for describing the thermal characteristics of building components," Building and Environment, vol. 43, no. 2, pp. 152-162, 2008.

[17] M. Maasoumy and A. S. Vincentelli, "Comparison of Control Strategies for Energy Efficient Building HVAC Systems," in Proceedings of the Symposium on Simulation for Architecture 83 Urban Design, SimAUD '14, (San Diego, CA, USA), pp. 11:1-11:8, Society for Computer Simulation International, 2014.

[18] H. Asan and Y. Sancaktar, "Effects of wall's thermophysical properties on time lag and decrement factor," Energy and Buildings, vol. 28, no. 2, pp. 159 - 166, 1998.

[19] D. Sturzenegger, D. Gyalistras, M. Gwerder, C. Sagerschnig, M. Morari, and R. S. Smith, "Model predictive control of a Swiss office building," in 11th REHVA World Congress Clima, vol. 2013, 2013.

[20] B. Huchuk, "Model-based predictive control of window shades," Master's thesis, Carleton University, 2014.

[21] J. A. Candanedo and V. Dehkordi, "ghMulti-Level Approach for Model-Based Predictive Control (MPC) in Buildings: A Preliminary Overview," tech. rep., Energy Systems Laboratory (Texas A\&M University), 2013.

[22] M. Maasoumy, A. Pinto, and A. Sangiovanni-Vincentelli, "Model-based hierarchical optimal control design for HVAC systems," in ASME 2011 Dynamic Systems and Control Conference and Bath/ASME Symposium on Fluid Power and Motion Control, pp. 271-278, American Society of Mechanical Engineers, 2011.

[23] C. D. Corbin, G. P. Henze, and P. May-Ostendorp, "A model predictive control optimization environment for real-time commercial building application," Journal of Building Performance Simulation, vol. 6, no. 3, pp. 159-174, 2013. 
[24] B. Coffey, F. Haghighat, E. Morofsky, and E. Kutrowski, "A software framework for model predictive control with GenOpt," Energy and Buildings, vol. 42, pp. 1084-1092, 72010.

[25] G. Zhou, P. Ihm, M. Krarti, S. Liu, and G. Henze, "Integration of an internal optimization module within EnergyPlus," in Proceedings of 8th International IBPSA Conference, Eindhoven, the Netherlands, 2003.

[26] L. Peeters, "The coupling of ESP-r and GenOpt: a simple case study," Lawrence Berkeley National Laboratory, 2010.

[27] L. Magnier and F. Haghighat, "Multiobjective optimization of building design using TRNSYS simulations, genetic algorithm, and Artificial Neural Network," Building and Environment, vol. 45, no. 3, pp. 739-746, 2010.

[28] M. Wetter, "Modelica-based modelling and simulation to support research and development in building energy and control systems," Journal of Building Performance Simulation, vol. 2, no. 2, pp. 143-161, 2009.

[29] S. McMurtry, "On configuration and control of the thermal plant for fuel cell micro-cogeneration," Master's thesis, Carleton University Ottawa, 2013.

[30] J. A. Clarke, Energy simulation in building design. Routledge, 2001.

[31] I. Beausoleil-Morrison, The adaptive coupling of heat and air flow modelling within dynamic whole-building simulation. PhD thesis, University of Strathclyde UK, 2000.

[32] R. Perez, R. Seals, and J. Michalsky, "All-weather model for sky luminance distributionPreliminary configuration and validation ," Solar Energy, vol. 50, no. 3, pp. $235-245,1993$.

[33] D. Thevenard and K. Haddad, "Ground reflectivity in the context of building energy simulation," Energy and Buildings, vol. 38, no. 8, pp. 972 - 980, 2006.

[34] B. Lomanowski, "Implementation of window shading models into dynamic wholebuilding simulation," Master's thesis, University of Waterloo, 2008.

[35] N. Kotey and J. Wright, "Simplified solar optical calculations for windows with venetian blinds," in Proceedings of the 31st Conference of the Solar Energy Society of Canada Inc.(SESCI), 2006.

[36] J. L. Wright, "Calculating center-glass performance indices of glazing systems with shading devices," Transactions-American Society of Heating Refrigerating and Air Conditioning Engineers, vol. 114, pp. 199-209, 2008.

[37] H. Shahid and D. Naylor, "Energy performance assessment of a window with a horizontal Venetian blind ," Energy and Buildings, vol. 37, no. 8, pp. 836 -843, 2005.

[38] I. Beausoleil-Morrison, "Personal correspondence," 2013. 
[39] Environment Canada, "Engineering data sets (CWEEDS); CWEC weather files," CWEEDS Appendix D, 2012.

[40] I. S. Walker and D. Wilson, The Alberta air infiltration model: AIM-2. Department of Mechanical Engineering, University of Alberta, 1990.

[41] I. Beausoleil-Morrison, F. Macdonald, M. Kummert, T. McDowell, R. Jost, and A. Ferguson, "The Design of an ESP-r and TRNSYS Co-Simulator," in Proc. Building Simulation, pp. 2333-2340, 2011.

[42] M. Wetter, "GenOpt Manual: Generic Optimization Program, Version 2.1. 0," University of California (through Lawrence Berkeley National Laboratory), Berkeley, 2008.

[43] M. Wetter and J. Wright, "A comparison of deterministic and probabilistic optimization algorithms for nonsmooth simulation-based optimization," Building and Environment, vol. 39, no. 8, pp. 989 - 999, 2004. Building Simulation for Better Building Design.

[44] F. Oldewurtel, A. Parisio, C. N. Jones, D. Gyalistras, M. Gwerder, V. Stauch, B. Lehmann, and M. Morari, "Use of model predictive control and weather forecasts for energy efficient building climate control," Energy and Buildings, vol. 45, pp. $15-27,2012$.

[45] M. Gwerder, D. Gyalistras, F. Oldewurtel, B. Lehmann, K. Wirth, V. Stauch, J. Tödtli, and C. J. Tödtli, "Potential assessment of rule-based control for integrated room automation," in 10th REHVA World Congress Clima, pp. 9-12, 2010.

[46] H. B. Gunay, W. O'Brien, I. Beausoleil-Morrison, and B. Huchuk, "On adaptive occupant-learning window blind and lighting controls," Building Research \&6 Information, vol. 42, no. 6, pp. 739-756, 2014. 


\section{Appendix A}

\section{MPC Results for East and West-facing Blinds}

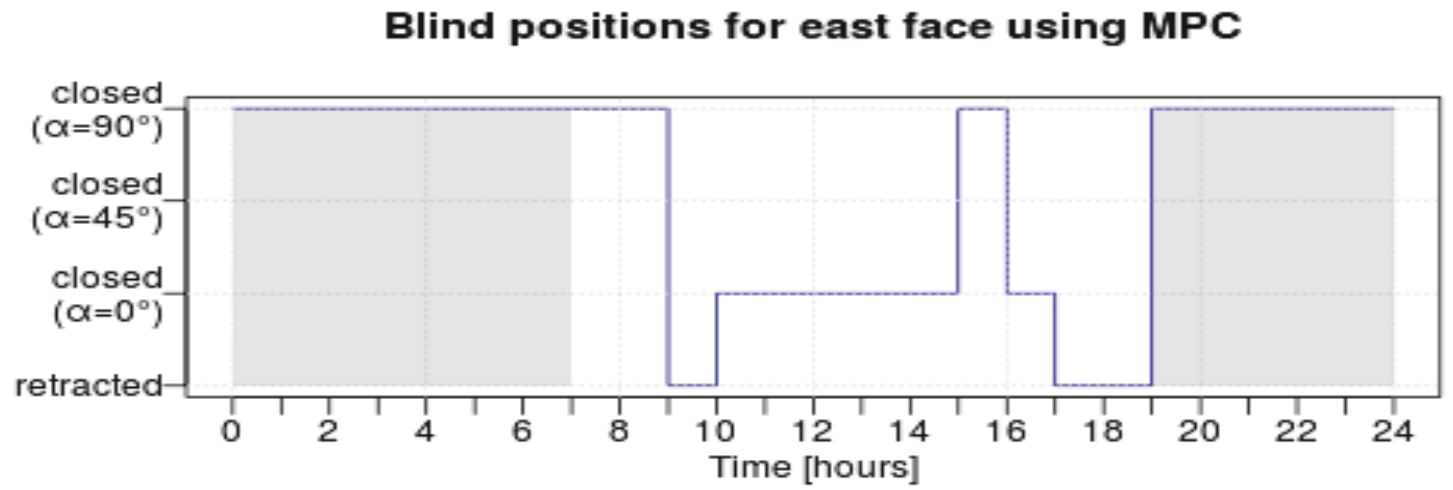

Blind positions for west face using MPC

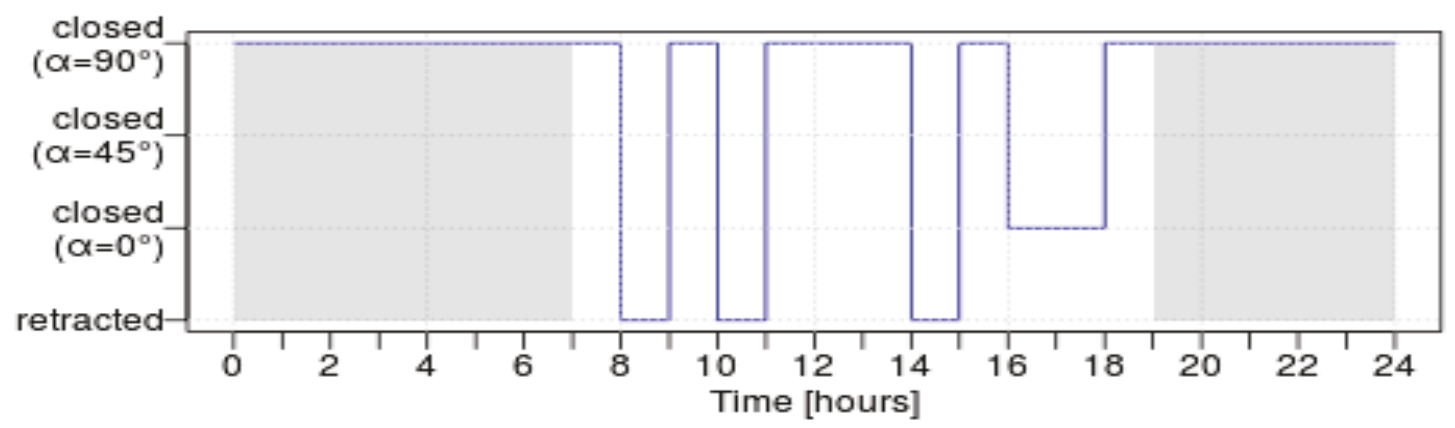

Figure A.1: Blind positions for east and west facing blinds for a single day in March using MPC 


\section{Appendix B}

\section{Hooke-Jeeves Algorithm}

First, the HJ algorithm describes the search space as a multi-dimensional grid. Each dimension corresponds to each varied parameter, $\left\{\boldsymbol{\alpha}_{1}, \ldots, \boldsymbol{\alpha}_{n}\right\}$, for $n$ variables. For example, the search space for a problem with two variables is represented in two dimensions. The initial perturbation in each direction is supplied by the user, which can be expressed as a vector, $\mathbf{P}^{0} \leftarrow\left\{\Delta \alpha_{1}, \ldots, \Delta \alpha_{n}\right\}$. For this work, initial perturbations were given as $90^{\circ}$. However, perturbations in all directions do not need to be equal. The algorithm evaluates the objective function at a user-defined starting point, $\boldsymbol{\alpha}^{(0)} \leftarrow\left(\alpha_{1}^{(0)}, \ldots, \alpha_{n}^{(0)}\right)$. The value of the objective function at this position is assigned the current, best iterate, $L_{\text {best }}$ (as it is the only iterate thus far).

Next, an exploratory search is initiated. For a problem with $n$ variables, the algorithm steps by $\Delta \alpha_{j}$ in the positive direction corresponding to a variable $\alpha_{j}$, where $1 \leq j \leq n$. This neighbouring position is given by $\boldsymbol{\alpha}_{j}^{(1)} \leftarrow\left(\alpha_{1}^{(0)}, \ldots, \alpha_{j}^{(0)}+\Delta \alpha_{j}, \ldots, \alpha_{n}^{(0)}\right)$. Then, the objective function at this neighbouring position is evaluated. If the objective function at this position improves over $L_{b e s t}$, the positive perturbation is retained. Else, the same variable is perturbed in the opposite direction, $\boldsymbol{\alpha}_{j}^{(1)} \leftarrow\left(\alpha_{1}^{(0)}, \ldots, \alpha_{j}^{(0)}-\Delta \alpha_{j}, \ldots, \alpha_{n}^{(0)}\right)$. If the negative perturbation improves the objective function, the negative perturbation is retained. For a successful perturbation (positive or negative), $L_{\text {best }} \leftarrow L\left(\boldsymbol{\alpha}^{(1)}\right)$. If neither perturbation results in an improvement, both perturbations are discarded and the second step is repeated for the next variable.

If the exploratory search is successful (one or more perturbations improve the objective function), the best position is now given by $\boldsymbol{\alpha}^{(1)}$, and the pattern move is initiated. The algorithm generates a new point, $\boldsymbol{\alpha}^{(2)}$ by moving through $\boldsymbol{\alpha}^{(1)}$ from 


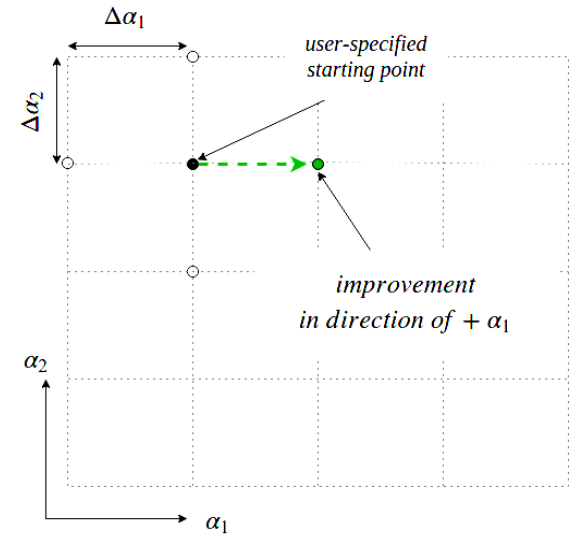

(a) Improvement from positive perturbation in first direction

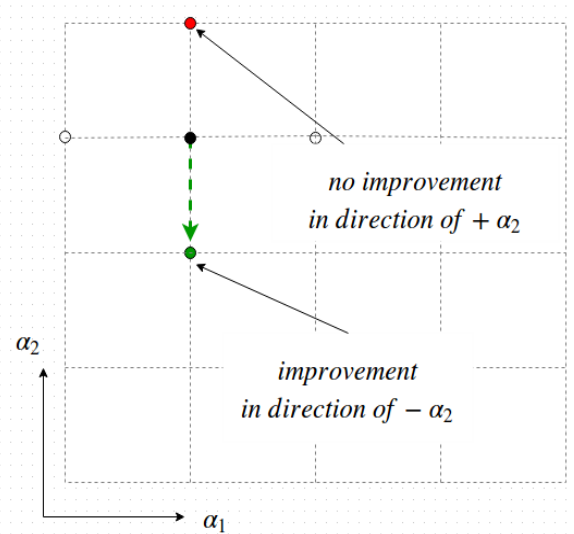

(b) Improvement from negative perturbation in second direction after evaluating non-improving, positive perturbation

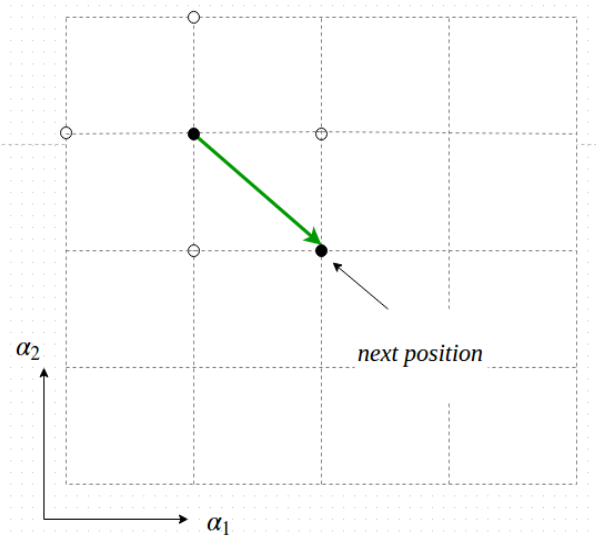

(c) Next center position for exploratory search

Figure B.1: Exploratory search for a two-variable optimization problem 


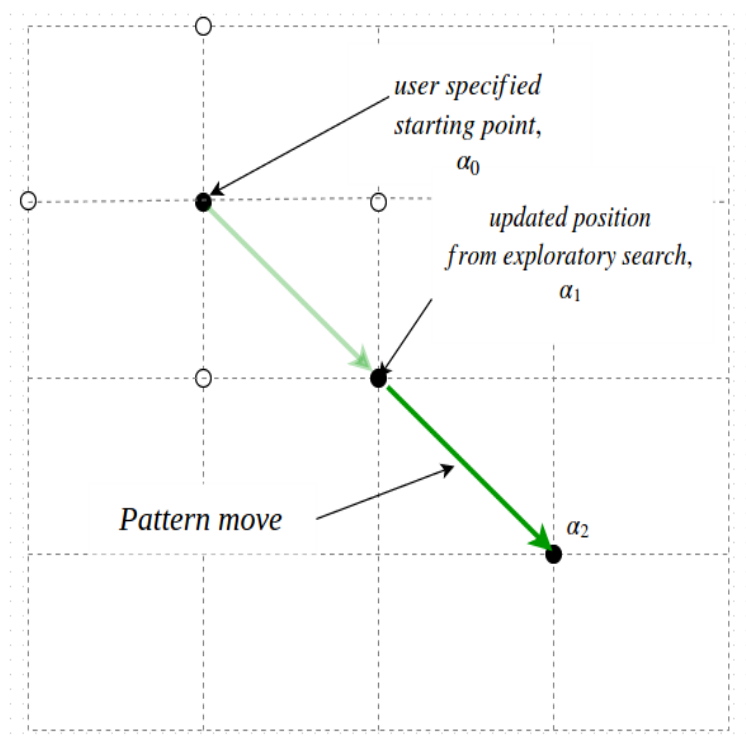

Figure B.2: Pattern move in the direction of improvement

$\boldsymbol{\alpha}^{(0)}$, such that:

$$
\boldsymbol{\alpha}^{(2)}=\boldsymbol{\alpha}^{(0)}+a\left[\boldsymbol{\alpha}^{(1)}-\boldsymbol{\alpha}^{(0)}\right]
$$

where $a$ is a positive acceleration factor that projects $\boldsymbol{\alpha}^{(2)}$ from $\boldsymbol{\alpha}^{(0)}$ along the same direction as $\boldsymbol{\alpha}^{(1)}$, but at $a$ times the distance. The HJ implementation in GenOpt uses a constant value of 2 for $a$ [42].

The pattern move is retained if it shows an improvement, and another pattern move is performed. Otherwise, another exploratory search is initiated using the same perturbation vector $\left(\mathbf{P}^{1} \leftarrow\left\{\Delta \alpha_{1}, \ldots, \Delta \alpha_{n}\right\}\right)$.

However, if the first exploratory search was unsuccessful, and there was no improvement in $L_{b e s t}$ from the initial starting point, the perturbations are made smaller in preparation for another exploratory search. A suggested step reduction variable of 2 was used for this work [43]. Based on this value, the perturbation vector becomes $\mathbf{P}^{1} \leftarrow \frac{\mathbf{P}^{0}}{2} \leftarrow\left\{\frac{\Delta \alpha_{1}}{2}, \ldots, \frac{\Delta \alpha_{n}}{2}\right\}$.

This process is repeated, until the required tolerance or maximum number of iterations is reached. 


\section{Appendix C}

\section{Files}

\section{C.1 GenOpt Files}

\section{C.1.1 Hybrid PSO/HJ Optimization Settings in Command file}

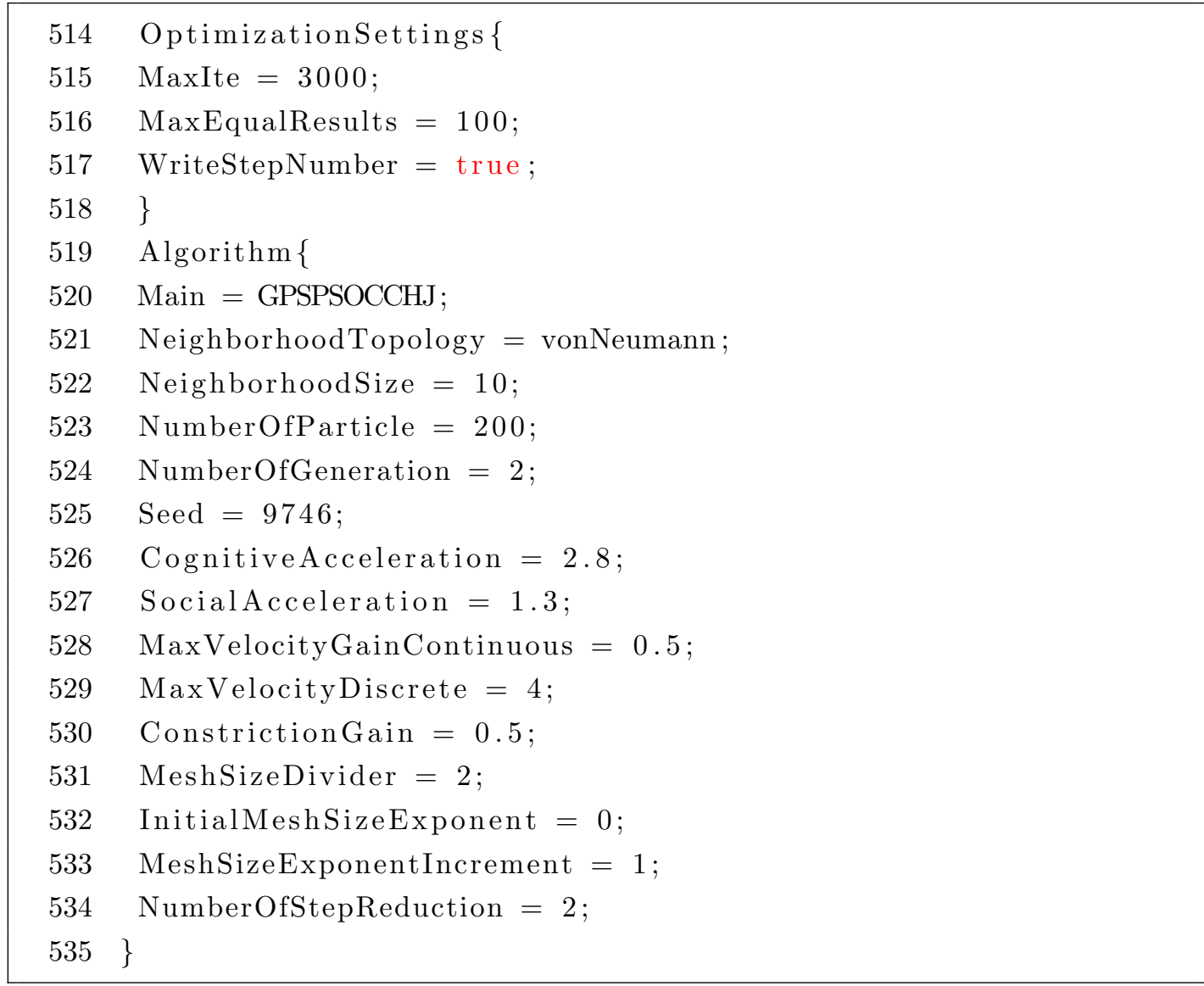




\section{C.1.2 Additional GenOpt Files}

GenOpt configuration file

URL:http://gearbox.mae.carleton.ca/ibeau_students_svn/tiwa/Rapini/ genOpt/bashSimulation.cfg

GenOpt command file

URL: http://gearbox.mae.carleton.ca/ibeau_students_svn/tiwa/Rapini/ genOpt/command. txt

GenOpt initiation file

URL:http://gearbox.mae.carleton.ca/ibeau_students_svn/tiwa/Rapini/ genOpt/optLinux.ini

StartPawnsimulations.sh

URL:http://gearbox.mae.carleton.ca/ibeau_students_svn/tiwa/Rapini/ genOpt/StartPawnSimulations.sh

\section{C.2 MPC Files}

\section{C.2.1 Queen ESP-r modifications}

This section shows the relevant modifications made for a simulation start day of March 18, using 7 warm-up days and a 5 minute timestep.

\section{Modifications to MZNUMA subroutine}

\begin{tabular}{|c|c|}
\hline 1136 & IF $(\mathrm{CLOSE}) \mathrm{n} \sin \mathrm{c}=\mathrm{n} \sin \mathrm{c}+1$ \\
\hline 1137 & $\mathrm{HOY}=((\mathrm{ISDS}-1) * 24)+((\mathrm{NSINC}) / 12.0)-(7 * 24)$ \\
\hline 1138 & IF (HOY.ge.1824) then ! HOY number of 12:00am on March 18 \\
\hline 1139 & IF $((\operatorname{MOD}(\mathrm{NSINC}, 288) \cdot \mathrm{ge} .84)$. and $(\mathrm{MOD}(\mathrm{NSINC}, 288) \cdot \mathrm{lt} .228))$ then \\
\hline 1140 & IF ( (MOD(NSINC, 12$) \cdot$ eq .0$))$ then \\
\hline 1141 & CALL system("dos2unix_/home/tiwa/MPC/RunGenOpt.sh") \\
\hline 1142 & CALL system("bash॰/home/tiwa/MPC/RunGenOpt.sh") \\
\hline 1143 & END IF \\
\hline 1144 & END IF \\
\hline 1145 & END IF \\
\hline
\end{tabular}




\section{Modifications to MZLS3 subroutine}

\begin{tabular}{|c|c|}
\hline 842 & $\mathrm{HOY}=((\mathrm{ISDS}-1) * 24)+((\mathrm{NSINC}) / 12.0)-(7 * 24)$ \\
\hline 843 & OPEN(65, FILE='/ home/tiwa/MPC/TFS_master . txt') \\
\hline 844 & DO i $1=1, \mathrm{MCOM}$ \\
\hline 845 & WRITE $(65, *) \quad(\operatorname{TFS}(\mathrm{i} 1, \mathrm{j} 1), \mathrm{j} 1=1, \mathrm{MS})$ \\
\hline 846 & END DO \\
\hline 847 & CLOSE $($ UNIT $=65)$ \\
\hline \multicolumn{2}{|l|}{848} \\
\hline 849 & $\operatorname{OPEN}(66, \mathrm{FILE}=$ '/ home/tiwa/MPC/TF A_master . txt' $)$ \\
\hline 850 & WRITE $(66, *)$ TFA \\
\hline 851 & CLOSE $(\mathrm{UNIT}=66)$ \\
\hline \multicolumn{2}{|l|}{852} \\
\hline 853 & $\mathrm{OPEN}\left(\mathrm{UNIT}=67, \mathrm{FILE}={ }^{\prime} /\right.$ home $/ \mathrm{tiwa} / \mathrm{MPC} / \mathrm{TFC} \_$master. $\left.\mathrm{txt}{ }^{\prime}\right)$ \\
\hline 854 & DO i $3=1, \mathrm{MCOM}$ \\
\hline 855 & $\mathrm{DO} \mathrm{j} 3=1, \mathrm{MS}$ \\
\hline 856 & $\operatorname{WRITE}(67, *) \quad(\mathrm{TFC}(\mathrm{i} 3, \mathrm{j} 3, \mathrm{k} 3), \mathrm{k} 3=1, \mathrm{MN})$ \\
\hline 857 & END DO \\
\hline 858 & END DO \\
\hline 859 & CLOSE $(\mathrm{UNIT}=67)$ \\
\hline \multicolumn{2}{|l|}{860} \\
\hline 861 & $\operatorname{OPEN}(68, \mathrm{FILE}=$ '/ home/tiwa/MPC/HOY_master . txt' $)$ \\
\hline 862 & WRITE $(68, *)$ HOY \\
\hline
\end{tabular}

\section{Modifications to CFC Control subroutine}

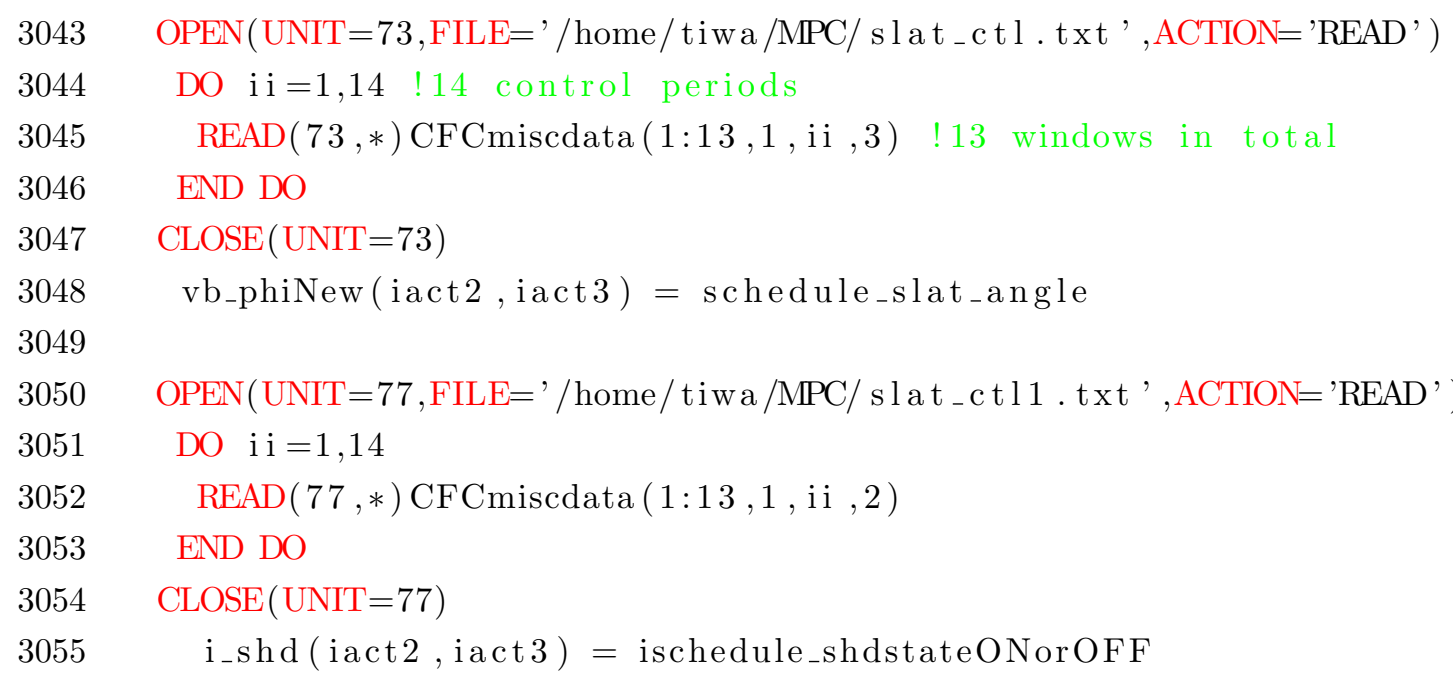




\section{C.3 Pawn ESP-r modifications}

\section{Modifications to MZLS5 subroutine}

\begin{tabular}{|c|c|}
\hline 2369 & $\mathrm{HOY}=((\mathrm{ISDS}-1) * 24)+((\mathrm{NSINC}) / 12.0)-(1 * 24)$ \\
\hline 2370 & $\operatorname{OPEN}(5, \mathrm{FILE}=$ '/ home/tiwa/MPC/HOY_Queen.txt' , ACTION='read ') \\
\hline 2371 & $\operatorname{READ}(5, *)$ HOY_Queen \\
\hline 2372195 & FORMAT( I4 , F8 .3 ) \\
\hline 2373 & CLOSE ( 5$)$ \\
\hline \multicolumn{2}{|l|}{2374} \\
\hline 2375 & IF (HOY.EQ.HOY_Queen) THEN \\
\hline \multicolumn{2}{|l|}{2376} \\
\hline 2377 & OPEN(19, FILE='/home/tiwa/MPC/TFS_Queen.txt', STATUS='old') \\
\hline 2378 & $\mathrm{DO}$ i $1=1, \mathrm{MCOM}$ \\
\hline 2379 & $\operatorname{READ}(19, *$, end $=199) \quad(\operatorname{TFS}(\mathrm{i} 1, \mathrm{j} 1), \mathrm{j} 1=1, \mathrm{MS})$ \\
\hline 2380192 & FORMAT( 14, F8.3) \\
\hline 2381 & END DO \\
\hline 2382199 & CONTINUE \\
\hline 2383 & $\operatorname{CLOSE}(19)$ \\
\hline \multicolumn{2}{|l|}{2384} \\
\hline 2385 & $\operatorname{OPEN}(33, \mathrm{FILE}=$ '/ home/tiwa/MPC/TFA_Queen.txt' , ACTION='read ') \\
\hline 2386 & $\operatorname{READ}(33, *$, end $=200) \quad(\operatorname{TFA}($ i 2$)$, i $2=1, \mathrm{MOOM})$ \\
\hline 2387193 & FORMAT( 14, F8.3) \\
\hline 2388200 & CONTINUE \\
\hline 2389 & $\operatorname{CLOSE}(33)$ \\
\hline \multicolumn{2}{|l|}{2390} \\
\hline 2391 & $\mathrm{OPEN}(4, \mathrm{FILE}=$ '/ home/tiwa/MPC/TFC_Queen.txt', ACTION='read' \\
\hline 2392 & $\mathrm{DO}$ i $3=1, \mathrm{MCOM}$ \\
\hline 2393 & DO j $3=1, \mathrm{MS}$ \\
\hline 2394 & $\operatorname{READ}(4, *, \mathrm{end}=201) \quad(\operatorname{TFC}(\mathrm{i} 3, \mathrm{j} 3, \mathrm{k} 3), \mathrm{k} 3=1, \mathrm{MN})$ \\
\hline 2395194 & FORMAT(I4， F8.3) \\
\hline 2396 & END DO \\
\hline 2397 & END DO \\
\hline 2398201 & CONTINUE \\
\hline 2399 & $\operatorname{CLOSE}(4)$ \\
\hline \multicolumn{2}{|l|}{2400} \\
\hline 2401 & END IF \\
\hline
\end{tabular}




\section{C.4 Additional MPC Files}

Queen 'bmatsv.F'

URL:http://gearbox.mae.carleton.ca/ibeau_students_svn/tiwa/

QueenESP-r/src/esrubps/bmatsv.F

Queen 'blibsv.F'

URL:http://gearbox.mae.carleton.ca/ibeau_students_svn/tiwa/

QueenESP-r/src/esrubld/blibsv.F

Queen 'CFC_therm_and_aux.F'

URL:http://gearbox.mae.carleton.ca/ibeau_students_svn/tiwa/

QueenESP-r/src/esrubld/CFC_thermal_and_aux.F

Pawn 'blibsv.F'

URL:http://gearbox.mae.carleton.ca/ibeau_students_svn/tiwa/PawnESP-r/ src/esrubld/blibsv.F

StartQueenSimulations.sh

URL:http://gearbox.mae.carleton.ca/ibeau_students_svn/tiwa/

StartQueenSimulations.sh

UpdateFiles.sh

URL:http://gearbox.mae.carleton.ca/ibeau_students_svn/tiwa/

UpdateFiles.sh

RunGenOpt.sh

URL:http://gearbox.mae.carleton.ca/ibeau_students_svn/tiwa/RunGenOpt. sh

Counter

URL:http://gearbox.mae.carleton.ca/ibeau_students_svn/tiwa/counter. txt 